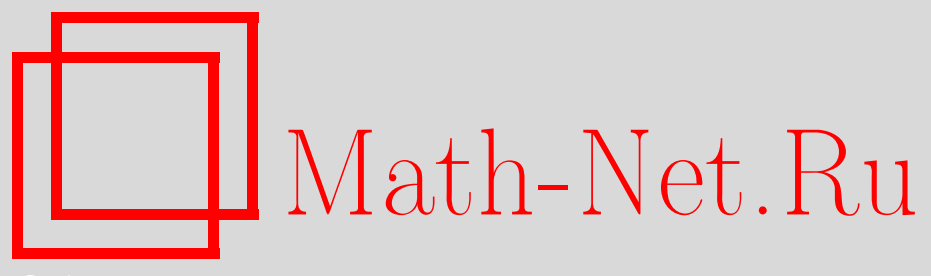

М. Деза, М. Дютур Сикирич, М. И. Штогрин, Фуллерены и диск-фуллерены, УМН, 2013, том 68, выпуск 4, 69128

DOI: https://doi.org/10.4213/rm9544

Использование Общероссийского математического портала Math-Net.Ru подразумевает, что вы прочитали и согласны с пользовательским соглашением http://www . mathnet.ru/rus/agreement

Параметры загрузки:

IP : 52.23 .180 .231

26 апреля 2023 г., 14:30:09

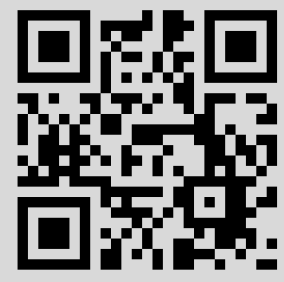




\section{Фуллерены и диск-фуллерены}

\section{М. Деза, М. Дютур Сикирич, М. И. Штогрин}

Геометрический фуллерен, или просто фуллерен, определяется как поверхность простого замкнутого выпуклого 3-мерного многогранника с 5и 6-угольными гранями. Фуллерены - это геометрические модели химических фуллеренов, класс которых образует очень важное семейство органических молекул. Широко ведущиеся исследования этих молекул в химии, физике, кристаллографии и т.д. стимулировали появление обширной литературы о фуллеренах в математической химии, комбинаторной и прикладной геометрии. В частности, было дано несколько обобщений понятия фуллерена, ориентированных на приложения.

Здесь мы предлагаем новое обобщение этого понятия: $n$-диск-фуллереном мы называем поверхность простого замкнутого выпуклого 3-мерного многогранника, взятую без ее $n$-угольной грани, если все остальные ее грани являются 5- и 6-угольными. Только 5- и 6-диск-фуллерены соответствуют геометрическим фуллеренам. Таким образом, понятие геометрического фуллерена нами обобщено со сферы на компактные односвязные двумерные многообразия с краем.

Двумерная поверхность называется неукорачиваемой, если она не содержит поясов - простых циклов, состоящих из 6-угольников, каждый из которых смежен с соседями по паре своих противоположных сторон. Мы исследуем укорачиваемость фуллеренов и $n$-диск-фуллеренов.

Библиография: 87 названий.

Ключевые слова: многоугольник, выпуклый многогранник, планарный граф, фуллерен, диск-фуллерен, лоскут.

DOI: $10.4213 / \mathrm{rm} 9544$

\section{СОДЕРЖАНИЕ}

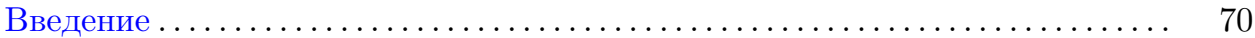

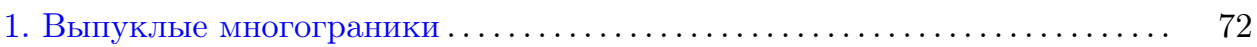

Второй автор поддержан грантом от фонда Александра фон Гумбольдта. Третий автор поддержан грантом Правительства РФ - договор 11.G34.31.0053, программой "Ведущие научные школы" (грант НШ-4995.2012.1) и РФФИ (грант № 11-01-00633).

(C) М. ДезА, М. Дютур Сикирич, М. И. Штогрин, 2013 
2. Фуллерены и диск-фуллерены. . . . . . . . . . . . . . . . . 76

2.1. Фуллерены и абстрактные фуллерены . . . . . . . . . . . . . 76

2.2. Диск-фуллерены и абстрактные диск-фуллерены............. 83

2.3. Строение фуллеренов и диск-фуллеренов ................. 94

2.4. Неукорачиваемые фуллерены и диск-фуллерены . . . . . . . . . . . 100

2.5. Обобщения диск-фуллеренов: компактный случай............. 108

2.6. Обобщения диск-фуллеренов: некомпактный случай .......... 116

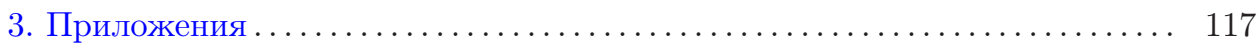

3.1. Параллелоэдры . . . . . . . . . . . . . . . . . . . . . 117

3.2. Женератриса................................... 120

3.3. Делоне и его тетраэдрический символ .................... 122

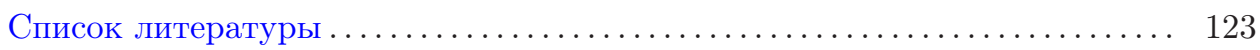

\section{Введение}

В 1985 г. была опубликована статья [64], в которой авторы представили молекулы $C_{60}$, т. е. бакминстерфуллерены, найденные при исследовании масс-спектров паров графита после лазерного облучения твердого образца. А спустя 11 лет Р. Кёрл, Х. Крото и Р. Смолли получили Нобелевскую премию в области химии 1996 г. за открытие фуллеренов. Возможность существования молекулы $C_{60}$ была предсказана в [68] и теоретически обоснована в [3].

Молекулу химического фуллерена изображают в виде планарного кубического графа. Этот граф единственным способом укладывается на сфере и разбивает ее на 5 - и 6 -угольники. В его вершинах располагаются атомы углерода $C$, а связи между атомами осуществляются по ребрам. Химический фуллерен это одна из многих аллотропных форм углерода $C$; другие основные аллотропные формы углерода - это графит, алмаз, углеродные нанотрубки, лонсдейлит, графен, карбин и т. д.

Наиболее известная молекула $C_{60}$ получила название бакминстерфуллерена, по имени американского архитектора и дизайнера Бакминстера Фуллера, предложившего для постройки куполов зданий применять 5- и 6-угольники. Молекула $C_{60}$ состоит из 60 атомов углерода $C$, расположенных в вершинах усеченного икосаэдра (см. рис. 1). Ребро, по которому смежны 5- и 6-угольник, имеет длину 1.434 ангстрем, по нему имеется одинарная связь $C-C$. Ребро, по которому смежны два 6-угольника, имеет длину 1.386 ангстрем, по нему имеется двойная связь $C=C$. Значит, модель молекулы $C_{60}$ не является реберным остовом архимедова тела. Подробности о химических фуллеренах см., например, в [64], [63], [68], [3], [54], [4], [5], [31], [11].

Геометрический фуллерен, или просто фуллерен - это поверхность простого выпуклого 3-мерного многогранника с 5- и 6-угольными гранями. С топологической точки зрения фуллерен - это замкнутое односвязное 2-мерное многообразие, т. е. сфера. С комбинаторной точки зрения это разбиение сферы на 
5- и 6-угольники с вершинами степени $q=3$. Фуллерен с $v$ вершинами (число $v$ всегда четно) и максимальной группой симметрии Aut $F$ мы будем обозначать через $F_{v}($ Aut $F)$. Фуллерен $F_{v}$ имеет 12 пятиугольных граней и $v / 2-10$ шестиугольных граней, т. е. $f_{5}=12$ и $f_{6}=v / 2-10$.

Много публикаций посвящено исследованиям не только фуллеренов в целом, но и их собственных частей - лоскутов (см. [57]). С топологической точки зрения лоскут - это односвязное 2-мерное многообразие с краем, т. е. диск. С комбинаторной точки зрения это разбиение диска на 5- и 6-угольники, все внутренние вершины которого имеют степень 3, а граничные имеют степень 3 или 2. Эти условия необходимы, но не достаточны для того, чтобы это разбиение было лоскутом.

В настоящей статье мы вводим понятие диск-фуллерена (см. определение 4 в п. 2.2), которое является обобщением понятия лоскута. С топологической точки зрения диск-фуллерен представляет собой компактное односвязное 2-мерное многообразие с краем, т. е. диск; с комбинаторной точки зрения - это разбиение диска на 5- и 6-угольники, в каждой вершине которого сходятся ровно три ребра. (Фуллерен без грани является специалъным лоскутом, который не имеет вершин степени 2.)

В вершине, принадлежащей краю диск-фуллерена, сходятся два граничных ребра и одно внутреннее. Диск-фуллерен, край которого содержит ровно $n$ ребер, мы называем $n$-диск-фуллереном. Если он имеет $v$ вершин и максимальную группу симметрии Aut $D F$, то будем обозначать его через $n-D F_{v}(\operatorname{Aut} D F)$, или просто $n$ - $D F$. Он содержит $n+6$ пятиугольных граней и $v / 2-n-5$ шестиугольных граней, т. е. $f_{5}=n+6, f_{6}=v / 2-n-5$. В предположении 1 из [29] указаны соотношения между $n, v$ и минимальным значением $\min f_{6}$ величины $f_{6}$ при заданном $n$ (обозначим его через $m_{3}(n)$ ), обеспечивающие существование $n$ - $D F$ с 3-связными скелетами. Более того, найдены все значения $m_{3}(n)$ при $n \leqslant 21$, а также оценка $m_{3}(n) \leqslant 6$ при $n \geqslant 12$.

Только 5- и 6-диск-фуллерены являются лоскутами, т. е. собственными частями фуллеренов, а при $n \neq 5,6$ никакой $n$-диск-фуллерен не может быть расширен до фуллерена.

Более общо, пусть разбиения круга и сферы таковы, что все ячейки являются 5- и 6-угольниками и в каждой вершине сходятся ровно три ребра. Тогда разбиения круга разделяются на два класса:

- собственные, если каждое из них является собственной частью разбиения сферы;

- несобственные, если никакое из них не есть собственная часть разбиения сферы.

Было бы интересно найти критерий распознания класса по заранее заданному разбиению круга.

Двумерная поверхность называется (не)укорачиваемой (см. определение 9), если она (не) содержит поясов (см. определение 8). Мы исследуем укорачиваемые и неукорачиваемые фуллерены и $n$-диск-фуллерены. Любой фуллерен или диск-фуллерен, обладающий поясом, можно укоротить, удалив из него внутренность пояса и отождествив обе компоненты его края; вместо пояса останется 
простой зигзаг (см. определение 6). В [27; табл. 7], найдены все 9 неукорачиваемых фуллеренов $F_{v}($ Aut $F)$ с $v \leqslant 200$, обладающих только простыми зигзагами. Высказано предположение, что других таких фуллеренов нет ни при каких $v$. Среди этих 9 фуллеренов $F_{140}(I)$ имеет максимальное число вершин и содержит 15 простых зигзагов. В теореме 2 ниже доказано, что неукорачиваемый фуллерен имеет не более 15 простых зигзагов; эта неулучшаемая оценка, возможно, сохранится для всех зигзагов.

С комбинаторной точки зрения реберный остов $n$-диск-фуллерена представляет собой кубический (3-валентный: все вершины имеют степень $q=3$ ) плоский граф $G$ с 5 - и 6-угольными внутренними гранями и $n$-угольной внешней гранью. Напомним, что в [29] даны соотношения между $n, v$ и $m_{3}(n)$, обеспечивающие существование таких 3 -связных графов $G$ при $n \leqslant 21$ (см. выше). При $n \leqslant 11$ все значения $m_{3}(n)$ для 3 -связных графов $G$ даны ниже в табл. 1 . При $n \geqslant 12$ в [29] построена серия 3 -связных графов $G$ с $f_{6}=6$, и поэтому $m_{3}(n) \leqslant 6$. Высказано предположение, что при всех $n \geqslant 12$ эта оценка достигается, причем на единственном $n-D F$.

При $12 \leqslant n \leqslant 21$ все значения $\min f_{6}$ для 2 -, но не 3 -связных графов $G$ (обозначим их через $\left.m_{2}(n)\right)$ приведены в табл. 2. После $n=22$ эта таблица повторяется с периодом 10 (см. теорему 1).

Если $n \geqslant 3$, то $n$-диск-фуллерен имеет выпуклую реализацию. Она описана в замечании 4 для 3-связного графа $G$ и в замечании 5 для 2-, но не 3 -связного графа $G$. Если число ребер, принадлежащих краю $n$-диск-фуллерена, совпадает с числом приграничных ячеек и все они являются 5-угольниками, то этот $n$ - DF называется $n$-наперстком (см. определение 7 ). Число простых зигзагов произвольного неукорачиваемого $n$-наперстка не превышает $n+1$, что подтверждает предложение 12 .

Фуллерены и диск-фуллерены, которым посвящена эта статья, тесно связаны с 3-мерными выпуклыми многогранниками, поэтому в качестве дополнения к следующему разделу мы добавили три приложения.

\section{1. Выпуклые многограники}

Теория фуллеренов и диск-фуллеренов тесно связана с теорией выпуклых многогранников в 3 -мерном евклидовом пространстве $\mathbb{R}^{3}$. Ниже под выпуклым многогранником мы, в основном, будем подразумевать не 3 -мерное тело $P$, а его граничную 2-мерную поверхность $\dot{P}=\partial P$.

Напомним основные комбинаторно-топологические теоремы, относящиеся к теории выпуклых многогранников.

ТЕОРЕМА ЭЙЛЕРА [52]. Если выпуклый многогранник имеет $v$ вершин, е ребер, $f$ граней, то числа $v, e, f$ связанъ формулой $v-e+f=2$.

ТЕОРЕМА УИТни [85]. Произволъный 3-связный планарный графб укладывается на двумерной сфере одним и только одним способом. 
ТЕОРЕМА ШТЕЙНИЦА [80]. Граф служит 1-скелетом выпуклого 3-мерного многогранника тогда и только тогда, когда он планарен и 3 -связен ${ }^{1}$.

Терминология, относящаяся к теории графов, взята из книги [60]. Однако впредь термин 1-скелет, т. е. реберный остов, мы заменим на более короткий скелет.

Напомним также три геометрические теоремы из теории выпуклых многогранников, которые понадобятся ниже.

Теорема Коши [8]. Изометричные замкнутые выпуклые многогранные поверхности в $\mathbb{R}^{3}$ конгруэнтны, если соответствующие по изометрии грани конгруэнтны.

Две изометричные замкнутые выпуклые многогранные поверхности с конгруэнтными гранями могут отличаться друг от друга лишь двугранными углами при соответствующих по изометрии ребрах. Если двугранный угол одной поверхности больше двугранного угла другой, Коши ставит на ее ребре знак +, а если меньше, то знак -, и доказывает следующие две леммы:

- если на ребрах выпуклого многогранника расставлены знаки + и - , то среди концов этих ребер найдется такая вершина, при обходе вокруг которой встретится меньше четырех перемен знаков;

о при обходе вокруг вершины изгибаемой поверхности выпуклого многогранного угла число перемен знаков в его ребрах всегда не меньше четырех.

Из этих двух лемм Коши заключает, что соответствующие двугранные углы равны, следовательно, многогранные поверхности конгруэнтны в целом.

Представим себе произвольный выпуклый многогранник таким, будто он склеен из картона. Пронумеруем все вершины многогранника и напишем эти номера на внешней стороне поверхности внутри каждого плоского угла вблизи его вершины. Разрежем многогранник по всем его ребрам. Он распадется на отдельные грани. Среди них имеются только две грани, у которых ребро имеет концы с одними и теми же двумя номерами. Следовательно, из этих рассыпанных граней однозначно можно построить абстрактную поверхность, у которой в каждой вершине сходятся те углы, в которых написан один и тот же номер. Эта абстрактная поверхность изометрична исходной выпуклой поверхности и имеет ту же комбинаторно-топологическую схему; определение этой схемы см. в работе [75]. Однако впредь нас будет интересовать вложение в $\mathbb{R}^{3}$ этой абстрактной поверхности в виде выпуклой поверхности и с теми же самыми гранями. Именно при этих условиях, согласно теореме Коши, получится либо исходная выпуклая поверхность, если номера вершин окажутся на внешней стороне поверхности, либо исходная поверхность, вывернутая наизнанку, если номера вершин окажутся на внутренней стороне поверхности. Ясно, что последняя поверхность зеркально симметрична исходной, значит, конгруэнтна ей.

\footnotetext{
${ }^{1}$ Граф называется $k$-связным, если он связен при удалении меньше чем $k$ любых его вершин [60].
} 
Простой многоГРАнник. Выпуклый 3-мерный многогранник, в каждой вершине которого сходятся ровно три ребра, называют простым или примитивным, см., например, [7] и [83].

В случае простого замкнутого выпуклого многогранника доказательство теоремы Коши является наиболее простым, а именно, его двугранные углы не могут измениться, так как поверхности телесных углов во всех вершинах являются трехгранными, а треугольник - фигура жесткая.

Теорема Коши для простого выпуклого многогранника легко распространяется с замкнутого многогранника на многогранник с краем - на собственную часть замкнутого многогранника, правда, с некоторыми ограничениями. Более общо, пусть 2-мерный полиэдр $P$, гомеоморфный кругу, вложен в $\mathbb{R}^{3}$ (значит, его граничные ребра составляют простой реберный цикл) и пусть

○ к граничной вершине (не) примыкает (ни) одно внутреннее ребро;

○ все внутренние ребра образуют связный граф (обозначим его через $G$ );

○ граф $G$ содержит неконцевые вершины и все они имеют степень $q=3$.

Тогда все вложения полиэдра $P$ в $\mathbb{R}^{3}$ конгруэнтны. При этом все грани предполагаются неизменными. Вложение можно заменить на погружение. Так, например, взяв в качестве оснований две антиподальные грани додекаэдра, рассмотрим его боковую поверхность. Разрежем ее кратчайшим реберным путем между основаниями. Получим диск, погруженный в $\mathbb{R}^{3}$. Он содержит 10 правильных 5-угольников и не может быть вложен в $\mathbb{R}^{3}$, а все его погружения в $\mathbb{R}^{3}$ конгруэнтны, если все 5-угольники сохраняются конгруэнтными.

АБСТРАКТНАЯ СФЕРА. Возьмем абстрактную двумерную поверхность, склеенную из евклидовых многоугольников. Отождествляемые стороны многоугольников равны. Пусть эта поверхность гомеоморфна стандартной сфере $\mathbb{S}^{2}$. Тогда посредством гомеоморфизма ее скелет вкладывается в $\mathbb{S}^{2}$ как граф $G$. Так как $G$ является связным, то каждая компонента связности области $\mathbb{S}^{2} \backslash G$ является односвязной. (В записи $\mathbb{S}^{2} \backslash G$ вложенный в сферу $\mathbb{S}^{2}$ граф $G$ мыслится как точечное подмножество в $\mathbb{S}^{2}$.) Она ограничена связным реберным циклом. Если ребро графа $G$ является мостом (т. е. если при его удалении нарушится связность), то оно входит дважды в границу примыкающей к нему области и при полном обходе вдоль границы оно проходится в противоположных друг другу направлениях. На $\mathbb{S}^{2}$ граф $G$ однозначно определяет клеточное разбиение, в котором 2-мерными клетками являются компоненты области $\mathbb{S}^{2} \backslash G$, 1-мерными клетками являются ребра графа $G, 0$-мерными клетками являются вершины графа $G ; 2$-мерные клетки называют также ячейками или гранями.

Напомним (см. [75]), что отождествленные ребра многоугольника должны быть противоположно ориентированы при циклическом обходе его края (для исключения пленок Мёбиуса). Среди разделяющих друг друга пар ребер отождествленными могут быть ребра лишь одной из пар (для исключения ручек). В одно ребро можно отождествить не более двух ребер (для исключения разветвлений в ребре). Все плоские углы, сходящиеся в одной вершине поверхности, должны составлять одну циклическую последовательность (для того чтобы окрестность вершины была гомеоморфна кругу). 
ТЕОРЕМА АЛЕКСАНДРОВА [1]. (i) Любъе две изометричные выпуклые замкнутые многогранные 2-мерные поверхности в $\mathbb{R}^{3}$ конгруэнтны.

(ii) Если вершины абстрактной двумерной сферы имеют положительную кривизну, то в $\mathbb{R}^{3}$ существует выпуклый многогранник, поверхность которого изометрична ей.

Напомним, что кривизна поверхности в ее вершине равна $2 \pi$ минус сумма плоских углов, сходящихся в этой вершине, т. е. $\omega=2 \pi-\sum \alpha$.

В теореме Александрова (ii) речь идет о существовании выпуклого многогранника, поверхность которого в общем случае является границей 3-мерного тела. Но в ней не исключаются также вырожденные многогранники, имеющие объем 0. В таком случае поверхность состоит из двух идентичных выпуклых плоских (2-мерных) многоугольников с отождествленными контурами, наложенных друг на друга и расположенных в $\mathbb{R}^{2}$. Критерий вырожденности выпуклого многогранника недавно был найден в [79].

В теореме Александрова (i) доказана единственность в классе изометричных выпуклых многогранных поверхностей, но уже без предположения, что при изометрическом отображении одной поверхности на другую грань отображается на грань. Напротив, грани и ребра априори могли бы быть совсем другими, однако так не бывает - в теореме (i) Александров доказывает это тем же методом, который впервые применил Коши.

На практике однозначно определяются вершины - это лишь те точки поверхности, в которых ее кривизна положительна.

Теорема Оловянишникова [67]. Любое компактное выпуклое тело в $\mathbb{R}^{3}$, граница которого изометрична поверхности замкнутого выпуклого многогранника в $\mathbb{R}^{3}$, конгруэнтно ему.

Оловянишников доказал единственность поверхности выпуклого многогранника в классе поверхностей всех выпуклых тел, а не только в классе поверхностей выпуклых многогранников. К большому сожалению, новых его теорем не было: в декабре 1941 г. Сергей Пантелеймонович Оловянишников погиб на фронте (см. [2; т. 3, с. 676]).

Итак, для выпуклых многогранников имеются три теоремы единственноcmu, а именно теоремы Коши, Александрова (i) и Оловянишникова, и каждая следующая теорема существенно усиливает предыдущую.

ТЕЛА ПЛАТонА. Платоновы тела - это правилъные многогранники; их пять (это доказал еще Евклид): тетраэдр, куб, октаэдр, додекаэдр и икосаэдр. Все грани правильного многогранника - правильные многоугольники, они конгруэнтны; многогранные углы во всех вершинах конгруэнтны. Группа симметрии правильного многогранника транзитивна на гранях, ребрах и вершинах.

ТЕлА АрхимеДА. Архимедовы тела - это полуправилъные многогранники. Их грани являются правильными многоугольниками; по меньшей мере две грани различны - иначе они платоновы; многогранные углы во всех вершинах 
конгруэнтны (это условие необходимое, но не достаточное). Группа симметрии полуправильного многогранника транзитивна на всех его вершинах; значит, это изогон. Существует 13 специальных архимедовых тел (два из них имеют левые и правые модификации, зеркально симметричные друг другу; кристаллографы называют их энантиоморфными) и две бесконечные серии - призмы и антипризмы.

ТЕлА ПуАнсо. Это правильные невыпуклые многогранники, называемые звездчатыми; их всего четыре - нашел Пуансо. Других правильных невыпуклых многогранников нет - это доказал Коши.

ТЕЛА ФЕДоровА. Это параллелоэдры - выпуклые 3-мерные многогранники, параллельные копии которых замощают 3 -мерное пространство $\mathbb{R}^{3}$. Есть ровно пять их типов (см. [53]). Случай многомерных параллелоэдров см. в п. 3.1.

Рисунки всех перечисленных выше многогранников имеются в [19]. Отметим, что в [21] было добавлено одно псевдоархимедово тело № 13 с конгруэнтными звездами во всех его вершинах, составленными из правильного 3-угольника и трех квадратов, о котором Делоне знал давно (см., например, [23]), но не причислял его к архимедовым телам. Сохраняя пояс из квадратов, одну из примыкающих к нему частей можно повернуть, как кубик Рубика, восстановить два других пояса из квадратов и вернуться к архимедову телу № 12 .

О многомерных параллелоэдрах мы продолжим в пп. 3.1 и 3.2, а теперь рассмотрим фуллерены и диск-фуллерены.

\section{2. Фуллерены и диск-фуллерены}

\section{1. Фуллерены и абстрактные фуллерены.}

ОПРЕДЕЛЕНИЕ 1. Поверхность простого замкнутого выпуклого 3-мерного многогранника назовем фуллереном, если все ее грани являются только 5- и 6-угольными.

При условиях определения 1 имеют место равенства

$$
v=v_{3}, \quad 2 e=3 v_{3}, \quad f=f_{5}+f_{6}, \quad 2 e=5 f_{5}+6 f_{6},
$$

где $v, e$ и $f$ - число вершин, ребер и граней, а $f_{k}$ - число $k$-угольных граней. Складывая соотношения (1), умноженные на $6,-2,6,-1$ соответственно и учитывая формулу Эйлера, имеем

$$
f_{5}=12
$$

Учитывая (2), можно переписать соотношения (1) в другом виде:

$$
v=2\left(f_{6}+10\right), \quad e=3\left(f_{6}+10\right), \quad f=1\left(f_{6}+10\right)+2 .
$$

При каждом $f_{6}$ число фуллеренов конечно. Числа $v, e, f$ являются наименьшими, если $f_{6}$ минимально. Если $f_{6}=0$, то это додекаэдр (комбинаторно). 


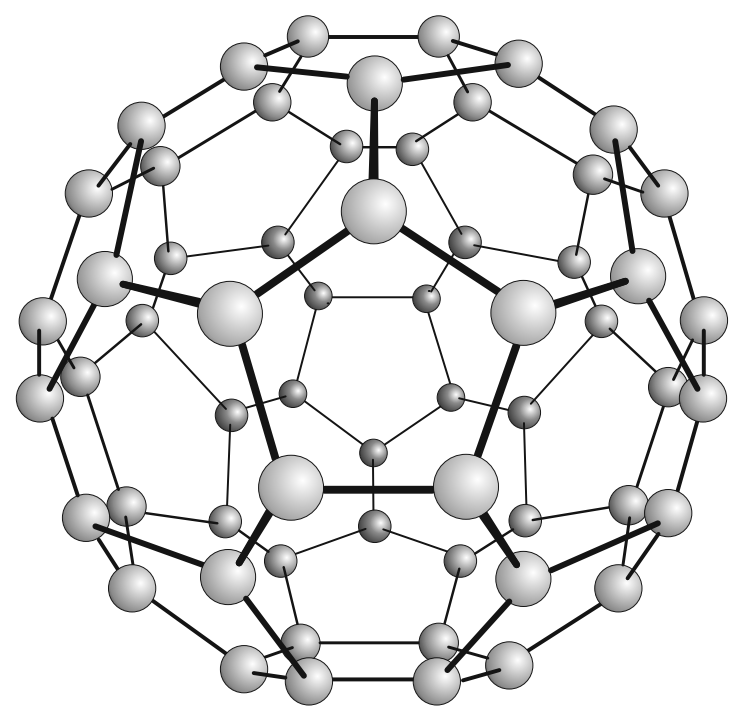

Рис. 1. Бакминстерфуллерен $C_{60}$

Фуллерен с $v$ вершинами и максимальной группой симметрии Aut $F$ мы обозначили через $F_{v}(\mathrm{Aut} F)$. В силу $(2)$ и (3) фуллерен $F_{v}$ имеет 12 пятиугольных и $v / 2-10$ шестиугольных граней. Первым открытым химиками фуллереном был $F_{60}\left(I_{h}\right)$. Этот фуллерен, как молекулу, химики обозначают через $C_{60}$, так как эта молекула содержит 60 атомов углерода $C$. Общепринятая ее модель изображена на рис. 1.

ОПРЕдЕлЕниЕ 2. Абстрактную сферу (т. е. абстрактную двумерную поверхность, гомеоморфную сфере $\mathbb{S}^{2}$ ) назовем абстрактным фуллереном, если

(i) она склеена из правильных 5- и 6-угольников;

(ii) все ее вершины имеют степень $q=3$.

Скелет абстрактного фуллерена, как реберный граф $G$, вложен в $\mathbb{S}^{2}$ так, что каждая компонента связности области $\mathbb{S}^{2} \backslash G$ является 5- или 6-угольником, быть может, с отождествленными ребрами и/или вершинами. Для разбиения сферы $\mathbb{S}^{2}$ на компоненты связности области $\mathbb{S}^{2} \backslash G$ опять имеем (1)-(3). Следовательно, граф $G$ связен и $v \geqslant 20$. Докажем, что каждая ячейка разбиения, будь она 5- или 6-угольной, ограничена простым реберным циклом.

ПредложениЕ 1. Для любого абстрактного фуллерена

(i) каждая ячейка ограничена простым реберным циклом;

(ii) пересечение каждых двух ячеек является связным.

ДокАзАтельство. (i) Докажем от противного. Пусть ячейка ограничена непростым реберным циклом. Тогда некоторые ребра и/или вершины 5- или 6-угольника должны быть отождествлены. Однако отождествление только вершин произвольной двумерной ячейки невозможно, так как иначе степень вершины была бы не меньше 4. Отождествление смежных ребер ячейки также 
невозможно, так как иначе их общая вершина имела бы степень 1. Если бы два смежных ребра ячейки были отождествлены с двумя другими смежными ребрами (принадлежащими ей или другой ячейке), то общая вершина этих двух смежных ребер имела бы степень 2.

Пусть, далее, отождествлены несмежные ребра ячейки. Тогда край ячейки в случае 5-угольника состоит из двух окружностей, соединенных мостом, а на какой-то из них имеется еще одна дополнительная вершина. Окружность без дополнительной вершины является краем 1-угольника, который должен быть ячейкой, так как $q=3$, но это противоречит тому, что все ячейки являются только 5- и 6-угольными. Если отождествлены несмежные стороны ячейки в случае 6-угольника, то край ячейки опять должен состоять из двух окружностей, соединенных мостом. При этих обстоятельствах предстоит рассмотреть следующие две возможности.

Случай 1. На одной из окружностей имеются две дополнительные вершины (если отождествлены стороны 6-угольника, которые не являются смежными или противоположными); в данном случае, поскольку $q=3$, должен существовать 1-угольник, что недопустимо, см. определение 2.

Случай 2. На обеих окружностях имеется по одной дополнительной вершине (если отождествлены противоположные стороны 6-угольника). В этом случае по любой из двух окружностей к данной 6-угольной ячейке примыкает либо 5-, либо 6-угольник. Но 5-угольник примыкать не может, иначе появится 1-угольник. Следовательно, примыкает 6-угольник. У него, как у исходного, отождествлены противоположные стороны и, начиная с него, устройство фуллерена периодически повторяется. Это противоречит тому, что фуллерен конечен. Следовательно, несмежные стороны 6-угольника не могут быть отождествлены. Итак, каждая ячейка ограничена простым реберным циклом.

(ii) Пусть два 6-угольника имеют три пары общих сторон. Тогда в разбиении сферы в силу равенства $q=3$ должны быть три 2-угольника, что недопустимо. Пусть две ячейки имеют две пары общих ребер. Тогда эти две ячейки составляют кольио (гомеоморфное боковой поверхности кругового цилиндра). Его край состоит из двух окружностей. Кроме вершин, расположенных на общих ребрах, на обеих окружностях могут находиться дополнительные вершины. Если на одной из двух этих окружностей находятся 4 дополнительные вершины, то к другой окружности должен примыкать 2-угольник, что недопустимо. Если на одной из окружностей расположены три дополнительные вершины, то на другой расположено не более одной дополнительной вершины, а это приводит либо к 2-угольнику, либо к 1-угольнику, что недопустимо. Если на каждой окружности имеется по две дополнительные вершины, то ввиду конечности реберного графа опять приходим к 1-угольнику. Значит, любые две ячейки либо пересекаются лишь по одному ребру, либо вовсе не пересекаются. Предложение доказано.

СледствиЕ 1. Скелет абстрактного фуллерена изоморфен скелету некоторого фуллерена. 
ДокАЗАТЕЛьСтво. Из предложения 1 и теоремы Штейница [80] ${ }^{2}$ следует, что существует выпуклый многогранник, скелет которого изоморфен скелету абстрактного фуллерена, так как он является планарным и 3 -связным ${ }^{1}$ кубическим графом: удаление трех вершин, смежных с четвертой, нарушает связность скелета, а удаление двух вершин не нарушает. Следствие доказано.

Дальнейшие исследования тесно связаны с так называемыми полиииклами.

ОПРЕдЕлЕниЕ 3 . Пусть заданы два натуральных числа $r \geqslant 3$ и $q \geqslant 3$. Тогда разбиение диска на $r$-угольники назовем $(r, q)$-полициклом, если

(i) степени всех внутренних вершин равны $q$;

(ii) степени всех граничных вершин не больше $q$.

Отметим, что в [36] имелось еще дополнительное третье условие

(iii) ячейки разбиения составляют клеточный комплекс,

которое следует из (i) и (ii) (см. [36]); отсюда же следует, что степени всех вершин не меньше двух.

ЗАмечАниЕ 1 . Все $(r, q)$-полициклы раскладываются на так называемые элементарные слагаемые. Перечень элементарных слагаемых $(5,3)$ - и $(3,5)$-полициклов имеется в [35]. Назовем $(r, q)$-полицикл нерасширяемым, если он не является собственной частью другого $(r, q)$-полицикла. Доказано, что существует ровно 7 нерасширяемых $(r, q)$-полициклов: 5 собственных - поверхности пяти платоновых тел, каждая взята без одной грани, и 2 несобственных октаэдр с расщепленной вершиной и икосаэдр с расщепленной вершиной, они изображены на рис. 2. Значит, существует всего лишь один конечный нерасширяемый $(5,3)$-полицикл - додекаэдр без грани. Никакой $(5,3)$-полицикл не может иметь лишь одну вершину степени 2. Не существует $(5,3)$-полицикла с ровно двумя вершинами степени 2 на краю полицикла, которые либо смежны, либо разделены одной вершиной степени 3. Подробности см. в [36], [35], [32].

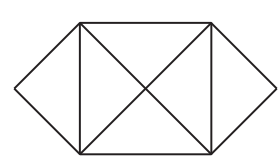

a)

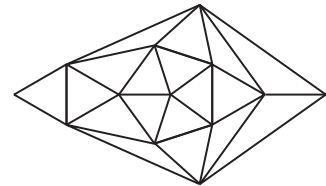

b)

Рис. 2. Расщепленные в вершине: а) октаэдр, b) икосаэдр

Теперь вернемся к фуллеренам.

ПреДЛОЖЕНИЕ 2. (i) При $f_{6}=1$ нет ни одного фуллерена.

(ii) Фуллерены существуют при каждом значении $f_{6} \geqslant 2$.

ДокАЗАтельство. Это предложение было доказано в [58]. Мы приведем новое доказательство, так как предложенный в нем метод и рисунки будут нужны ниже (в теореме 1).

\footnotetext{
2 Это рукопись из наследия Штейница, которую дополнил и издал Радемахер.
} 
(i) Доказывается от противного. Пусть $f_{6}=1$. Тогда дополнение 6-угольника до фуллерена состоит только из 5-угольников и представляет собой конечный нерасширяемый $(5,3)$-полицикл. Однако это не додекаэдр без грани (см. замечание 1). Получено противоречие. Значит, $f_{6} \neq 1$.

(ii) При $f_{6}=2$ существует фуллерен $F_{24}\left(D_{6 d}\right)$, его называют бочка (см. рис. 3, a)).

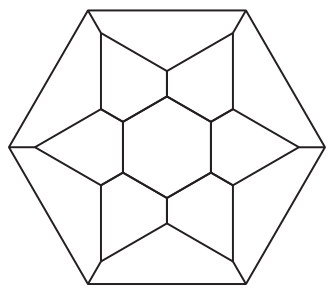

a)

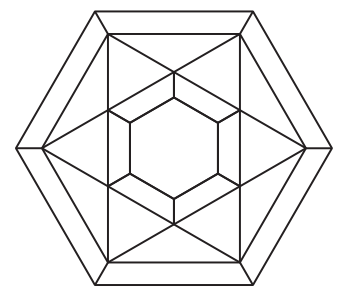

b)

Рис. 3. Бочка и ее выпуклые вложения: а) по Штейницу (т. е. комбинаторно); b) по Александрову (т. е. метрически, с правильными 5- и 6-угольниками), а точнее, диаграммы Шлегеля этих вложений

На рис. 4 изображены два лоскута вида а) и вида b), т. е. два двусмысленных лоскута Эндо-Крото (см. [57]). Они разные внутри, но обладают одинаковой границей. Обозначим через $\varphi$ операцию, при которой лоскут вида а) перестраивается в лоскут вида b). Пусть фуллерен $F_{v}$ содержит лоскут вида а). Тогда после операции $\varphi$ лоскут вида а) перестроится в лоскут вида b), а фуллерен $F_{v}$, содержащий лоскут вида а), перестроится в фуллерен $F_{v+2}$, содержащий лоскут вида b). Операция $\varphi$ увеличивает $f_{6}$ на единицу.

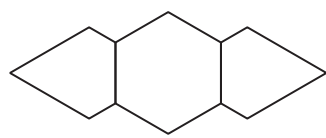

a)

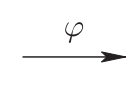

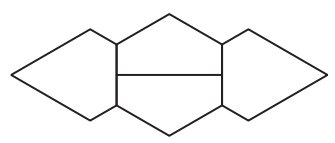

b)

Рис. 4. Два двусмысленных лоскута Эндо-Крото

Фуллерен $F_{24}\left(D_{6 d}\right)$ (бочка), изображенный на рис. 3 , а), имеет ровно две 6-угольные грани. Он содержит лоскут вида а) (см. рис. 4). После операции $\varphi$ получится фуллерен с тремя 6-угольниками.

На рис. 5, а) изображено 1-е кольцо (корона) вокруг 6-угольника (с одним 5 -угольником из 2-го кольца) и операция $\varphi$, примененная первый раз. Обозначим ее через $\varphi_{1}$. Операция $\varphi_{1}$ разбила 6 -угольник на два 5 -угольника. Возник новый 6-угольник, примыкающий к отмеченной вершине. Этот 6-угольник и примыкающий к отмеченной вершине 5-угольник, не причастный к операции $\varphi_{1}$, входят в новый лоскут вида а) (см. рис. 4). Применив к нему операцию $\varphi_{2}$ (см. рис. $\left.\left.5, \mathrm{~b}\right)\right)$, получаем новый фуллерен, у которого 4 шестиугольника. Так операцию $\varphi$ можно повторить любое число раз, см. рис. 5 (вертушка 


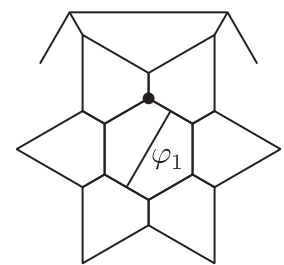

a)

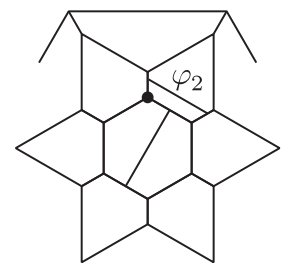

b)

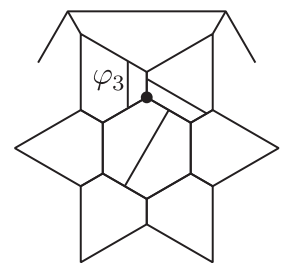

c)

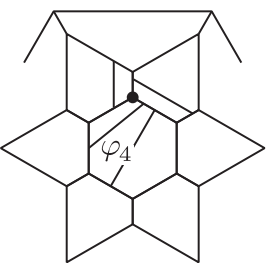

d)

Рис. 5. Вертушка операций $\varphi_{i}$

операций $\varphi_{i}, i=1,2, \ldots$, вокруг отмеченной вершины). Каждый раз прибавляется 6-угольник. Значит, для любого заранее заданного натурального числа $N \geqslant 2$ найдется такой фуллерен, для которого $f_{6}=N$. Предложение доказано.

Докажем, что при $f_{6}=2$ имеется только один фуллерен - бочка. В самом деле, в 1-м кольце вокруг 6-угольника нет другого 6-угольника. В противном случае оба 6-угольника в фуллерене были бы смежны, а после удаления их вместе с общим ребром получился бы нерасширяемый $(5,3)$-полицикл, которого не существует (см. замечание 1 и [35]). Во 2-м кольце также нет 6-угольника, в противном случае после удаления обоих 6-угольников и расщепления моста, которым соединены контуры 6-угольников фуллерена, на два новых ребра с двумя новыми вершинами, получился бы элементарный $(5,3)$-полицикл, которого также не существует. Значит, есть 1-е кольцо из 6 пятиугольников вокруг одного 6-угольника и есть 1-е кольцо из 6 пятиугольников вокруг другого 6-угольника. Всего 2 шестиугольника и 12 пятиугольников. Вместе они составляют единственный фуллерен.

ЗАмечАниЕ 2. Бочка, чей скелет изображен на рис. 3, а), имеет два основания - равные и правильные 6-угольники, а также 12 боковых граней - все 5-угольники. Боковая поверхность бочки, взятая без двух 5-угольных граней, смежных по ребру, которое не пересекается с основаниями, вложена в $\mathbb{R}^{3}$ и гомеоморфна кругу. Если бы 5-угольники были правильными, то она была бы не вложена, а погружена в $\mathbb{R}^{3}$, точнее, погружена в боковую поверхность додекаэдра, о чем уже было сказано выше. Следовательно, 5-угольные грани не могут быть правильными, так как бочка не совпадает с додекаэдром.

Заметим, что при $f_{6}=3$ также существует только один фуллерен $F_{26}\left(D_{3 h}\right)$ (см. [54]).

ЗАмЕчАниЕ 3. Возьмем абстрактную двумерную сферу, построенную из правильных евклидовых 5- и 6 -угольников, $q=3$, и обсудим вопрос о существовании ее реализации в виде поверхности выпуклого многогранника в $\mathbb{R}^{3}$. Так как ячейки евклидовы и правильны, то для абстрактной сферы получена некоторая специальная метрика неотрицательной кривизны. По теореме Александрова (ii) (см. раздел 1) существует и притом единственный выпуклый многогранник, изометричныц рассматриваемой абстрактной сфере. Вершинами многогранника являются только точки, в которых кривизна поверхности 
положительна. Точка абстрактной сферы, в которой сходятся три правильных 6-угольника, не может быть вершиной соответствующего ей выпуклого многогранника. Что касается ребер выпуклого многогранника, то каждое из них является кратчайшей между двумя вершинами многогранника. Однако обратное не верно: не каждая кратчайшая между двумя вершинами абстрактной сферы становится ребром. Лишь в редких частных случаях удается распознать те кратчайшие между вершинами абстрактной сферы положительной кривизны, которые станут ребрами при ее реализации в виде выпуклого многогранника.

Недавно был найден [79] критерий вырожденности выпуклого многогранника. Ребрами вырожденного выпуклого многогранника являются все однократные кратчайшие между вершинами (и только они). С помощью этого критерия найдено новое доказательство теоремы Зильберберг [86] о существовании невырожденного выпуклого многогранника с любыми заранее заданными кривизнами в вершинах его поверхности.

Отметим, что фуллерен $F_{60}\left(I_{h}\right)$ с $f_{6}=20$ может иметь вид поверхности одного из архимедовых тел. Моделью молекулы $C_{60}$ служит скелет усеченного икосаэдра (с той же группой симметрии $I_{h}$ ), чьи 6-угольные грани не являются правильными (см. рис. 1).

Фуллерен $F_{80}\left(I_{h}\right)$ с $f_{6}=30$, как и любой другой фуллерен, также реализуется в виде выпуклого многогранника по теореме Штейница. Таким является додекаэдр со стесанными ребрами, см. [56]; в [56] уже были рассмотрены фуллерены, но они были названы медиалъными многогранниками. Его 6-угольные грани опять не являются правильными. Соотношение между длинами его ребер, не эквивалентных по группе $I_{h}$, может быть выбрано произвольным.

Он не реализуется в виде выпуклого многогранника с правильными 5- и 6-угольными гранями. А выпуклый многогранник, существующий по теореме Александрова (с правильными 5- и 6-угольниками), представляет собой ромбоикосододекаэдр, который комбинаторно изоморфен икосаэдру с усеченными вершинами и ребрами. Метрика этого многогранника такова, что прямоугольная грань вместе с $2 / 3$ треугольных граней составляют правильный шестиугольник, изогнутый по двум диагоналям. Выпуклая оболочка изогнутого 6-угольника ограничена двумя изогнутыми 6-угольниками - один из них исходный, а другой состоит из двух трапеций.

Удалим из ромбоикосододекаэдра эту выпуклую оболочку. Получим замену изогнутого 6-угольника, состоящего из прямоугольника и двух 3-угольников, на изогнутый 6-угольник, состоящий из двух трапеций. Осуществим эту замену с каждым изогнутым правильным 6-угольником. Тогда наш выпуклый многогранник перестроится в невыпуклый, состоящий из правильных 5-угольников и изогнутых 6-угольников. Это еще одна реализация, но уже не выпуклая, поверхности в $\mathbb{R}^{3}$, изоморфной фуллерену $F_{80}\left(I_{h}\right)$. Эта реализация имеет другую внутреннюю метрику: в вершинах, в которых сходятся "6-угольники" (изогнутые и не правильные), кривизна поверхности отрицательна.

В обоих случаях реберный остов является одним и тем же, если диагонали "6-угольника" не считать ребрами. Ребра "6-угольника", принадлежащие его краю, некомпланарны. Компланарны ли ребра "6-угольника" молекулы $C_{80}\left(I_{h}\right)-$ неизвестно. 


\section{2. Диск-фуллерены и абстрактные диск-фуллерены.}

ОПРЕДЕЛЕНИЕ 4. Поверхность простого замкнутого выпуклого 3-мерного многогранника без внутренности ее $n$-угольной грани, $n \geqslant 3$, назовем $n$-дuскфуллереном или просто диск-фуллереном, если все остальные ее грани являются 5- и 6-угольными. При $n=5,6$ назовем диск-фуллерен особым.

Вернув $n$-угольную грань в ее прежнее положение (см. определение 4), мы получаем

$$
v=v_{3}, \quad 2 e=3 v_{3}, \quad f=f_{5}+f_{6}+f_{n}, \quad 2 e=5 f_{5}+6 f_{6}+n f_{n},
$$

где $f_{n}=1, n \neq 5,6$. Складывая соотношения (4), умноженные на $6,-2,6,-1$ соответственно и учитывая формулу Эйлера, мы имеем

$$
f_{5}=n+6 .
$$

Учитывая (5), можно переписать соотношения (4) в другом виде:

$$
v=2\left(f_{6}+n+5\right), \quad e=3\left(f_{6}+n+5\right), \quad f=1\left(f_{6}+n+5\right)+2 .
$$

Из соотношений (6) следует, что при каждом фиксированном $n$ числа $v, e$ и $f$ минимальны при наименьшем значении $f_{6}$. Если $f_{6}=0$, то это додекаэдр без грани (комбинаторно).

Если $n$-диск-фуллерен имеет $v$ вершин и максимальную группу симметрии Aut $D F$, то будем обозначать его через $n$ - $D F_{v}$ (Aut $D F$ ) или просто $n$ - $D F$. Любой $n$ - $D F_{v}$ содержит $n+6$ пятиугольных граней и $v / 2-n-5$ шестиугольных граней, т. е. $f_{5}=n+6$ и $f_{6}=v / 2-n-5$. Он является собственной частью фуллерена тогда и только тогда, когда $n=5$ или $n=6$.

ОПРЕДЕЛЕНИЕ 5 . Абстрактным $n$-диск-фуллереном, $n \geqslant 3$, назовем $n$-угольник, склеенный из 5- и 6-угольников, если во всех вершинах разбиения сходятся ровно 3 ребра $(q=3)$.

ПреДЛОжЕНИЕ 3. Для абстрактного n-диск-фуллерена

(i) каждая ячейка ограничена простым реберным ииклом;

(ii) пересечение каждых двух ячеек является связным.

ДокАЗАТЕЛьство. (i) В определении 5 не требуется, чтобы 5- и 6-угольные ячейки были ограничены простыми реберными циклами, однако это так и доказывается точно так же, как в случае абстрактных фуллеренов, только тут дополнительно используется неравенство $n \geqslant 3$. Таким образом, любая ячейка абстрактного $n$ - $D F$ гомеоморфна диску.

(ii) Точно так же, как и для абстрактного фуллерена, доказывается, что непустое пересечение двух 5- и/или 6-угольных ячеек абстрактного $n$ - $D F$ является связным. Предложение доказано.

Предложение 3 аналогично предложению 1, из которого вытекает следствие 1. Однако аналогичного следствия из предложения 3 не вытекает, точнее, оно распространяется не на все $n-D F$. 
В самом деле, рассмотрим 8- $D F_{74}\left(C_{2 \nu}\right)$. На рис. 6 он представлен в виде ненормального (т.е. в нем есть ячейки, смежные не по целым сторонам) разбиения диска. Малой вариацией его легко превратить в нормальное. Однако его нельзя представить в виде поверхности выпуклого многогранника без 8-угольной грани, так как имеется несвязное пересечение 6-угольника с 8-угольным краем. Скелет этого 8- $D F_{74}$ является 2-, но не 3-связным плоским графом $\left(\right.$ см. сноску $\left.{ }^{1}\right)$. При удалении двух вершин, расположенных на вертикальной оси симметрии диск-фуллерена $8-D F_{74}\left(C_{2 \nu}\right)$, нарушается связность скелета, а при удалении какой-либо одной вершины связность не нарушается.

Таким образом, при переходе от обычных $n$ - $D F$ к абстрактным класс $n$-дискфуллеренов пополняется необычными диск-фуллеренами, в каждом из которых хотя бы одна ячейка имеет несвязное пересечение с краем $n-D F$.

На рис. 6 имеются три необычных диск-фуллерена 8- $D F_{74}\left(C_{2 \nu}\right), 9-D F_{74}\left(C_{\nu}\right)$ и $10-D F_{74}\left(C_{2 \nu}\right)$ с изоморфными скелетами. Причина изоморфности связана с тем, что скелеты являются 2-, но не 3-связными. По совсем другим причинам два диск-фуллерена, полученные из одного фуллерена при удалении разных 5- или 6-угольных граней, также имеют изоморфные скелеты. Однако, если скелет $n$ - $D F$ является 3 -связным, то, по теореме Уитни, при $n \neq 5,6$ существует одна и только одна его укладка на плоскости, при которой внешняя грань n-угольна (см. [85]).

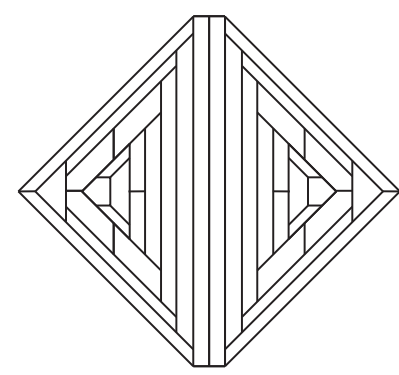

8- $D F_{74}\left(C_{2 \nu}\right)$

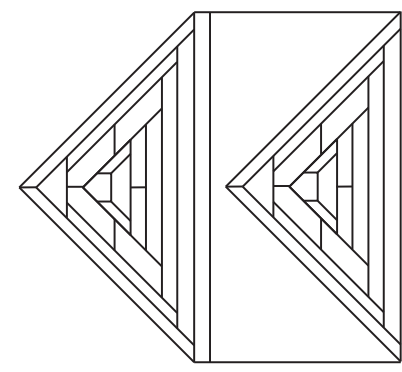

9- $D F_{74}\left(C_{\nu}\right)$

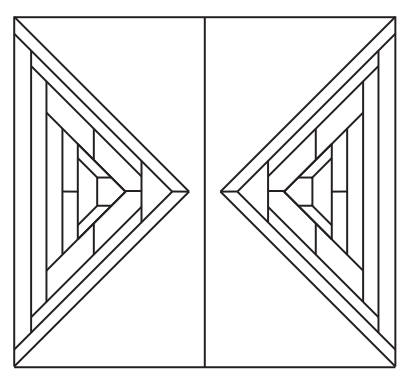

$10-D F_{74}\left(C_{2 \nu}\right)$

Рис. 6. Три диск-фуллерена с изоморфными скелетами

Если скелет $n$ - $D F_{v}($ Aut $D F$ ) изоморфен 2-, но не 3-связному графу $G$, то всегда имеем Aut $D F \subset$ Aut $G$, однако не всегда получаем Aut $D F \sim$ Aut $G$. Так, например, на рис. 7 даны два фрагмента диск-фуллерена с одинаковыми группами симметрии; однако эти группы по-разному расположены относительно двух ребер, на которых эти фрагменты подвешены в диск-фуллерен. В случае b) группа Aut $D F$ является собственной подгруппой группы Aut $G$.

ЗАмЕчАниЕ 4 . В определении 4 была дана выпуклая реализация $n-D F$ в виде замкнутой многогранной поверхности без ее $n$-угольной грани. Эта поверхность расположена в $\mathbb{R}^{3}$, но не в $\mathbb{R}^{2}$. Однако, если вне выпуклого многогранника в $\mathbb{R}^{3}$ взять точку $O$, достаточно близкую к внутренней точке $n$-угольной грани, то при центральной проекции из точки $O$ многогранник можно спроектировать на $n$-угольную грань. Получим еще одну выпуклую реализацию 


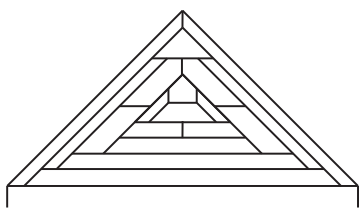

a)

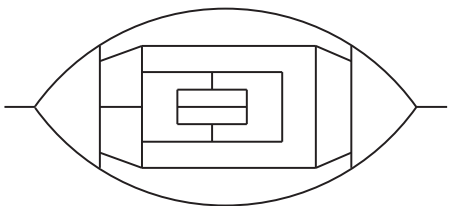

b)

Рис. 7. Два фрагмента необычного диск-фуллерена

$n$ - $D F$ в виде выпуклого 2-мерного $n$ - $D F$, расположенного в $\mathbb{R}^{2}$ и взятого вместе с его примитивным (в каждой вершине сходятся 3 ребра) разбиением на 5и 6-угольники. Эта проекция называется диаграммой Шлегеля. Для нее скелет является плоским кубическим графом с $n$-угольной внешней гранью.

Кроме абстрактного $n$ - $D F$ мы рассматривали абстрактную сферу, вернув ей удаленную ранее $n$-угольную грань. Можно рассматривать также произвольную абстрактную сферу, склеенную из любого числа 5 - и 6 -угольников и одного $n$-угольника с $n \geqslant 3$ и имеющую кубический скелет.

Следовательно, на сфере $\mathbb{S}^{2}$ опять мы имеем граф $G$, задающий на ней клеточное разбиение: двумерные клетки - компоненты области $\mathbb{S}^{2} \backslash G$, одномерные клетки - ребра графа $G$, нульмерные клетки - вершины графа $G$. Опять имеют место соотношения (4)-(6). Однако, если из сферы удалить внутренность $n$-угольной ячейки, то диск-фуллерен не получится в том случае, когда $n$-угольная область на $\mathbb{S}^{2}$ ограничена непростым реберным циклом (если скелет 1-, но не 2-связен).

Так, например, рассмотрим два 3-DF, изображенных на рис. 17 в [29], взяв на сфере $\mathbb{S}^{2}$ каждый в 3 -угольнике другого. На сторонах 5-угольников, принадлежащих краям, возьмем по одной дополнительной вершине. Соединив эти вершины ребром (точнее, мостом), получим разбиение сферы $\mathbb{S}^{2}$ на 5-, 6-угольники и одну 10-угольную область, ограниченную непростым реберным циклом. При удалении этой области не получится 10-DF. При восстановлении области разбиение сферы $\mathbb{S}^{2}$ не обретет реализацию в виде выпуклого многогранника в $\mathbb{R}^{3}$, обладающего 10-угольной гранью, или в виде выпуклого 10 -угольника в $\mathbb{R}^{2}$, так как скелет разбиения является 1 -, но не 2-связным $\left(\right.$ см. сноску $\left.{ }^{1}\right)$ : удаление вершины, принадлежащей мосту, нарушает связность скелета. (См. аналогичный пример 2 в п. 2.4.)

Таким образом, если скелет рассматриваемой абстрактной сферы

○ 1-, но не 2-связен, то ей не соответствует $n$-диск-фуллерен;

○ 2-, но не 3-связен, то ей соответствует необычный $n$-диск-фуллерен;

○ 3-связен, то ей соответствует обычный $n$-диск-фуллерен.

В двух последних случаях скелет абстрактной сферы изоморфен скелету абстрактного $n$ - DF. Впредь будем полагать, что край $n$-угольника на абстрактной сфере является простым реберным циклом. Следовательно, при удалении из сферы внутренности $n$-угольника получится абстрактный $n$ - $D F$. Он изоморфен обычному $n$ - $D F$, если его скелет 3 -связен, или необычному $n$ - $D F$, если 
его скелет 2-, но не 3-связен. Учитывая определение 5, предложение 3 и замечание 4 , мы получаем следующее предложение.

ПрЕДЛОЖЕНИЕ 4. Если скелет абстрактного n-диск-фуллерена 3-связен, то он имеет выпуклую реализацию в $\mathbb{R}^{3}$, не расположенную в $\mathbb{R}^{2}$, а также выпуклую реализацию в $\mathbb{R}^{2}$.

КРИтЕРИй 1. Абстрактный n-диск-фуллерен изоморфен обычному $n$-дискфуллерену тогда и только тогда, когда пересечение его края с любой ячейкой связно, т.е. его скелет 3-связен.

ЗАмЕчаниЕ 5. Если скелет абстрактного $n$ - $D F$ является 2-, но не 3 -связным, то он имеет выпуклую реализацию в $\mathbb{R}^{2}$. Имеется также реализация в $\mathbb{R}^{3}$ в виде выпуклой многогранной поверхности с краем, который не расположен в $\mathbb{R}^{2}$. Кроме того, имеется реализация в $\mathbb{R}^{3}$ в виде невыпуклой многогранной поверхности. Ее можно получить так. Выпуклую реализацию обозначим через $P$. Поверхность $P$ содержит ячейку $Q$, которая имеет несвязное пересечение с краем $\dot{P}=\partial P$. Разность $P \backslash Q$ также несвязна, значит, она состоит по меньшей мере из двух компонент связности. Отразив одну из компонент связности от плоскости ячейки $Q$, мы получим искомую невыпуклую реализацию. Такую реализацию имеет каждый необычный $n-D F$.

Таким образом, каждый абстрактный $n$ - $D F$ допускает выпуклую реализацию. Вид выпуклой реализации подробно описан в замечаниях 4 и 5 .

ПреДЛОЖЕНИЕ 5. Если скелет $n$-диск-фуллерена 3-связен $u n \geqslant 7$, то $f_{6} \geqslant 2$.

Доказательство. Докажем от противного. Пусть $f_{6}=0$. Тогда $n$ - $D F$ является конечным нерасширяемым $(5,3)$-полициклом. Однако существует всего лишь один конечный нерасширяемый $(5,3)$-полицикл - додекаэдр без грани (см. замечание 1 ), для которого $n=5$, а не $n \geqslant 7$. Получено противоречие. Значит, $f_{6} \neq 0$.

Пусть, далее, $f_{6}=1$. Тогда предстоит рассмотреть следующие два случая.

1) Если пересечение 6-угольника с краем диск-фуллерена непусто, то это ребро, так как скелет кубический и 3-связен. Удалив это ребро, получим $(5,3)$-полицикл с двумя вершинами степени 2; он нерасширяемый, так как $n \geqslant 7$; но это не додекаэдр без грани, для которого $n=5$ (см. замечание 1$)$.

2) Если 6-угольник не пересекается с краем, то первое кольцо (корона) вокруг него состоит из шести 5-угольников, пересечение каждого с 6-угольником связно. Соседние 5-угольники смежны, т. е. пересекаются по ребру. Несоседние 5-угольники не пересекаются. В самом деле, вершины внешнего края кольца имеют в нем чередующиеся степени 3 и 2. Две вершины степени 3 совпасть не могут, так как в противном случае образовалась бы вершина степени не меньше 4, что для диск-фуллерена недопустимо. Две вершины степени 2 также совпасть не могут, так как в противном случае совпали бы два примыкающих к ним ребра, два других конца которых имеют степень 3. Вершина степени 2 и вершина степени 3, принадлежащие несмежным 5-угольникам, также не могут совпасть, так как иначе совпали бы примыкающие к ним ребра кратчайшего 
пути между ними, расположенного на краю кольца, что невозможно, так как концы этих ребер принадлежат смежным 5-угольникам.

Итак, все 12 вершин внешнего края кольца различны. K половине этих вершин, имеющих степень 2 в кольце, примыкают 6 ребер диск-фуллерена, не принадлежащих кольцу. Никакие два из них не совпадают - при совпадении соседних ребер имелся бы 3-угольник, а при совпадении несоседних ребер имелся бы самопересекающийся многоугольник. Концы всех этих ребер также различны - иначе был бы 4-угольник или самопересекающийся многоугольник. Значит, любые два соседних ребра (из 6) вместе с двумя ребрами внешнего края первого кольца являются ребрами 5-угольника, принадлежащего второму кольцу. Его внешний край имеет 6 ребер. А так как каждая вершина этого края имеет степень 3 , то $n=6$. Получено противоречие с $n \geqslant 7$. Значит, $f_{6} \neq 1$. Предложение доказано.

В этом доказательстве найден единственный $n$ - $D F$ с $f_{6}=0$ (это додекаэдр без грани) и единственный $n-D F$ с $f_{6}=1$ (это бочка $F_{24}\left(D_{6 d}\right)$ без основания, т. е. $\left.6-D F_{24}\left(C_{6 \nu}\right)\right)$. Подчеркнем, что оба они остаются единственными $n$ - $D F$ с $f_{6}<2$ при всех $n \geqslant 1$.

В случае 3-связных скелетов в [29] построена серия $n$-DF, $n \geqslant 12$, с $f_{6}=6$, следовательно, подтверждена оценка $m_{3}(n) \leqslant 6$; предполагается, что эта оценка достигается при всех $n \geqslant 12$.

ПрЕДЛОЖЕНИЕ 6. Если скелет $n$-диск-фуллерена 2-связен, но не 3-связен и $n \geqslant 12, \operatorname{mo} f_{6} \geqslant 4$.

ДокАзАтельство. Согласно условиям, существует ячейка, пересечение которой с краем $n$ - $D F$ несвязно. Схемы таких пересечений даны на рис. 8, a)-d).

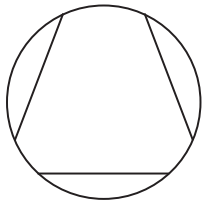

a)

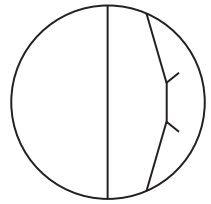

b)

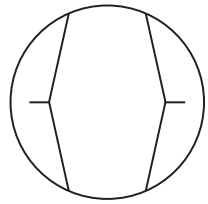

c)

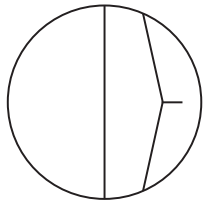

d)

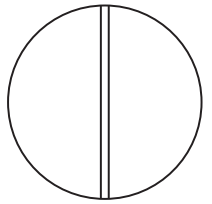

e)

Рис. 8. а)-d) - все несвязные пересечения ячейки с краем диска; е) диск разбит хордой на два сегмента

В случае а) 6-угольная ячейка пересекает край по трем ребрам. Остальные три ребра являются хордами, отсекающими от диска три сегмента. Докажем от противного, что в каждом сегменте есть 6-угольник. Если хотя бы один сегмент не содержит 6-угольников, то соединим центр 6-угольника с серединами его сторон, расположенных на краю диска, а каждый сегмент, содержащий 6-угольник, заменим на тот, который не содержит 6-угольников. В итоге получим конечный нерасширяемый $(5,3)$-полицикл, т. е. додекаэдр без грани (см. замечание 1), а он без хорды. Получено противоречие. Значит, в каждом сегменте есть 6-угольник, а весь диск содержит четыре 6-угольника. 
В случае b) в правом сегменте есть еще один 6-угольник, отличный от уже имеющегося (рис. 8, b)). В самом деле, соединим радиусами середину хорды с граничными вершинами 6-угольника, не принадлежащими хорде. Эти два радиуса вырезают 5-угольник из 6-угольника. Сектор, содержащий этот 5 -угольник, представляет собой $(5,3)$-полицикл с одной вершиной степени 2 , если исходный сегмент не содержит другого 6-угольника. Однако такого $(5,3)$-полицикла нет (см. замечание 1). Значит, в правом сегменте есть еще один 6-угольник. Если слева к хорде примыкает 6-угольник, то диск содержит четыре 6-угольника; а если примыкает 5-угольник, то см. случай d).

В случае с) соединим дополнительным ребром середины сторон 6-угольника, расположенные на краю диска, а потом см. случай $\mathrm{d})$.

В случае d) сначала докажем, что правый сегмент содержит 6-угольник (см. рис. $8, \mathrm{~d})$ ). В самом деле, если в правом сегменте нет 6 -угольников, то он и сегмент, ему симметричный относительно хорды, вместе составят конечный нерасширяемый $(5,3)$-полицикл, что невозможно (см. замечание 1$)$. Значит, в правом сегменте есть 6-угольник. Покажем, что есть еще и второй 6-угольник.

Если имеющийся 6-угольник пересекает край диска, то с учетом случаев a), b), c), рис. 8, достаточно рассмотреть случай, когда пересечение состоит из одного ребра. В таком случае мы удалим из сегмента это ребро и построим идентичный экземпляр, получающийся при повороте на угол $\pi$ вокруг середины хорды, как на рис. 8, е). Получится разбиение диска на 5-угольники, если правый сегмент не содержит второго 6-угольника. Это разбиение представляет собой конечный нерасширяемый $(5,3)$-полицикл с четырьмя вершинами степени 2. Но таких $(5,3)$-полициклов нет (см. замечание 1$)$.

Далее, если 6-угольник не пересекает край диска, то займемся исследованием возможного устройства сегмента. Так как все приграничные ячейки являются 5-угольниками, то с тем 5-угольником, который примыкает к исходной хорде, смежны два других 5-угольника. Если оба они примыкают к краю еще раз (т.е. пересечение каждого с краем диска несвязно, рис. 9, а)), то в правой части сегмента имеются два новых сегмента - подсегменты исходного сегмента. В каждом новом сегменте есть 6-угольник, что и требовалось доказать.

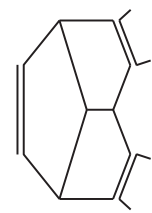

a)

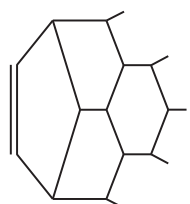

b)

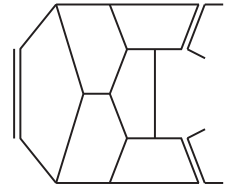

c)

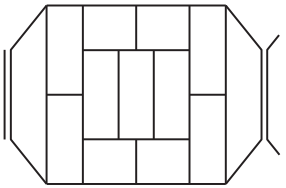

d)

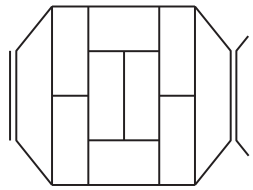

e)

Рис. 9. Сегмент с 5-угольником, примыкающим к хорде

Пусть оба 5-угольника не примыкают к краю еще раз (т. е. пересечение каждого с краем диска связно), но они смежны с 6-угольником (см. рис. 9, b)). Тогда прямолинейный отрезок, соединяющий вершины 6-угольника, соседние 
с левой его вершиной, разбивает 6-угольник на 3-угольник и 5-угольник. Заменим этот 3-угольник и три 5-угольника из сегмента, расположенные слева, на один новый 5-угольник, обладающий вершиной степени 2 (ее можно расположить в середине хорды). Если бывший сегмент не содержит другого 6 -угольника, то полученное взамен него разбиение представляет собой $(5,3)$-полицикл с одной вершиной степени 2, что невозможно (см. замечание 1). Значит, исходный сегмент обязан содержать другой 6-угольник.

Пусть теперь оба 5-угольника не примыкают ни к краю еще раз, ни к 6-угольнику, а примыкают к 5-угольнику и последний примыкает к краю (см. рис. 9, с)). Тогда в правой части сегмента имеются два подсегмента. В каждом подсегменте имеется 6-угольник, что и требовалось доказать.

Пусть, далее, оба 5-угольника не примыкают ни к краю еще раз, ни к 6-угольнику, а примыкают к 5-угольнику и последний примыкает к 6-угольнику $($ см. рис. $9, \mathrm{~d}))$. Тогда, при отсутствии в ближайшем окружении другого 6-угольника, сегмент имеет хорду. Значит, сегмент имеет подсегмент, в котором есть другой 6-угольник, что и требовалось доказать.

Пусть, наконец, оба 5-угольника не примыкают ни к краю еще раз, ни к 6-угольнику, а примыкают к 5-угольнику, причем последний примыкает к следующему 5-угольнику (см. рис. 9, е)). Тогда исходный сегмент имеет еще одну хорду. Значит, имеется подсегмент. Для него возможны все уже перечисленные варианты, в том числе е). Вариант е) может повториться лишь конечное число раз. Он не может быть завершающим, так как этот сегмент имеет хорду, отсекающую подсегмент. Остальные варианты приводят к двум 6-угольникам в сегменте. Предложение доказано.

В этом доказательстве показано, что в каждом сегменте, который отрезан от диска хордой, имеются два 6-угольника, т. е. $f_{6} \geqslant 2$. Поэтому в некоторых частных случаях имеется более сильный результат, чем тот, который сформулирован в предложении 6. Так, например, диск на рис. 8, а) имеет семь 6-угольников, а диск на рис. 8, с) имеет пять 6-угольников. Уточнение относится не только к дискам, но и к их сегментам. Так, например, сегменты на рис. 9, а) и с), разумеется, целые, имеют по четыре 6-угольника, а сегмент на рис. 9, d) имеет три 6-угольника.

Мы начнем дальнейшее исследование величины $\min f_{6}$ при произвольном $n$ с нахождения $\min f_{6}$ для сегментов, ограниченных небольшим числом ребер. Для каждого из них $f_{6} \geqslant 2$. Пусть сегмент, отрезанный хордой от диска, имеет $j$ ребер на краю диска. Тогда циклическая последовательность степеней вершин ${ }^{3}$, расположенных на границе сегмента, имеет вид $(2,2,3, \ldots, 3)=$ $(2)^{2}(3)^{j-1}$. Легко видеть, что $j \geqslant 4$. Как оказалось, $f_{6}=2$ при $j=7,8$. На два таких сегмента разбит 15-диск-фуллерен, изображенный на рис. 10, а).

При $j=7$ есть еще один сегмент, в котором к хорде примыкает 5-угольник, a c 5-угольником смежны два 6-угольника: правый сегмент на рис. 10, а), для него $j=8$, имеет ребро, удаление которого делает сегмент зеркально симметричным, но уже с $j=7$. Уже при $j=17$ сегмент с $f_{6}=2$ имеет хорду,

\footnotetext{
${ }^{3}$ Ее называют граничным кодом (см. [30], [59], [28], а также определение 12 в п. 2.5).
} 


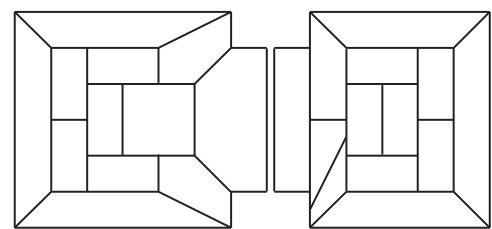

a)

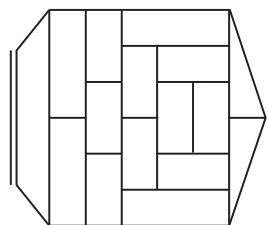

b)

Рис. 10. а) $15-D F_{48}\left(C_{1}\right)$ разбит на два сегмента; b) сегмент с $f_{6}=3$

отрезающую от него подсегмент. Уже при $j=15$ сегмент с $f_{6}=3$ содержит 6 -угольник, который имеет несвязное пересечение с краем сегмента.

При остальных $j, 4 \leqslant j \leqslant 16$, имеет место неравенство $f_{6} \geqslant 3$. Однако лишь при $j=6,7,8,9,10,15,16$ есть сегменты с $f_{6}=3$. Например, при $j=6$ имеется сегмент, изображенный на рис. 11, а). При $j=10$ имеется сегмент, изображенный на рис. 10, b). Если два смежных 5-угольника, принадлежащих сегменту с $j=10$, для которых один конец общего ребра лежит на краю сегмента, а другой конец принадлежит 6-угольнику, объединить в один 6-угольник, то получим другой сегмент, обладающий параметром $j=9$. Сегменты с $j=15$ и $j=16$ изображены на рис. $11, \mathrm{~b})$ и с).

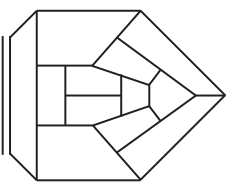

a)

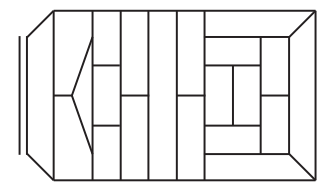

b)

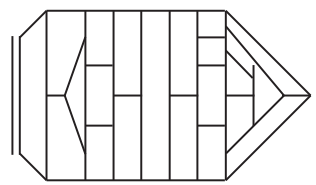

c)

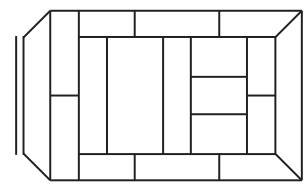

d)

Рис. 11. Четыре сегмента: а), b) и с) с $f_{6}=3$; d) с $f_{6}=4$

Отметим, что при $j=4,5,11,12,13,14$ имеет место оценка $\min f_{6} \geqslant 4$. Сегмент с $f_{6}=4$ при $j=11$ изображен на рис. $\left.11, \mathrm{~d}\right)$. При $4 \leqslant j \leqslant 14$ ни один из рассматриваемых сегментов не имеет подсегментов.

В [29] при $n \geqslant 12$ построена серия $n$ - $D F$ с 3-связным скелетом, для которых $f_{6}=6$. Следовательно, при $n \geqslant 12$ для всех $n$ - $D F$ с 3-связными скелетами имеют место оценки $\min f_{6} \leqslant 6$, т. е. $m_{3}(n) \leqslant 6$. Напомним предположение 1 из [29]: $n-D F_{v}$ существует тогда и только тогда, когда $v \geqslant 2\left(m_{3}(n)+n+5\right)$, $n \geqslant 1$, за исключением невозможных случаев $(n, v)=(1,42),(3,24),(5,22)$, где $m_{3}(n)$ - наименьшее значение $f_{6}$ при заданном $n$ для $n$ - $D F$ с 3 -связными скелетами. Все такие значения $m_{3}(n)$ при $3 \leqslant n \leqslant 11$ даны в табл. 1 .

ТАБлицА 1. Наименьшие значения $f_{6}$ для обычных (скелет 3-связен) $n-D F$ с $3 \leqslant n \leqslant 11$

\begin{tabular}{|r||r|r|r|r|r|r|r|r|r||}
\hline$n$ & 3 & 4 & 5 & 6 & 7 & 8 & 9 & 10 & 11 \\
\hline$m_{3}(n)$ & 3 & 2 & 0 & 1 & 3 & 4 & 6 & 7 & 8 \\
\hline
\end{tabular}


Теорема 1. Пусть $n \geqslant 12$, пусть скелет $n$-диск-фуллерена 2-связен, но не 3-связен, и пусть $m_{2}(n)$ - минимум $f_{6}$ в таком $n$-диск-фуллерене. Тогда:

(i) $m_{2}(n)=4$, если $n \equiv 4,5,6(\bmod 10)$;

(ii) $m_{2}(n)=5$, если $n \equiv 2,3,7,8(\bmod 10)$;

(iii) $m_{2}(n)=6$, если $n \equiv 0,1,9(\bmod 10)$.

Доказательство. (i) На рис. 10, а) изображен $15-D F_{48}\left(C_{1}\right)$. Этот $15-D F$ разбит хордой на два сегмента. Левый сегмент и сегмент, зеркально симметричный ему относительно хорды, составляют 14- $D F$. Правый сегмент и сегмент, зеркально симметричный ему относительно хорды, составляют 16- DF. Для этих трех диск-фуллеренов имеем $f_{6}=4$. Оба сегмента любого из них можно раздвинуть и вставить между ними произвольное количество $(5,3)$-полициклов, идентичных изображенному на рис. 9, е). Других $n$ - DF с $f_{6}=4$ не существует.

(ii) Случай $n=12$ занимает особое положение. Два сегмента, идентичных изображенному на рис. 11, a), составляют 12-DF. Между сегментами можно вставить слагаемое, изображенное на рис. 9, е). Два сегмента, изображенных на рис. 11, а) и с), составляют 22-DF. Для каждого из них $f_{6}=6$. Однако это не $m_{2}(n)$ при $n=12$ и $n=22$. В самом деле, пусть к хорде сегмента примыкает 5-угольник, с которым смежны два 6-угольника, а все остальные ячейки сегмента суть 5-угольники; это сегмент с $f_{6}=2$ при $j=7$. Тогда диск, составленный из двух таких сегментов, представляет собой $14-D F$ с $f_{6}=4$. Объединив два 5-угольника, смежных по хорде, в 6-угольник, получим 12- DF с $f_{6}=5$ (см. [29]). Это минимальный $12-D F_{44}\left(C_{2 \nu}\right)$ (см. замечание 9 в п. 2.4).

Сегмент с $f_{6}=2$ при $j=7$ и сегмент, изображенный на рис. $\left.11, \mathrm{~b}\right)$, составляют 22- $D F$. Между сегментами можно вставить любое число $(5,3)$-полициклов, изображенных на рис. 9, е). Левый сегмент, изображенный на рис. 10, а), и сегмент на рис. 11, а) составляют $13-D F$ с $f_{6}=5$. Между сегментами можно вставить любое число $(5,3)$-полициклов, изображенных на рис. 9 , е). На рис. 10 левый сегмент а) вместе с сегментом b) составляют 17-DF, а правый сегмент а) и сегмент b) составляют $18-D F$. В обоих случаях $f_{6}=5$. Между сегментами можно вставить любое число $(5,3)$-полициклов, изображенных на рис. 9 , е).

(iii) Сегмент с $f_{6}=2$ при $j=8$, изображенный на рис. 10, а) справа, и сегмент с $f_{6}=4$ при $j=11$, изображенный на рис. $\left.11, \mathrm{~d}\right)$, составляют $19-D F$ с $f_{6}=6$. Два сегмента с $f_{6}=3$ при $j=10$, изображенные на рис. $\left.10, \mathrm{~b}\right)$, составляют $22-D F$ с $f_{6}=6$. Сегмент с $f_{6}=3$ при $j=6$ (см. рис. 11, а)) и сегмент с $f_{6}=3$ при $j=15$ (см. рис. $11, \mathrm{~b})$ ) составляют 21-DF с $f_{6}=6$. Между сегментами можно вставить любое число (5,3)-полициклов, изображенных на рис. 9, е).

Таким образом, осталось лишь подтвердить, что $m_{2}(n) \neq 5$ в случае (iii). Пусть разбиение диска с $f_{6}=5$ не имеет ребра, которое является хордой (см. рис. 8, c)). Тогда середины противоположных сторон 6-угольника, расположенных на краю диска, соединим новым ребром. Получим новое разбиение диска с $f_{6}=4$. Значит, $j=7$ или $j=8$. Точнее, такими могут быть завершающие сегменты, а между ними возможны вставки, изображенные на рис. 9, е). После удаления нового ребра вернемся к старому разбиениию диска с $f_{6}=5$. Число ребер на краю диска равно $7+7-2=12,7+8-2=13$ или $8+8-2=14$. При $n=12,13$ опять имеем $m_{2}(n)=5$, однако $m_{2}(n)=4$ при $n=14$. 
Пусть разбиение диска с $f_{6}=5$ имеет ребро, которое является хордой. Тогда

○ либо один сегмент с $f_{6}=2$, другой сегмент с $f_{6}=3$, а между ними возможны вставки, изображенные на рис. 9 , е),

○ либо два сегмента с $f_{6}=2$, одна вставка с $f_{6}=3$, изображенная на рис. 9, d), а также возможны вставки, изображенные на рис. 9 , е).

Во втором случае число ребер на краю диска равно $7+7+12=26,7+8+12=$ 27 или $8+8+12=28$. При $n=27,28$ опять имеем $m_{2}(n)=5$, однако мы имели $m_{2}(n)=4$ при $n=26$. На этом подтверждение завершено.

В случаях (i), (ii), (iii) рассмотрены все $n \geqslant 12$. При сохранении числа ребер края количество 6-угольников $n$ - $D F$ может быть сделано равным любому заранее заданному натуральному числу, большему $4,5,6$ соответственно. Это достигается применением вертушки операций $\varphi_{i}, i=1,2, \ldots$ (см. рис. 5).

Значит, существует неограниченное множество обычных и необычных $n$ - $D F$, обладающих граничным кодом $(3,3, \ldots, 3)=(3)^{n}$, если $n \geqslant 12$ (см. [29], сноску $^{3}$, табл. 2, а также [28] и [38]). Теорема доказана.

При $n \leqslant 21$ все значения $m_{2}(n)$ для $n$ - $D F$ с 2 -, но не 3 -связными скелетами, приведены в табл. 2. В ней все минимальные $n$ - $D F$ при $n \leqslant 11$ были найдены компьютерным подсчетом. Они единственны, кроме $n=9$ и 11 ; в минимальных исключительных $n$ - $D F-$ т. е. в одном $1-D F_{40}\left(C_{s}\right)$ и одном $2-D F_{26}\left(C_{2 \nu}\right)-$ все $n+6$ пятиугольников организованы в блок, противоположный $n$-угольнику; при $n=8,9,10,11$ имеются один 8- $D F_{72}\left(C_{2 v}\right)$, два 9- $D F_{62}\left(C_{s}\right)$, один $10-D F_{50}\left(C_{2 v}\right)$, два $11-D F_{48}\left(C_{s}\right)$. Все 6 этих минимальных необычных $n-D F$ напоминают химические нанотрубки (продолговатые фуллерены) - они состоят из похожих блоков из 5-угольников, разделенных 6-угольниками; см. также замечания 9 и 10. Аналогичный $n-D F$ был изображен на рис. 6 , а), но он не минимален.

ТАБлица 2. Наименьшие значения $f_{6}$ для необычных (скелет только 2-связен) $n-D F$

\begin{tabular}{|r||r||r|r|r|r||r|r|r|r|r|r|r|r|r|r||}
\hline$n$ & 2 & 8 & 9 & 10 & 11 & 12 & 13 & 14 & 15 & 16 & 17 & 18 & 19 & 20 & 21 \\
\hline$m_{2}(n)$ & 6 & 23 & 17 & 10 & 8 & 5 & 5 & 4 & 4 & 4 & 5 & 5 & 6 & 6 & 6 \\
\hline
\end{tabular}

Таблица 2 периодически повторяется: при $n \geqslant 22$ имеет место равенство $m_{2}(n)=m_{2}(10+n-[n / 10])$, где квадратные скобки обозначают целую часть. Мы предполагаем, что $m_{3}(n)=6$, значит, $m_{1}(n)=m_{2}(n)$, если $n \geqslant 22$ (см. [29]). Конечно, $m_{1}(n)=m_{3}(n)$ при $n \geqslant 19, n \equiv 0,1,9(\bmod 10)$. Число $n-D F$, на которых достигается $m_{1}(n)$, равно 1 при $n=1, \ldots, 8$ и $2,3,8$ при $n=9,10,11$ соответственно. Число $n$ - $D F$, на которых достигается $m_{3}(n)$, равно 1 при $3 \leqslant$ $n \leqslant 21$, кроме $n=9,10,11$, и, возможно, при всех $n \geqslant 22$. Значения $m_{2}(n)$ для $n \geqslant 12$ даны в теореме 1 . См. также табл. 4 в п. 2.5 .

Построим 8-DF $72\left(C_{2 v}\right)$. Возьмем правильный 8-угольник. Двумя параллельными хордами разделим его на две трапеции и прямоугольник. Объявив середины хорд вершинами, превратим прямоугольник в 6-угольник, а трапеции в 5-угольники. Из трех вершин 5-угольника со степенью 2 выпустим три ребра, направленных по биссектрисам углов. Их свободные концы служат вершинами треугольника, контур которого является внутренним краем кольца, 
составленного из трех многоугольников, примыкающих к краю трапеции. Все три превратим в 6-угольники, разбив две стороны треугольника на два ребра, а одну на три. Из полученных четырех вершин степени 2 выпустим 4 ребра. Их свободные концы служат вершинами 4-угольника, контур которого является внутренним краем 2-го кольца, составленного из четырех многоугольников, примыкающих к 1-му кольцу. Все четыре превратим в 6-угольники, разбив три стороны 4-угольника на два ребра, а одну на три. Из полученных пяти вершин степени 2 выпустим 5 ребер. Их свободные концы служат вершинами 5-угольника, контур которого является внутренним краем третьего кольца, составленного из многоугольников, примыкающих ко второму кольцу. Середины сторон 5-угольника объявим вершинами и выпустим из них 5 ребер. Их свободные концы являются вершинами последнего 5-угольника.

Устройство одного из 9- $D F_{62}\left(C_{s}\right)$ отличается от $8-D F_{72}\left(C_{2 v}\right)$ тем, что одна из двух трапеций заменяется на правильный 5-угольник. Он также разбивается на ячейки, но к его краю примыкают 4 шестиугольника, а не три, как в случае трапеции. Кроме того, два 6-угольника, смежные с центральным 6-угольником, смежны с пятым 6-угольником, а остальные ячейки 5-угольные.

О $10-D F_{50}\left(C_{2 v}\right)$ и одном $11-D F_{48}\left(C_{s}\right)$ сказано в п. 2.5, см. подслучай 1.2 .

Для доказательства теоремы 1 нужно было найти все сегменты с $f_{6}=2$ и $f_{6}=3$, для которых пересечение края с любой ячейкой связно. На первый взгляд, эта задача казалась очень сложной, так как уже для $f_{6}=4$ имеется бесконечная серия сегментов, для которых пересечение края с любой ячейкой связно. Она задается параметром $j=13+k$, где $k \in \mathbb{N}$. Однако задача была решена при помощи специальной вычислительной программы. Показано, что в случаях $f_{6}=2$ и $f_{6}=3$ имеется только 15 искомых сегментов: три с $f_{6}=2$ и двенадцать с $f_{6}=3$. Они изображены в табл. 3 .

ТАБлицА 3. Все сегменты с $f_{6}=2$ и $f_{6}=3$ и связными пересечениями края с ячейками
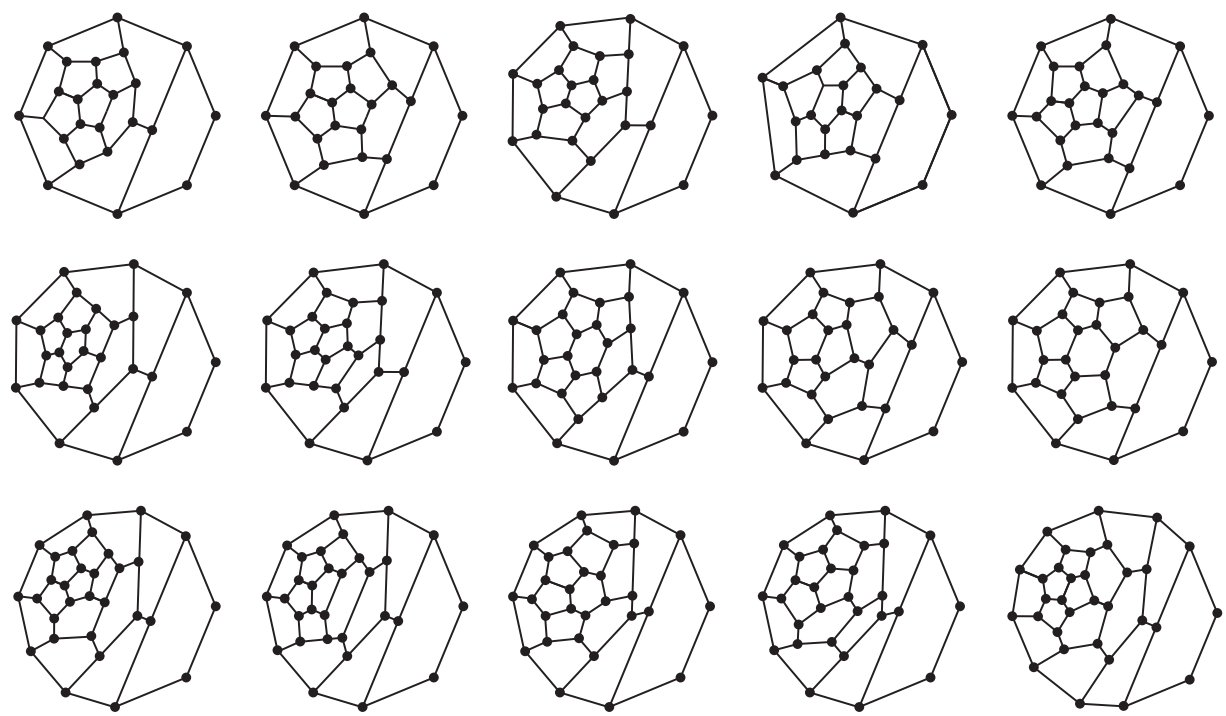
Все эти 15 сегментов являются обобщенными диск-фуллеренами. Они расширяемы, так как каждый обладает ребром, концы которого являются вершинами степени 2. Однако ни один из них не является лоскутом, т. е. не может быть расширен до фуллерена.

Отметим также, что были найдены аналогичные 5 сегментов с $f_{6}=4$ при $j \leqslant 14$ (при $j=14$ это наименьший представитель упомянутой выше серии, соответствующий наименьшему $k=1$ ) и 11 сегментов с $f_{6}=5$ при $j \leqslant 13$, но их перечень мы здесь не приводим.

\section{3. Строение фуллеренов и диск-фуллеренов.}

ОпредЕлЕниЕ 6 . Замкнутый реберный путь в скелете фуллерена или дискфуллерена называется зигзагом (см. введение), если при перемещении вдоль этого пути происходит чередование поворота то влево, то вправо во всех вершинах. Зигзаг называется простым, если он не имеет самопересечений. См. также [25] и [26].

Простой зигзаг произвольного фуллерена или диск-фуллерена не может содержать меньше 10 ребер, в чем легко убедиться. Значит, если все зигзаги являются простыми, то их количество не превышает $e / 5$, так как ребра ровно дважды покрываются всеми зигзагами.

ЗАмечАниЕ 6. (i) Если два зигзага пересекаются, то каждая компонента связности пересечения зигзагов состоит из одного ребра. В каждом из них пересечение является трансверсалъным - участки зигзагов вблизи общего ребра находятся по разные стороны друг от друга. Это свойство имеет место и для самопересекающегося зигзага.

(ii) Каждая из $n$ пар смежных ребер края любого $n$ - $D F$ порождает зигзаг, быть может, самопересекающийся. Только такие зигзаги пересекают край и их число не больше $n$.

(iii) Если ребро не принадлежит краю диск-фуллерена, а оба конца ребра принадлежат краю, то зигзаг, содержащий это ребро, самопересекается. Если зигзаг пересекает край и является простым, то при циклическом обходе зигзага на нем будут чередоваться два ребра края диск-фуллерена и не менее двух ребер, не принадлежащих краю.

ПреДлОжЕНИЕ 7. Пересечение ячейки произвольного n-диск-фуллерена (или фуллерена) с его простым зигзагом является связным.

ДокАзАтЕльство. Ячейка фуллерена или диск-фуллерена не может иметь лишь одно общее ребро с зигзагом. Непустое пересечение 5-угольника с простым зигзагом содержит два и только два смежных ребра. Докажем от противного, что две противоположные пары смежных ребер 6-угольника не могут принадлежать простому зигзагу. Сначала докажем это для фуллерена.

Пусть две противоположные пары смежных ребер 6-угольника принадлежат простому зигзагу. Тогда ячейка, смежная с 6-угольником по ребру, не принадлежащему зигзагу, имеет несвязное пересечение с зигзагом. Значит, это 6-угольник, второй после исходного. Со вторым смежен третий, имеющий несвязное пересечение с зигзагом, и т. д. Всевозможные варианты завершения 


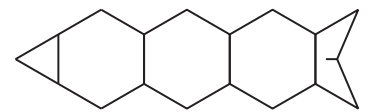

a)

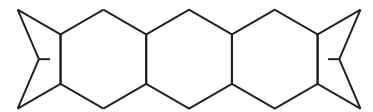

b)

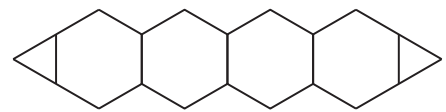

c)

Рис. 12. При несвязном пересечении зигзага с 6-угольником найдется $m$-угольник с $m \neq 5,6$

этого процесса (здесь в оба конца) изображены на рис. 12. Однако все они невозможны для фуллерена.

Для диск-фуллерена доказательство проводится аналогично, но со следующей поправкой. Если первый 6-угольник, имеющий с зигзагом общие две противоположные пары смежных сторон, расположен с внутренней стороны от зигзага, доказательство точно такое же. Пусть, далее, первый 6-угольник расположен с внешней стороны. Тогда второй 6-угольник мы выбираем с той стороны, в которой находится (в качестве внутренней) та часть зигзага, которая является внутренней относительно цикла, состоящего из другой части зигзага и стороны первого 6-угольника, не принадлежащей зигзагу. Со вторым 6-угольником смежен третий, имеющий несвязное пересечение с зигзагом, и т. д. Как и для фуллерена, этот процесс (тут лишь в один конец) не может завершиться 6-угольником. Предложение доказано.

СлЕДСТВИЕ 2. Число ячеек, примыкающих к простому зигзагу с любой его стороны, равно половине числа его ребер. Имеется исключение: при подсчете числа ячеек диск-фуллерена, примыкающих к его зигзагу с внешней стороны, не нужно учитывать те ребра зигзага, которые лежат на его границе.

Теперь выделим среди диск-фуллеренов некоторые специальные их виды наперстки.

ОПРЕДЕЛЕНИЕ 7. Если все приграничные ячейки (абстрактного) $n$-дискфуллерена являются 5 -угольниками, число которых равно $n$, то будем называть его (абстрактным) n-наперстком.

ЗАмЕчАниЕ 7. При удвоении наперстка (т. е. при отождествлении граничных точек двух идентичных наперстков) получится разбиение сферы на 5- и 6 -угольники. В этом разбиении $n$ вершин имеют степень 4 . При этом бывшие приграничные 5-угольники в удвоении разбиваются на пары, в каждой из которых они смежны по бывшему ребру края. Каждую такую пару заменим на 6-угольник. Внутренние точки бывших ребер края станут внутренними точками новых 6-угольников, а вершины степени 4 станут внутренними точками их противоположных сторон. В итоге получится фуллерен. Здесь каждый из двух исходных идентичных наперстков заполняет ровно половину фуллерена, но не является лоскутом в смысле [57]: при расширении наперстка до фуллерена его комбинаторное устройство не сохраняется.

Два сегмента, идентичных сегменту, изображенному на рис. 10, b), составляют 20- $D F$, все приграничные ячейки которого являются 5-угольниками. Ясно, 
что он не является наперстком, так как число его приграничных 5-угольников равно 18, а не 20.

ПримеР 1. Зафиксируем число $n \geqslant 7$ и построим $n-3$ концентрических окружностей радиусов $1,2, \ldots, n-4, n-3$. Используя эти окружности и единичные отрезки, соединяющие выделенные точки на них, которые будут вершинами, построим скелет (реберный остов) искомого наперстка. А именно, между соседними окружностями мы разместим соответственно по $6,7,8, \ldots, n-1, n, n$ единичных отрезков. (Лишь в последнем кольце между окружностями мы сохраним число таким же, как в предпоследнем кольце. В частности, при $n=7$ в трех кольцах между окружностями будут расположены $6,7,7$ отрезков соответственно.) Эти отрезки вместе с дугами окружностей составляют скелет наперстка, который заполняет весь круг радиуса $n-3$.

Теперь выберем вершины. На окружности радиуса 1 выбираем 6 вершин ${ }^{4}$, которые разделяют ее на 6 элементарных дуг. Из них вдоль радиусов окружностей выпустим 6 единичных отрезков, заканчивающихся в 6 вершинах на окружности радиуса 2. Добавим на ней еще 7 вершин, разделив 5 элементарных дуг на две части, а оставшуюся одну на три части. Из добавленных 7 вершин выпустим вдоль радиусов 7 единичных отрезков, заканчивающихся в 7 вершинах на окружности радиуса 3. На окружности радиуса 3 добавим еще 8 вершин, разделив одну (единственную: если другую, то будет семиугольник) элементарную дугу на три части, а остальные 6 элементарных дуг на две части, и из добавленных 8 вершин выпустим 8 единичных отрезков, заканчивающихся в 8 вершинах на окружности радиуса 4. Так поступаем до тех пор, пока выпущенные $n$ единичных отрезков не зададут на предпоследней окружности $n$ вершин. Разделив каждую элементарную дугу предпоследней окружности на две части, выпустим из добавленных $n$ вершин $n$ единичных отрезков, концы которых отметят $n$ вершин на последней окружности. Построение завершено.

Есть пять 5-угольников в первом кольце между окружностями, один 5-угольник в предпоследнем кольце, $n$ пятиугольников в последнем кольце. Все остальные ячейки суть 6-угольники. Получен $n$-диск-фуллерен. К его краю примыкают $n$ пятиугольников из $n+6$ (см. (5)). Это $n$-наперсток.

Нетрудно проверить, что $n$-наперстки существуют при любом $n \geqslant 5$, но не при $n \leqslant 4$.

ЛЕмма 1. Все приграничные 5-уголъники произволъного наперстка составяяют иилиндр, один край которого совпадает с краем наперстка, а другой край является простым зигзагом.

ДокАЗАТЕЛЬСтво. Возьмем произвольный наперсток и рассмотрим циклическую последовательность 5-угольников, примыкающих к его краю. Все 5-угольники этой последовательности различны. В самом деле, каждый из них имеет лишь одно ребро на краю наперстка, так как их число равно числу ребер края. Соседние 5-угольники последовательности смежны по ребру,

\footnotetext{
${ }^{4}$ Точно так же строится другая серия наперстков, если выбор начать с пяти вершин, а не шести.
} 
один конец которого принадлежит краю наперстка. Докажем от противного, что несоседние 5-угольники последовательности не пересекаются. Пусть они пересекаются. Тогда рассмотрим два случая.

Случай 1. Одна и та же точка $A$ является общей вершиной несоседних 5 -угольников, которая в обоих 5-угольниках противоположна ребру, принадлежащему краю наперстка. Так как $q=3$, то оба 5-угольника имеют общее ребро $A B$. В звезде вершины $B$ имеется третья ячейка, которая имеет общее ребро $B C$ с одним 5-угольником и ребро $B D$ с другим. Вершины $C$ и $D$ принадлежат краю наперстка. Так как к краю примыкают только 5-угольники, то третья ячейка является 5-угольником, который должен иметь несвязное пересечение с краем наперстка. Получено противоречие.

Случай 2. Два 5-угольника имеют общее ребро $A B$, где $A$ противоположна ребру края в одном 5 -угольнике, а $B$ противоположна ребру края в другом. В звезде вершины $B$ имеется третья ячейка, смежная с первым 5-угольником последовательности по ребру, один конец которого принадлежит краю наперстка. Значит, третья ячейка является 5-угольником. Третий и второй 5-угольники имеют общее ребро, обозначим его $B C$. В звезде вершины $C$ сходятся второй, третий и четвертый 5 -угольники, из них четвертый и третий имеют общее ребро $C D, \ldots$ и т. д. Цепь $A B C D \ldots$ продолжается однозначно и неограниченно. (Две полоски 5-угольников, одна с четными номерами, другая с нечетными, не могут замкнуться в цилиндр, у которого две компоненты края. Однако эти две полоски не могут замкнуться и в лист Мёбиуса, хотя у него только одна компонента края.) Опять получено противоречие. Лемма доказана.

Пары сторон приграничных 5-угольников, смежных в вершине, противоположной стороне 5-угольника, принадлежащей краю наперстка, составляют простой зигзаг. Это следует из того, что все приграничные ячейки являются 5-угольниками, а они различны, так как это наперсток.

Если приграничные ячейки $n-D F$ являются 5 -угольниками, то пары сторон этих 5-угольников, смежных в вершине, противоположной стороне, принадлежащей краю $n$ - $D F$, составляют самопересекающийся зигзаг, если это не наперсток. Но если все приграничные ячейки $n$ - $D F$ являются 5-угольниками, составляющими цилиндр, второй компонентой края которого служит простой зигзаг, то этот $n-D F$ является наперстком.

Таким образом, в силу определения 7, предложения 4 и критерия 1 , мы получаем следующее утверждение.

СлеДСтвиЕ 3. Скелет произвольного абстрактного наперстка изоморфен скелету некоторого наперстка, т.е. он 3-связен.

ПреДЛОЖЕНИЕ 8. Диск, вырезанный из фуллерена или n-диск-фуллерена простым зигзагом, содержит ровно 6 пятиуголъников.

ДокАЗАТЕЛЬСтво (см. также [26]). Обозначим вырезанный зигзагом $Z$ диск через $D$. (Имеются два таких диска в случае фуллерена и только один в случае диск-фуллерена.) Степенями вершин зигзага $Z$ в диске $D$ являются чередующиеся друг с другом числа 3 и 2 . K каждой паре граничных ребер диска $D$, смежных в его вершине степени 3 , приклеим свой 5-угольник. (Число 
этих 5-угольников равно половине числа ребер зигзага.) Отождествив ребра 5 -угольников, примыкающих к вершинам степени 2 в диске $D$, получим наперсток. Кроме этих приграничных 5-угольников, наперсток содержит ровно шесть 5-угольников, которые принадлежат диску D. Предложение доказано.

СлеДСТвИЕ 4. Из леммы 1 и следствия 2 получаем, что для произвольного $n$-наперстка имеет место оченка $f_{6} \geqslant n-6$. Значит, при $n \geqslant 13$ это не минимальный $n-D F$.

Диск $D$, фигурирующий в предложении 8, составляет половину некоторого фуллерена, так как он и зеркально симметричный ему диск, повернутый на $2 \pi / z$, где $z$ - число ребер зигзага, составляют фуллерен. Он также является лоскутом (при расширении этого диска до фуллерена его комбинаторное устройство сохраняется, см. определение 11 ниже и [57]). Напомним следующее определение (см. введение).

ОПредЕлЕниЕ 8. Если фуллерен или диск-фуллерен содержит циклическую последовательность 6-угольников, в которой каждый 6-угольник по паре своих противоположных сторон смежен с соседними 6-угольниками, но не смежен с несоседними, то эта последовательность составляет пояс. В работах [36], [37], [26], [27] пояс назван железной дорогой.

Каждый 6-угольник фуллерена или диск-фуллерена принадлежит не более чем трем поясам. Обе компоненты края пояса одинаковы - это равные простые зигзаги.

Разрежем фуллерен с поясом по серединной линии пояса. Тогда каждый 6-угольник пояса распадется на два 5-угольника, а фуллерен распадется на два наперстка. Эти наперстки не обязаны быть одинаковыми и не являются лоскутами.

ЛЕмма 2. Если фуллерен или диск-фуллерен имеет простой зигзаг, с одной и той же стороны от которого ко всем его ребрам примыкают только 6-угольники, то они составляют пояс.

ДокАзАТЕЛьство. Примыкающий к зигзагу 6-угольник содержит два смежных ребра зигзага (см. предложение 7), число таких 6-угольников вдвое меньше числа ребер зигзага (см. следствие 2). Возьмем в циклической цепочке 6-угольников два соседних 6-угольника. Они смежны по ребру. Один конец этого ребра принадлежит зигзагу. Пусть другой конец ребра, обозначим его через $A$, принадлежит третьему 6-угольнику, примыкающему к данному зигзагу по двум ребрам, смежным в вершине, диаметрально противоположной вершине $A$. Тогда третий 6 -угольник смежен с каждым из первых двух. Пусть ребро $A B$ является пересечением третьего 6-угольника со вторым. Тогда вершина $B$ принадлежит некоторой четвертой ячейке (ввиду $q=3$ ). А так как один конец ребра, по которому четвертая ячейка смежна с третьей, принадлежит зигзагу, то четвертая ячейка является 6-угольником, примыкающим к данному зигзагу. Пусть ребро $B C$ является пересечением четвертого 6-угольника со вторым. Тогда вершина $C$ принадлежит пятой ячейке, точнее, 6-угольнику, примыкающему к данному зигзагу (как и в случае четвертой ячейки). Пусть 
ребро $C D$ является пересечением пятого 6-угольника с четвертым. Тогда, как и выше, вершина $D$ принадлежит шестому 6-угольнику, примыкающему к данному зигзагу, и т. д.

Если, наконец, номера второго и третьего 6-угольников поменять местами, то мы получим две цепочки 6-угольников, одна с четными номерами, другая с нечетными номерами, смежных по серединной ломаной $A B C D \ldots$. Ломаная $A B C D \ldots$ является бесконечной. (Она не может замкнуться. Если бы ломаная $A B C D \ldots$ замкнулась, то она имела бы либо четное число звеньев, либо нечетное. Однако оба случая невозможны: в первом случае две цепочки 6-угольников не могут замкнуться в цилиндр, у которого две компоненты края; во втором случае они не могут замкнуться в запрещенный (см. выше) лист Мёбиуса, хотя у него одна компонента края.) Получено противоречие.

Таким образом, примыкающие к зигзагу 6-угольники, расположенные от него с одной стороны, не пересекаются, если они не соседние в циклической последовательности. Значит, они составляют пояс. Вторая компонента края пояса также является простым зигзагом. Лемма доказана.

В лемме 1 требуется, чтобы число приграничных 5-угольников было равно числу ребер края. Тогда в циклической последовательности несоседние 5-угольники не совпадают и не пересекаются.

В лемме 2 не требуется, чтобы количество 6-угольников, примыкающих к простому зигзагу с одной стороны, было равно половине числа ребер зигзага. Несмотря на это, в циклической последовательности несоседние 6-угольники не совпадают и не пересекаются.

Доказательства лемм 1 и 2 не случайно похожи друг на друга. Лемму 1 можно считать частным случаем леммы 2 - достаточно разрезать пояс вдоль серединной линии и получить наперсток.

ЗАмЕчАниЕ 8. На неориентируемой двумерной поверхности зигзаг может иметь либо четное число ребер, либо нечетное. Однако диск и сфера ориентируемы и поэтому для них каждый зигзаг имеет четное число ребер.

ПреДЛОжеНИЕ 9. Предположим, что два простых зигзага некоторого фуллерена не пересекаются друг с другом. Тогда:

(i) фуллерен имеет по менвшей мере один пояс;

(ii) оба зигзага имеют одно и то же число ребер.

ДокАзАтельство. (i) Два простых зигзага $Z_{1}$ и $Z_{2}$ разрезают фуллерен на два диска и кольцо. В каждом диске по шесть 5-угольников, значит, в кольце лишь 6-угольники. По лемме 2 есть пояс.

(ii) Между зигзагами $Z_{1}$ и $Z_{2}$ расположены только 6-угольники. Применим лемму 2. Если один край пояса совпадает с $Z_{1}$, а другой край пояса не совпадает с $Z_{2}$, то имеется второй пояс. Если другой край второго пояса не совпадает с $Z_{2}$, то имеется третий пояс, и т. д. Через конечное число шагов получим пояс, другой край которого совпадает с $Z_{2}$. Оба края этих поясов имеют одну и ту же длину. Предложение доказано. 
Заметим, что смежные ребра ячейки диск-фуллерена не принадлежат его краю, так как $q=3$. Значит, 6-угольник имеет на краю не более чем три ребра, а 5-угольник - не более чем два ребра.

Теперь более подробно исследуем наперстки. Простой зигзаг наперстка может быть расположен относительно его края по-разному. В силу предложения 8 пересечение простого зигзага с краем наперстка имеет не более трех компонент связности. Если есть ровно три компоненты, то диск, который фигурирует в предложении 8, содержит шесть 5-угольников, приграничных для наперстка. Этот диск имеет симметрию $C_{3 \nu}$. Если есть ровно две компоненты, то диск имеет 4 приграничных 5-угольника для наперстка и два неприграничных. Если есть только одна компонента, то диск имеет два приграничных 5-угольника для наперстка и 4 неприграничных. Если простой зигзаг не пересекается с краем наперстка, то все шесть 5-угольников, принадлежащих диску, не являются приграничными.

ПрЕДЛОжЕНИЕ 10. Если два простых зигзага некоторого наперстка не пересекаются ни с его краем, ни между собой, то

(i) этот наперсток имеет хотя бы один пояс;

(ii) оба зигзага имеют одну и ту же длину.

ДокАзАТЕльство. (i) В силу предложения 8 каждый простой зигзаг вырезает из наперстка диск, содержащий шесть 5-угольников. Они неприграничные, так как зигзаг не пересекается с краем. Если диски, вырезаемые из наперстка обоими зигзагами, не пересекаются, то наперсток содержит 12, а не 6 неприграничных 5-угольников, что невозможно ввиду равенства (5). Значит, один диск находится внутри другого и все шесть 5-угольников находятся в меньшем из них. Между зигзагами находятся лишь 6-угольники и в силу леммы 2 имеется пояс.

(ii) Если второй край пояса не совпадает с другим зигзагом, то к нему по другую сторону опять примыкают только 6-угольники, которые составляют второй пояс, и т.д. Через конечное число шагов получим пояс, компонентой края которого служит другой из исходных двух зигзагов. Оба края каждого пояса имеют одну и ту же длину. Предложение доказано.

2.4. Неукорачиваемые фуллерены и диск-фуллерены. Так как для каждого $n \geqslant 1$ количество $n$ - $D F$ неограничено, то целесообразно выделить среди них такую базовую совокупность, что любой $n-D F$ получается из некоторого $n-D F$ базовой совокупности посредством некоторой простой операции. В качестве такой совокупности мы взяли $n-D F$ без поясов. Это своеобразное приведение. Зададим отдельный шаг этого своеобразного приведения вместе с определением самой операции приведения.

ШАГ ПРИВЕДЕНИЯ. Если $n$-диск-фуллерен имеет пояс, то операцию удаления внутренности пояса и отождествления его граничных зигзагов назовем укорачиванием $n$-диск-фуллерена. 
Необходимо отметить, что этот шаг неоднозначен. Если пояс не пересекается с краем $n-D F$, то после удаления внутренности этого пояса, который обладает внутренним краем $Z_{1}$ и внешним краем $Z_{2}$, останутся диск с краем $Z_{1}$ и кольцо с внутренним краем $Z_{2}$. Они объединяются в новый $n-D F$ ровно $z$ разными способами, где $z$ - число ребер того простого зигзага $Z$, в который отождествляются зигзаги $Z_{1}$ и $Z_{2}$. Так, например, на рис. 13 имеются два диск-фуллерена $7-D F_{72}\left(C_{1}\right)$ и $7-D F_{54}\left(C_{1}\right)$. Первый из них найден с помощью вычислительной программы (см. замечание 11 , (ii) ниже). Второй получен из первого приведением $7-D F_{72}\left(C_{1}\right) \rightarrow 7-D F_{54}\left(C_{1}\right)$.
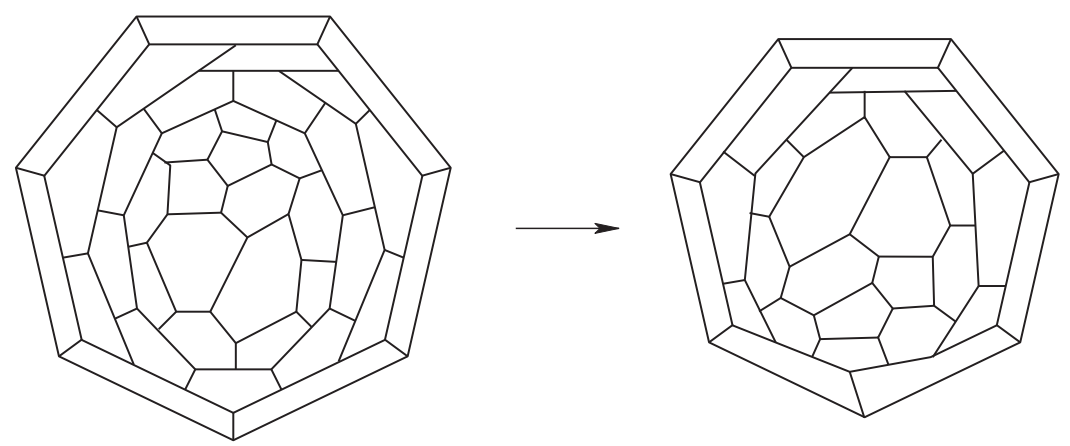

Рис. 13. Укорачиваемый 7- $D F_{72}\left(C_{1}\right)$, имеющий только простые (их 11$)$ зигзаги, и одна из операций его приведения

Здесь нами выбран тот шаг приведения, при котором диск с краем $Z$, расположенный в 7-DF $F_{54}\left(C_{1}\right)$, получается из диска с краем $Z_{1}$, расположенного в $7-D F_{72}\left(C_{1}\right)$, посредством поворота на угол $\pi$. Такой угол поворота имеется тогда и только тогда, когда число $z / 2$ является нечетным. Во всяком случае имеются $z / 2$ нетривиальных поворотов на угол вида $(2 k+1) 2 \pi / z$ с сохранением лицевой стороны и $z / 2$ зеркальных поворотов, меняющих лицевую сторону на оборотную. Отметим, что $7-D F_{54}\left(C_{1}\right)$ имеет всего лишь два зигзага - один простой длины 18 (с ним отождествлены зигзаги $Z_{1}$ и $Z_{2}$ ), а другой самопересекающийся.

Пусть, далее, зигзаг $Z_{2}$ пересекается с краем $n$ - $D F$. Тогда к краю $n$ - $D F$ приклеим $n$-угольник. Получим сферу. От нее при удалении внутренности пояса останутся два диска с краями $Z_{1}$ и $Z_{2}$. Отождествим их одним из $z$ способов и удалим приклеенный $n$-угольник. Получим новый $n$ - $D F$.

ОПРЕДЕЛЕНИЕ 9. Диск-фуллерен, обладающий хотя бы одним поясом, мы будем называть укорачиваемым. Диск-фуллерен без пояса мы будем называть неукорачиваемым.

Из любого диск-фуллерена после конечного числа шагов приведения можно получить неукорачиваемый диск-фуллерен. Например, $7-D F_{54}\left(C_{1}\right)$ на рис. 13 , справа, неукорачиваем. 
Любой диск-фуллерен с простым зигзагом $Z$ можно удлинить - разрезать его по зигзагу $Z$ на две части и вставить объединяющий их пояс. Операция удлинения обратна операции укорачивания и также неоднозначна. Диск-фуллерен без простого зигзага нельзя ни укоротить, ни удлинить.

Все сказанное имеет место не только для диск-фуллеренов, но и для фуллеренов. При применении операции укорачивания иногда встречаются случаи увеличения числа простых зигзагов. Однако число 6-угольников всегда уменьшается. Следовательно, из любого укорачиваемого фуллерена после конечного числа шагов можно получить неукорачиваемый фуллерен.

Напомним, что при любом $n \geqslant 3$ абстрактный $n$ - $D F$ изоморфен обычному $n-D F$ тогда и только тогда, когда его скелет 3 -связен, в силу критерия 1.

При $1 \leqslant n \leqslant 6$ (исключительные случаи $n=1,2$ будут исследованы ниже) любая ячейка произвольного абстрактного $n$ - $D F$ может пересекаться с его $n$-угольным краем не более чем по одному ребру. Следовательно, при $3 \leqslant n \leqslant 6$ каждый абстрактный $n$ - $D F$ изоморфен обычному $n$ - $D F$. Как оказалось, это же свойство сохраняется и при $n=7$. Однако уже при $n=8$ это не всегда так, что подтверждается следующими двумя примерами.

ПримеР 2. Рассмотрим два 2-DF, в каждом из которых одна из двух приграничных ячеек является 5-угольной. Пусть на сфере $\mathbb{S}^{2}$ каждый из них расположен внутри 2-угольника другого. Тогда на ребрах 2-угольников, принадлежащих 5-угольникам, отметим по одной дополнительной вершине и соединим их мостом. Получим разбиение сферы на 5- и 6-угольники и одну 8-угольную область. После удаления из разбиения 8-угольной области ожидаемый абстрактный 8-DF не получится, так как скелет построенного разбиения 1-связен, но не 2-связен.

ПримеР 3. Рассмотрим два 3-DF, в каждом из которых две из трех приграничных ячеек являются 5-угольными. Пусть на сфере $\mathbb{S}^{2}$ каждый из них расположен внутри 3-угольника другого. Тогда на ребрах 3-угольников, принадлежащим 5-угольникам, отметим по одной дополнительной вершине. Рассмотрим на краю каждого диск-фуллерена пару новых ребер, смежных в той вершине, которая принадлежала двум бывшим 5-угольникам. Соединим дополнительные вершины двумя новыми ребрами так, чтобы рассматриваемые пары ребер стали противоположными парами ребер нового 6-угольника. Получим разбиение сферы на 5-, 6-угольники и единственный 8-угольник. Новый 6 -угольник и 8-угольник имеют два общих ребра. После удаления из сферы внутренности 8-угольника получится необычный 8-DF: его скелет 2-, но не 3-связен. Он имеет выпуклую реализацию, описанную в замечании 5.

Пример 3 показывает, что для получения $n$ - $D F$ при $n \geqslant 8$ нужно дополнительно потребовать, чтобы непустое пересечение каждого 5- и 6-угольника с $n$-угольным краем было ребром.

Эти требования выполняются для всех наперстков в примере 1. Каждый из них не имеет ни одного пояса, что подтверждает следующий критерий.

КРИтЕРИй 2. Если хотя бъ один неприграничный 5-уголъник наперстка смежен с приграничным, то этот наперсток неукорачиваем. 
ДокАЗАтельство. Пусть край наперстка имеет $n$ ребер. Тогда наперсток содержит $n$ приграничных 5-угольников. Так как неприграничный 5 -угольник смежен с приграничным, то имеется совокупность из не менее чем $n+1$ пятиугольников, которая является связной. Если бы наперсток имел пояс, то эти не менее чем $n+1$ пятиугольников находились бы по одну сторону от пояса. По другую сторону от пояса находились бы не более чем 5 пятиугольников, а должно находиться 6 , см. предложение 8. Получено противоречие. Значит, критерий имеет место.

Таким образом, при любом $n \geqslant 7$ в примере 1 нами построен наперсток без пояса. Если же ни один неприграничный 5-угольник не смежен с хотя бы одним приграничным, то наперсток имеет пояс (что следует из леммы 2), т. е. он является укорачиваемым.

Вернемся к фуллеренам. В силу определений 6, 9 и предложения 9 имеет место следующее утверждение.

Предложение 11. (i) Если фуллерен является неукорачиваемым, то все его простые зигзаги попарно пересекаются.

(ii) Укорачиваемый фуллерен или диск-фуллерен имеет по менъшей мере два простых зигзага одинаковой длины.

Лемма 3. Для укорачиваемого фуллерена или наперстка все его пояса, попарно не имеющие общих внутренних точек, составляют цилиндр. Оба края иилиндра примыкают к 5-угольникам.

ДокАзАТЕльство. Разобьем его на два случая - один для фуллерена, другой для наперстка.

Случай фуллерена. По разные стороны от пояса расположены два диска, в каждом имеются по шесть 5-угольников (см. предложение 8). Другой пояс, не имеющий общих внутренних точек с первым, находится в одном из дисков. Если оба пояса не имеют общих граничных точек, то между ними заключен цилиндр (кольцо), состоящий только из 6-угольников. В силу леммы 2 в этом цилиндре имеется последовательность поясов, в которой соседние пояса смежны по зигзагу. Пояса из последовательности заполняют новый цилиндр. Если вне этого цилиндра к его краю примыкают только 6-угольники, то по лемме 2 они составляют пояс. Присоединим его к цилиндру. После конечного числа шагов мы получим цилиндр, оба края которого упираются в 5-угольники.

Случай наперстка. Все $n$ приграничных 5-угольников расположены по одну и ту же сторону от произвольного пояса наперстка, так как они составляют кольцо, гомеоморфное боковой поверхности кругового цилиндра, а оно связно. Докажем от противного, что по другую сторону от пояса расположены все остальные 6 пятиугольников. Пусть там расположено меньше шести 5-угольников. Тогда серединный реберный цикл, разрезающий пояс на два цилиндра, вырезает из наперстка диск. Диск представляет собой новый наперсток. Число 5-угольников в новом наперстке должно равняться числу приграничных 5-угольников плюс 6 . Однако по предположению внутри нового наперстка имеется меньше шести старых 5-угольников. Получено противоречие. Значит, по другую сторону от пояса расположены ровно шесть 5-угольников. Все они не являются приграничными ячейками наперстка. 
По ту сторону от другого пояса, которая является диском, находятся эти же шесть 5-угольников, так как только они не являются приграничными. В самом деле, если бы упомянутые два диска не пересекались, то наперсток содержал бы не 6, а 12 неприграничных 5-угольников, что невозможно в силу (5). Значит, один диск находится внутри другого и все шесть 5-угольников находятся в меньшем из них. Дополнением одного диска до другого служит цилиндр.

В цилиндре между поясами находятся лишь 6-угольники. В нем имеется последовательность поясов, в которой соседние пояса смежны по зигзагу. Эти пояса заполняют цилиндр. (Этот цилиндр может состоять только из двух исходных поясов, если они смежны.) С одной стороны цилиндра находятся 6 неприграничных 5-угольников, с другой стороны цилиндра находятся $n$ приграничных 5-угольников. Если к краю цилиндра извне примыкают только 6-угольники, то по лемме 2 они составляют пояс. Присоединим его к цилиндру. После конечного числа шагов мы получим цилиндр, оба края которого примыкают к 5-угольникам. К одному краю примыкает хотя бы один из неприграничных 5-угольников, к другому краю примыкают все $n$ приграничных 5-угольников. Следовательно, все построенные нами пояса составляют цилиндр. Обе компоненты края цилиндра упираются в 5-угольники. Лемма доказана.

Заметим, что все пояса любого наперстка попарно не пересекаются и принадлежат единственному цилиндру. Каждый 6-угольник наперстка принадлежит не более чем одному поясу. Если есть пояс, содержащий данный 6-угольник наперстка, то в двух других попытках построить пояс, содержащий этот 6-угольник и соответствующий каждой из двух других пар противоположных его сторон, мы наткнемся на один из $n$ приграничных 5-угольников наперстка.

Любой другой диск-фуллерен может иметь несколько цилиндров. В силу леммы 1 и замечания 6, (ii) число простых зигзагов неукорачиваемого $n$-наперстка не меньше 1 и не больше $n+1$ :

ПРЕДЛОЖЕНИЕ 12. (i) Любой наперсток имеет хотя бы один простой зигзаг, который не пересекается с его краем.

(ii) Неукорачиваемый наперсток имеет ровно один простой зигзаг, который не пересекается с краем, значит, количество простых зигзагов $n$-наперстка не превышает $n+1$.

ЗАмЕчАниЕ 9. Неукорачиваемый диск-фуллерен может иметь не менее чем два простых зигзага, которые не пересекаются с краем. Так, например, возьмем два наперстка, каждый из которых есть додекаэдр без грани. На двух смежных ребрах края каждого из них добавим по одной вершине. Соединим эти вершины двумя ребрами так, чтобы эти два ребра стали противоположными сторонами 6-угольника, объединяющего оба бывших наперстка в один диск-фуллерен. Этот неукорачиваемый 12-DF имеет два простых зигзага, не пересекающихся с краем и между собой. (Кстати, он является минимальным $12-D F_{44}\left(C_{2 \nu}\right)$, см. [29].) Неукорачиваемые 8-, 9- и 10- $D F$, изображенные на рис. 6, также имеют по два простых зигзага, не пересекающихся с краем и между собой. 
ЗАмЕчАниЕ 10. Диск-фуллерен с двумя непересекающимися простыми зигзагами, но без пояса, можно удлинить так, что получится диск-фуллерен с двумя непересекающимися поясами и не принадлежащими одному цилиндру. (Значит, лемма 3 не обобщается с наперстков на все диск-фуллерены.) Независимо друг от друга, каждый из этих двух простых зигзагов позволяет удлинять рассматриваемый диск-фуллерен любое заранее заданное число раз. См. также замечание 11, (iv).

Лемма 4. Пусть фуллерен или наперсток является неукорачиваемым. Тогда с каждой стороны от любого простого зигзага имеется хотя бы один примыкающий к нему 5-угольник.

ДокАЗАТЕЛЬство. К простому зигзагу наперстка примыкают не менее чем по два 5-угольника с каждой стороны, если он пересекает край. Поэтому впредь будем считать, что зигзаг не пересекает край.

Если неукорачиваемый фуллерен или наперсток имеет простой зигзаг и является неукорачиваемым, то по обе стороны от простого зигзага имеются примыкающие к нему 5-угольники. Докажем от противного. Если бы с какой-либо стороны от простого зигзага не было примыкающего 5-угольника, то все примыкающие к нему ячейки были бы 6 -угольниками. По лемме 2 они составляли бы пояс, и фуллерен или наперсток был бы укорачиваем. Получено противоречие. Лемма доказана.

Каждая из 5 пар смежных сторон 5-угольника принадлежит зигзагу, быть может, самопересекающемуся. А так как для произвольного фуллерена $f_{5}=12$, то число всех зигзагов, примыкающих к 5-угольникам фуллерена, не превышает 60. Из леммы 4 следует, что к каждому простому зигзагу неукорачиваемого фуллерена примыкают не менее двух 5-угольников. Поэтому такой фуллерен имеет не более 30 простых зигзагов. Однако эта оценка улучшаема.

Любая из $n$ пар смежных ребер края наперстка порождает зигзаг, быть может, самопересекающийся. Он пересекается с краем. С каждой стороны к нему примыкают не менее двух 5-угольников. Неукорачиваемый наперсток не имеет поясов, значит, он имеет лишь один простой зигзаг, не пересекающийся с краем. Общее число его простых зигзагов не больше $n+1$. Эта оценка неулучшаема.

Лемма 5. Пусть фуллерен имеет простой зигзаг, $\kappa$ которому с одной его стороны примыкает только один 5-угольник. Тогда он имеет также и самопересекающийся зигзаг.

ДокАЗАТЕЛЬСтво. Пусть с одной стороны от простого зигзага $Z$ к нему примыкает только один 5-угольник. Все остальные примыкающие ячейки 6-угольники, составляющие разомкнутую цепочку. В силу предложения 7 каждый 6-угольник этой цепочки имеет только два ребра, принадлежащие зигзагу $Z$ (или, что то же самое, никакие два 6-угольника цепочки не имеют общих внутренних точек, т. е. все 6-угольники цепочки являются различными).

Докажем, что несоседние 6-угольники цепочки не пересекаются (по граничным точкам). В самом деле, возьмем в этой цепочке 6-угольников два соседних 6-угольника. Они смежны по ребру. Лишь один конец этого ребра принадлежит зигзагу $Z$ (см. выше). Предположим, что другой конец ребра, обозначим 
его через $A$, принадлежит третьему 6-угольнику, примыкающему к зигзагу $Z$ по двум ребрам, смежным в вершине, диаметрально противоположной вершине $A$. Тогда эти три 6-угольника разбивают зигзаг $Z$ на две части.

Не теряя общности, можно считать, что второй 6-угольник примыкает к той части, к которой примыкают только 6-угольники разомкнутой цепочки. Третий 6-угольник смежен с каждым из первых двух. Пусть ребро $A B$ является пересечением третьего 6-угольника со вторым. Тогда ввиду 3 -валентности вершина $B$ принадлежит некоторой четвертой ячейке. Однако один конец ребра, по которому четвертая ячейка смежна с третьей, принадлежит зигзагу $Z$. Следовательно, четвертая ячейка является 6-угольником, примыкающим к зигзагу $Z$. Пусть ребро $B C$ является пересечением четвертого 6-угольника со вторым. Тогда вершина $C$ принадлежит пятой ячейке, точнее, 6-угольнику, примыкающему к зигзагу $Z$ (как и в случае четвертой ячейки). Пусть ребро $C D$ является пересечением пятого 6-угольника с четвертым. Тогда, как и выше, вершина $D$ принадлежит шестому 6-угольнику, примыкающему к данному зигзагу, и т.д. Если номера второго и третьего 6-угольников поменять местами, то мы получим две цепочки 6-угольников, одна с четными номерами, другая с нечетными, смежных по серединной ломаной $A B C D \ldots$ Ломаная $A B C D \ldots$ является бесконечной. Получено противоречие.

Значит, 6-угольники разомкнутой цепочки не имеют общих граничных точек, если они не являются соседними в этой цепочке.

Пары смежных сторон 6-угольников разомкнутой цепочки, противоположных парам тех их смежных сторон, которые принадлежат зигзагу $Z$, составляют ломаную $\Lambda$, которая является собственной частью некоторого зигзага; в нем дважды пройдено одно и то же ребро исходного 5-угольника, которое противоположно той вершине 5-угольника, в которой смежны две его стороны, принадлежащие простому зигзагу $Z$. (Разомкнутая ломаная $\Lambda$ и это ребро вместе составляют замкнутую ломаную, но не зигзаг, а его часть.) Лемма доказана.

Тривиальным следствием из леммы 5 является следующая альтернатива.

АльтернативА. Если фуллерен имеет только простые зигзаги, то среди ячеек, примыкающих к каждому зигзагу с одной стороны,

(а) либо имеется по меньшей мере два 5-угольника,

(b) либо нет ни одного 5-угольника, все только 6-угольники.

Если фуллерен имеет только простые зигзаги, а среди ячеек, примыкающих к какому-либо из зигзагов, имеется ровно два 5-угольника, то оба они находятся по одну сторону от этого зигзага.

Лемма 5 подтверждает предположение 8, (iii) из [26].

Теорема 2. Пусть все зигзаги фуллерена являются простыми, и пусть все они попарно пересекаются. Тогда

(i) $к$ каждому зигзагу с каждой его стороны примыкают по менъшей мере два 5-угольника;

(ii) количество всех зигзагов не превосходит 15 (оценка неулучшаема). 
Доказательство. (i) Так как все зигзаги являются простыми и они попарно пересекаются (значит, не существует поясов), то в силу альтернативы (а) с каждой стороны к зигзагу примыкают по два 5-угольника.

(ii) K любому 5 -угольнику примыкают не более 5 зигзагов. А так как $f_{5}=12$, то число всех зигзагов не превышает $5 f_{5}=60$. В силу (i) к любому простому зигзагу примыкают не менее четырех 5-угольников. Значит, фуллерен имеет не более $5 f_{5} / 4=15$ зигзагов. Теорема доказана.

Все попарно непересекающиеся пояса фуллерена составляют цилиндр, упирающийся своими краями в 5-угольники, и мы имеем следующее утверждение.

СлЕДСТвИЕ 5. Число иилиндров фуллерена, каждый из которых составлен из всех попарно непересекающихся поясов, не больше 15. (Напомним, что число иилиндров наперстка, составленных из всех его поясов, не больше 1.)

Теорема 3. Если п-диск-фуллерен неукорачиваем, а все зигзаги, не пересекаюшие его край, являются простыми, то

(i) $к$ ним с любой стороны примыкают по два 5-угольника;

(ii) количество этих зигзагов не превышает $5(n+6) / 4$;

(iii) оба 5-угольника находятся по одну и ту же сторону от такого зигзага, если к нему примыкают только два 5-угольника.

Доказательство аналогично доказательству теоремы 2. Здесь в случае (i) нами для простоты указана только нижняя оценка.

ЗАмЕчАНИЕ 11. (i) Если все зигзаги $n$ - DF являются простыми, то их общее число не превышает $n+5 f_{5} / 4=n+5(n+6) / 4$. Это следует из теоремы 3, (ii) и замечания 6 , (ii) (что число зигзагов, пересекающих край $n$ - $D F$, не больше $n$ ).

(ii) При $n \leqslant 15$ и $f_{6} \leqslant 25$ есть ровно один $n$ - $D F, n \neq 5,6$, имеющий только простые зигзаги (см. рис. 13 , слева). Это $7-D F_{72}\left(C_{1}\right)$ с $f_{6}=24, f_{5}=13$. Он найден с помощью вычислительной программы. Среди всех 11 его зигзагов имеются два длины 18 и девять длины 20; семь зигзагов длины 20 пересекают край. Значит, оценка, указанная в замечании 6 , (ii) в данном случае достигается. Два зигзага длины 18 не пересекаются. Они являются компонентами края единственного пояса: данный диск-фуллерен является укорачиваемым. Однако существуют также и неукорачиваемые диск-фуллерены, которые имеют два непересекающихся простых зигзага (см. замечание 10).

(iii) На рис. 14 задан неукорачиваемый диск-фуллерен $30-D F_{336}\left(C_{6 \nu}\right)$ с $f_{5}=36, f_{6}=133$.

Он имеет 18 зигзагов, все простые: один зигзаг длины 72 с группой $C_{6 \nu}$; два зигзага длины 66 с группой $C_{3 \nu}$; шесть зигзагов длины 58 с группой $C_{s}$; три зигзага длины 56 с группой $C_{2 \nu}$; шесть зигзагов длины 48 с группой $C_{s}$. Это не наперсток, хотя он также выглядит как подсолнух.

(iv) При $n=4 k+12$, где $k \in \mathbb{N}$, имеется неукорачиваемый $n$ - $D F$, который имеет $2 k+1$ простых зигзагов. При $k=5$ это $32-D F_{154}\left(C_{2 \nu}\right)$, изображенный на рис. 15. Он имеет 11 простых зигзагов и 4 самопересекающихся зигзага; последнее число одно и то же при каждом $k$. (В частности, он имеет больше двух 


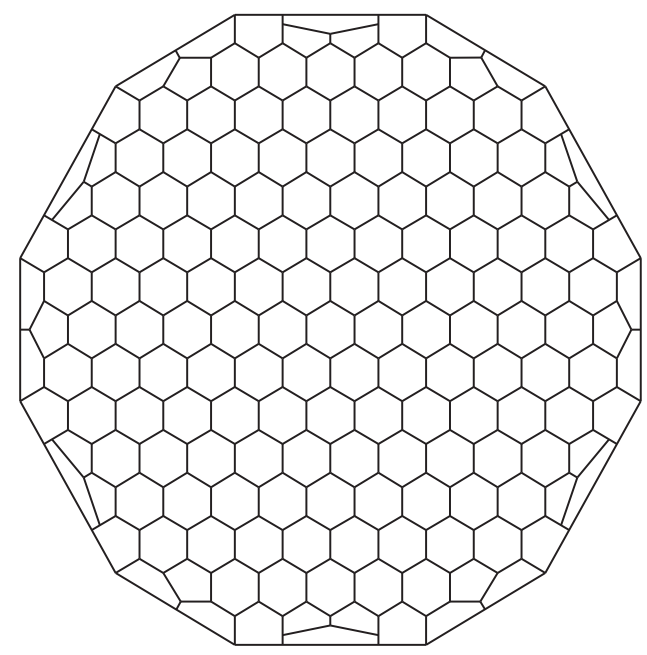

Рис. 14. Неукорачиваемый $30-D F_{336}\left(C_{6 \nu}\right)$ с только простыми зигзагами (их 18)

попарно непересекающихся простых зигзагов, значит, после удлинения посредством каждого из этих зигзагов он будет иметь больше двух попарно непересекающихся поясов.) Количество простых зигзагов растет с ростом числа $k$. Таким образом, число простых зигзагов неукорачиваемого диск-фуллерена может быть сколь угодно большим.

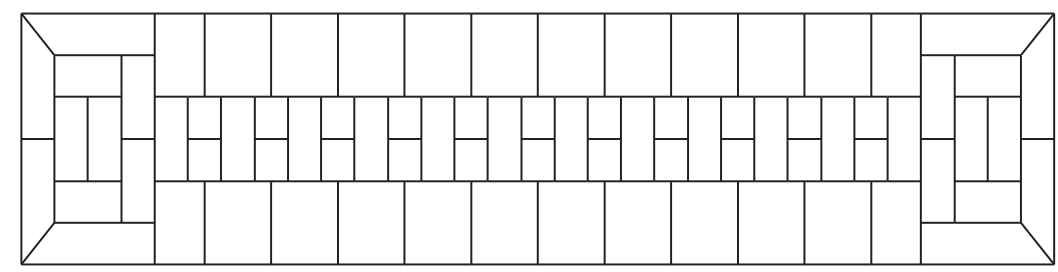

Рис. 15. Неукорачиваемый 32- $D F_{154}\left(C_{2 \nu}\right) ; 11$ из всех его 15 зигзагов простые

Интересно, для каких $n$ существуют неукорачиваемые $n$ - $D F$ со сколь угодно большим числом простых зигзагов.

2.5. Обобщения диск-фуллеренов: компактный случай. В определении диск-фуллеренов имелись ограничения на число ребер края диска и степени вершин в разбиении его на 5- и 6-угольники. Теперь мы ослабим все эти ограничения. Кроме обычных и необычных $n-D F$, вершины которых имеют степень 3 , мы будем рассматривать также обобщенные $n$ - $D F$, обладающие вершинами степени 2 (на краю) и исключительные $n$ - $D F$ с $n=1,2$. 
ОПРедЕЛЕНиЕ 10. Разбиение $n$-угольника на 5- и 6-угольники, внутренние вершины которого имеют степень 3 , а граничные имеют степень 3 или 2, назовем обобщенным n-диск-фуллереном.

В частности, сегменты на рис. 9, 10, 11 и в табл. 3 являются обобщенными диск-фуллеренами.

Случай 1: обобщенные $n-D F, n \geqslant 3$, с вершинами степени 2 (на краю). $\mathrm{K}$ краю обобщенного $n$ - $D F$ приклеим "внешний” $n$-угольник. Получим разбиение сферы, для нее

$$
v=v_{2}+v_{3}, \quad 2 e=2 v_{2}+3 v_{3}, \quad f=f_{5}+f_{6}+f_{n}, \quad 2 e=5 f_{5}+6 f_{6}+n f_{n},
$$

где $f_{n}=1$. Складывая соотношения (7), умноженные на $6,-2,6,-1$ соответственно, и учитывая формулу Эйлера, мы получаем

$$
f_{5}=n+6-2 v_{2} .
$$

Складывая соотношения (7), умноженные на 10, $-3,10,-2$, имеем

$$
v_{3}=2\left(f_{6}+n+5-2 v_{2}\right) .
$$

Учитывая (8) и (9), соотношения (7) можно переписать в виде

$$
v=2\left(f_{6}+n+5\right)-3 v_{2}, \quad e=3\left(f_{6}+n+5\right)-5 v_{2}, \quad f=f_{6}+n+7-2 v_{2} .
$$

Из соотношений (10) следует, что при фиксированном $n, n \neq 5,6$, число вершин, ребер и граней зависит от двух параметров $f_{6}$ и $v_{2}$. (При $v_{2}=0$ мы вернемся к обычным и необычным $n$ - $D F$.)

Из соотношений $(8)$ и $f_{5} \geqslant 0$ получаем неравенство

$$
2 v_{2} \leqslant n+6 \text {. }
$$

В частности, при $f_{5}=0$ неравенство (11) превратится в равенство

$$
2 v_{2}=n+6
$$

а так как вершины степени 2 лежат на краю, то $v_{2} \leqslant n$, значит, $n \geqslant 6$.

В равенстве (12) число $n$ является четным, но $n \neq 2,4,8$. Так как $f_{5}=0$, то диск составлен из одних 6-угольников. Это диск, вложенный в разбиение $\left(6^{3}\right)$, или диск, погруженный в разбиение $\left(6^{3}\right)$. Наличие таких дисков означает, что оценка (11) неулучшаема.

Далее разделим рассматриваемый случай на два подслучая.

Подслучай 1.1: лоскуты, или подфуллерены (собственные части фуллеренов).

ОПРЕДЕЛЕНИЕ 11. Разбиение $n$-угольника на 5- и 6-угольники, которое можно дополнить до фуллерена, мы будем называть подфуллереном; в [57] он называн лоскутом. Фуллерен без грани мы будем называть особым диск- фуллереном (он всегда является лоскутом). 
Как и выше, приклеив к краю лоскута "внешний" $n$-угольник, получим (7)-(10). А так как

$$
0 \leqslant f_{5} \leqslant 12,
$$

то мы получаем ограничение для числа вершин степени 2 , а именно

$$
\frac{n}{2}-3 \leqslant v_{2} \leqslant \frac{n}{2}+3 .
$$

Следовательно, при любом фиксированном $n$ число $v_{2}$ может иметь не более чем 7 значений.

Если $v_{2}=n / 2$ и степени вершин края обобщенного $n$ - $D F$ строго чередуются, то он является лоскутом, так как его край является зигзагом и два таких $n$ - $D F$ вместе составляют фуллерен. Такие лоскуты существуют при каждом четном $n \geqslant 10$. При $n=10$ таким лоскутом является половина поверхности додекаэдра. При $n \geqslant 12$ это подтверждает пример 1, в котором нужно заменить число $n$ на $n / 2$, а также удалить все приграничные 5 -угольники.

В данном подслучае исследуются лишь обобщенные диск-фуллерены и прилагательное "обобщенные", ради краткости, будем опускать. Напомним, что обычный $n-D F$ является обобщением специального лоскута - фуллерена без грани, т. е. особого диск-фуллерена.

Итак, лоскут - это диск, который является собственной частью простого $(q=3)$ выпуклого многогранника с 5- и 6-угольными гранями. Здесь под многогранником мы опять понимаем не тело $P \in \mathbb{R}^{3}$, а его поверхность $\partial P=\dot{P}$. Та собственная часть поверхности $\dot{P}$, которая задает лоскут, обозначим его через $D$, ограничена простым реберным циклом, который обозначим через $C$. Цикл $C$ разбивает поверхность $\dot{P}$ на два диска $D$ и $\dot{P} \backslash \operatorname{int} D$, где $D \cap(\dot{P} \backslash \operatorname{int} D)=C$. Таким образом, оба диска $D$ и $\dot{P} \backslash \operatorname{int} D$ являются лоскутами (см. определение 11).

Все вершины цикла $C$ имеют степень 2 на $C$ и степень 3 на поверхности $\dot{P}$. Если вершина цикла $C$ имеет степень 2 на диске $D$, то она имеет степень 3 на $\dot{P} \backslash \operatorname{int} D$, и наоборот (диски равноправны).

Если диск $\dot{P} \backslash \operatorname{int} D$ содержит более одной грани, то внутри него имеется хотя бы одно ребро, которое разделяет между собой имеющиеся грани. А так как скелет поверхности $\dot{P}$ является связным, то внутри диска $\dot{P} \backslash \operatorname{int} D$ найдется ребро, вершина которого принадлежит $C$. Эта вершина имеет степень 2 в диске $D$, так как $q=3$. В том и только том случае, когда диск $\dot{P} \backslash \operatorname{int} D$ содержит только одну грань, все вершины диска $D$ имеют степень 3 (см. определение 4 ).

Пусть лоскут $D$ не является особым. Тогда $D$ имеет хотя бы одну вершину степени 2. Она принадлежит $C$. Однако вершина степени 2 не может быть только одна. В самом деле, если бы вершина степени 2 была одна, то скелет поверхности $\dot{P}$ был бы 1-, а не 2-связным, так как при удалении этой вершины нарушилась бы связность, значит, поверхность $\dot{P}$ не была бы фуллереном.

Итак, число вершин степени 2 не меньше двух. Оно равно двум лишь тогда, когда диск $\dot{P} \backslash \operatorname{int} D$ содержит только две грани, а эти вершины являются концами ребра, по которому они смежны. (Эти грани являются 5- и/или 6-угольными, так как $\dot{P}$ - фуллерен.) В самом деле, если бы эти две вершины не были соединены ребром, то скелет поверхности $\dot{P}$ являлся бы 2-, а не 
3-связным, так как при удалении этих двух вершин нарушилась бы связность и поверхность $\dot{P}$ не была бы фуллереном. Значит, в общем случае $D$ содержит не менее трех вершин степени 2 , а $\dot{P} \backslash \operatorname{int} D$ содержит не менее трех вершин степени 3. Диски $D$ и $\dot{P} \backslash \operatorname{int} D$ можно поменять местами, следовательно, в общем случае цикл $C$ имеет не меньше 6 ребер.

На самом деле, цикл $C$ содержит ровно 5 или 6 ребер тогда и только тогда, когда он является краем ячейки фуллерена $\dot{P}$. Во всех остальных случаях число его ребер не меньше 8.

ОпредЕлЕНиЕ 12. Циклическая последовательность степеней вершин, расположенных на границе обобщенного диск-фуллерена, называется его граничным кодом (см. также сноску $\left.{ }^{3}\right)$.

Итог сказанному выше подводит следующее предложение.

ПРЕДЛОЖЕНИЕ 13. (i) Любой обобщенный диск-фуллерен с ровно одной вершиной степени 2 не являтся лоскутом.

(ii) Обобщенный диск-фуллерен с двумя вершинами степени 2 является лоскутом тогда и только тогда, когда он имеет граничный код $(2,3,3,3,2,3,3,3)$, $(2,3,3,3,2,3,3,3,3)$ или $(2,3,3,3,3,2,3,3,3,3)$.

Особый диск-фуллерен - это либо 5-DF с $f_{5}=11$ и граничным кодом $(3,3,3,3,3)=(3)^{5}$, либо 6 - $D F$ с $f_{5}=12$ и граничным кодом $(3,3,3,3,3,3)=$ $(3)^{6}$. При $q=3$ только особый диск-фуллерен можно расширить до фуллерена, восстановив удаленную его грань. А при $q=3, n \neq 5,6$ никакой другой $n$-диск-фуллерен не обладает этим же свойством: не нарушив комбинаторного строения, его нельзя дополнить до фуллерена, так как недостающая до сферы грань не 5- или 6-угольная.

Существует неограниченное множество особых диск-фуллеренов с фиксированным граничным кодом (см., например, предложение 2, (ii) и рис. 5).

Тривиальный лоскут, который имеет только одну ячейку или только две ячейки, однозначно определяется своим граничным кодом, а именно $(2,2,2,2,2)$, $(2,2,2,2,2,2),(2,2,2,3,2,2,2,3),(2,2,2,3,2,2,2,2,3)$ или $(2,2,2,2,3,2,2,2,2,3)$.

Подслучай 1.2: обобщенные $n$-диск-фуллерены, не являющиеся лоскутами. Аналогично замечанию 1, диск-фуллерен называется нерасширяемым, если он не является собственной частью другого диск-фуллерена. Так, например, если все вершины имеют степень 3, то диск-фуллерен нерасширяем. На рис. 16 представлены 4 примера: а) обычный 4-DF; b) и с) - два обобщенных $5-D F ; \mathrm{d})$ обобщенный 6- $D F$. Все четыре не являются лоскутами. Первые три нерасширяемы. Четвертый расширяем, причем бесконечным множеством способов. Если к половине края, ограниченного вершинами степени 2, приклеить 6-угольник, то получится расширяемый 6- $D F$, у которого опять есть две вершины степени 2, но они смежны, т. е. являются концами граничного ребра. K нему по этому ребру можно приклеить любую цепочку из $(5,3)$-полициклов, изображенных на рис. 9, е), как в теореме 1. Если по другой части края приклеить 6 -угольник, то получится минимальный $2-D F_{26}\left(C_{2 \nu}\right)$, но он уже нерасширяемый. Два упомянутых 6-DF, как два сегмента с отождествленными хордами 


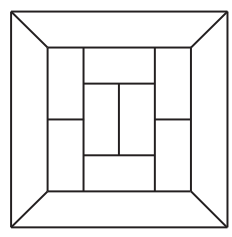

a)

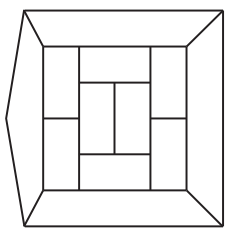

b)

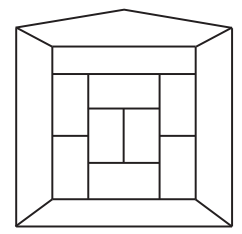

c)

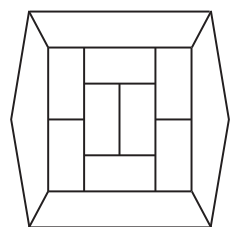

d)

Рис. 16. Диск-фуллерены, не являющиеся лоскутами

(см. рис. 8, е)), объединяются в минимальный необычный $10-D F_{50}\left(C_{2 \nu}\right)$. Один такой $6-D F$ и 7-DF, изображенный на рис. 11, а), объединяются в минимальный необычный $11-D F_{48}\left(C_{s}\right)$. См. также табл. 4.

ПримеР 4. Возьмем любой наперсток из примера 1. На каждой элементарной дуге последней окружности возьмем по одной дополнительной вершине. Получим обобщенный $2 n-D F$. Последнее кольцо между окружностями состоит из 6 -угольников, значит, $f_{5}=6$. На последней окружности имеются $n$ вершин степени 3 и $n$ вершин степени 2. Этот обобщенный $2 n-D F$ составляет половину фуллерена: он вместе с идентичным экземпляром, отраженным от края и повернутым на $\pi / n$, составляют фуллерен. (После склейки общий край двух $2 n$ - $D F$ становится простым зигзагом.) Этот $2 n$ - $D F$ является лоскутом.

ПримеР 5. Пусть число $n \geqslant 7$, рассматриваемое в примере 1 , является четным. Тогда последняя окружность состоит из четного числа дуг. Зададим циклическую нумерацию дуг. Дуги с нечетными номерами оставим элементарными, а на каждой дуге с четным номером возьмем по одной дополнительной вершине. Получим $n / 2$ добавленных вершин, расположенных на краю диска. Теперь край содержит всего $n+n / 2$ вершин: $n$ вершин степени 3 и $n / 2$ вершин степени 2. Приграничные ячейки суть $n / 2$ пятиугольников и $n / 2$ шестиугольников. Это обобщенный $(3 n / 2)-D F$, являющийся лоскутом при $n=10,12$, но не являющийся лоскутом при любом другом четном $n \geqslant 8$.

Пример 6. В примере 5 выпустим из дополнительных $n / 2$ вершин $n / 2$ единичных отрезков, концы которых отметят $n / 2$ вершин на дополнительно добавленной окружности (см. пример 1). Получим новый диск-фуллерен, его край содержит $n / 2$ вершин. Все приграничные ячейки суть 6 -угольники. В предпоследнем кольце между окружностями содержится $n / 2$ пятиугольников. Это $(n / 2)-D F$.

Диск-фуллерен, построенный в примере 5, является расширяемым, а именно, он расширяется до диск-фуллерена, построенного в примере 6 .

Случай 2: обычные $n$-DF, необычные $n$-DF и исключительные $n$ - $D F$ c $n \geqslant 1$. Назовем $n$-DF исключительным, если $n=1$ или 2. Каждый его 5 -угольник, как и в случае $n \geqslant 3$, опять ограничен простым реберным циклом (в противном случае в силу $q=3$ должны быть два 1-угольника). Два 5-угольника могут пересекаться лишь по одному ребру (в противном случае в силу $q=3$ должны быть либо два 1-угольника, либо два 2-угольника, либо 
1-угольник и 2-угольник). Точно так же 5- и 6-угольник могут пересекаться друг с другом только по одному ребру.

Однако 6-угольник ограничен непростым реберным циклом тогда и только тогда, когда он смежен с $n$-угольником при $n=1$, а 6-угольник, не смежный с 1-угольником, ограничен простым реберным циклом. Два 6-угольника пересекаются по двум сторонам, если оба они примыкают к $n$-угольному краю при $n=2$ или оба они смежны с самопересекающимся 6-угольником при $n=1$. Значит, при $n \geqslant 3$ все 5 - и 6 -угольники ограничены простыми реберными циклами и каждое их непустое пересечение друг с другом является ребром.

Теперь будем рассматривать всю совокупность диск-фуллеренов из данного пункта, включая обычные $n-D F$, необычные $n$ - $D F$ и исключителные $n-D F$.

При $n \geqslant 8$ имеются простые $(q=3)$ разбиения сферы на 5 -, 6-угольники и один $n$-угольник, для которых скелет 1-, но не 2-связен, однако эти разбиения не приводят к $n$-диск-фуллеренам.

Отметим, что скелет $n$-диск-фуллерена является

○ 1-, но не 2-связным при $n=1$;

○ 2-, но не 3-связным при $n=2$;

○ 3 -связным при $3 \leqslant n \leqslant 7$;

○ 2-связным при $n \geqslant 8$.

Все наименьшие значения $f_{6}$ при $n \leqslant 21$ приведены в табл. 1 и 2 .

Каждое $m_{1}(n)$, т. е. наименьшее значение $f_{6}$ при данном $n$, достигается при $n \geqslant 2$ на $n-D F$ с

о только 3 -связным скелетом при $3 \leqslant n \leqslant 10$;

○ 3 -, а также 2-, но не 3 -связным скелетом при $n=11,19,20,21$; возможно, и при $n \geqslant 22, n \equiv 0,1,9(\bmod 10)$;

○ 2-, но не 3 -связным скелетом при $n=2,12, \ldots, 18$; возможно, и при $n \geqslant 22$, $n \not \equiv 0,1,9(\bmod 10)$.

Напомним также, что при каждом $n \geqslant 1$, число вершин $n$ - $D F$ минимально при наименьшем значении $f_{6}$, что следует из $(6)$.

Случай 3: обобщенные $n$-диск-фуллерены с $n \geqslant 1$. Сначала рассмотрим тот частный случай, когда обобщенный $n$ - $D F$ имеет вершину степени 2 и $n=1$ или $n=2$. Покажем, что это невозможно. В самом деле, наличие одной вершины степени 2 при $n=1$ влечет $f_{1}=1$. Наличие двух вершин степени 2 при $n=2$ влечет $f_{2}=1$. Наличие только одной вершины степени 2 при $n=2$ влечет $f_{6} \geqslant 0, f_{5}=1, f_{1}=1$. Следовательно, случай 3 является формальным объединением случаев 1 и 2 , не более.

Таким образом, в каждом из трех случаев уделено внимание тем диск-фуллеренам, которые привели к их обобщению. Теперь все $n$ - $D F$ мы разделяем на следующие четыре семейства:

$\alpha$ : обычные $n$-диск-фуллерены, $n \geqslant 3$, т. е. те $n$ - $D F$, для которых скелет 3-связен;

$\beta$ : необычные $n$-диск-фуллерены, $n \geqslant 3$, для которых скелет 2-связен, но не 3-связен;

$\gamma$ : исключительные $n$-диск-фуллерены, т. е. $n$ - $D F$, для которых либо $n=1$, либо $n=2$;

$\delta$ : обобщенные $n$-диск-фуллеренъ, $n \geqslant 3$, для которых имеется вершина степени 2. 
ТАБлицА 4. Наименьшие значения $f_{6}$ для $n$ - $D F$ из $\alpha \cup \beta \cup \gamma, \beta \cup \gamma$ и $\alpha$

\begin{tabular}{|r||r|r||r|r|r|r|r|r|r|r|r||}
\hline$n$ & 1 & 2 & 3 & 4 & 5 & 6 & 7 & 8 & 9 & 10 & 11 \\
\hline$m_{1}(n)$ & 14 & 6 & 3 & 2 & 0 & 1 & 3 & 4 & 6 & 7 & 8 \\
\hline$m_{2}(n)$ & - & 6 & - & - & - & - & - & 23 & 17 & 10 & 8 \\
\hline$m_{3}(n)$ & - & - & 3 & 2 & 0 & 1 & 3 & 4 & 6 & 7 & 8 \\
\hline
\end{tabular}

\begin{tabular}{|r||r|r|r|r|r|r|r|r|r|r||r|}
\hline$n$ & 12 & 13 & 14 & 15 & 16 & 17 & 18 & 19 & 20 & 21 & $\geqslant 22$ \\
\hline$m_{1}(n)$ & 5 & 5 & 4 & 4 & 4 & 5 & 5 & 6 & 6 & 6 & $\min \left\{m_{2}, m_{3}\right\}$ \\
\hline$m_{2}(n)$ & 5 & 5 & 4 & 4 & 4 & 5 & 5 & 6 & 6 & 6 & см. теоремy 1 \\
\hline$m_{3}(n)$ & 6 & 6 & 6 & 6 & 6 & 6 & 6 & 6 & 6 & 6 & $\leqslant 6$ \\
\hline
\end{tabular}

В семействах $\alpha, \beta, \delta$ имеются лоскуты, а также диск-фуллерены, не являющиеся лоскутами. Никакой $n-D F$ из семейства $\gamma$ не является лоскутом. Среди $n-D F$ из семейства $\alpha$ имеются подсемейство наперстков и подсемейство особыx $n$ - $D F$, каждый из которых является фуллереном без грани (т.е. с $n=5$ и $n=6)$.

Напомним, что для $n-D F$ из семейства $\delta$ справедливы равенства (8), (9), т. е. $f_{5}=n+6-2 v_{2}$ и $f_{6}=2 v_{2}+v_{3} / 2-n-5$, которые превращаются в (5) и первое равенство из (6) при $v_{2}=0$.

Объединим табл. 1 и 2 в сводную таблицу (см. табл. 4) со значениями следующих трех функций от $n$ :

$$
m_{1}(n)=\left.\min f_{6}\right|_{\alpha \cup \beta \cup \gamma}, \quad m_{2}(n)=\left.\min f_{6}\right|_{\beta \cup \gamma}, \quad m_{3}(n)=\left.\min f_{6}\right|_{\alpha} .
$$

Все циклические последовательности из $n$ чисел 3 и 2 распадаются на следующие три типа:

первый тип - граничные коды лоскутов (собственных частей фуллеренов);

второй mun - граничные коды $n$-диск-фуллеренов, которые не являются лоскутами;

третий тип - все остальные циклические последовательности чисел 3 и 2. В самом деле, каждая циклическая последовательность из чисел 3 и 2 либо является граничным кодом диск-фуллерена, либо нет. Если она является граничным кодом лоскута, то она не может быть граничным кодом диск-фуллерена, не являющегося лоскутом. Это следует из того, что дополнение лоскута до фуллерена служило бы также дополнением до фуллерена и для диск-фуллерена, не являющегося лоскутом, если бы он имел тот же граничный код.

Если в граничном коде лоскута заменить 3 на 2, а 2 на 3, то получится граничный код другого лоскута, так как они дополняют друг друга до фуллерена. В граничном коде лоскута между соседними вершинами степени 3 находятся не более 4 вершин степени 2, а между вершинами степени 2 - не более 4 вершин степени 3.

Если в граничном коде диск-фуллерена, не являющегося лоскутом, заменить 3 на 2, а 2 на 3, то граничный код другого диск-фуллерена не получится, иначе вместе они составляли бы фуллерен и были бы лоскутами. В граничном коде диск-фуллерена, не являющегося лоскутом, между соседними вершинами степени 3 находятся не более 4 вершин степени 2, однако нет никаких ограничений на число вершин степени 3 , которые могут находиться между соседними вершинами степени 2. 
Граничные коды всех диск-фуллеренов из семейств $\alpha, \beta, \gamma$, представленных выше, состоят только из чисел 3 . Как оказалось, все циклические последовательности из $n$ чисел 3 принадлежат либо первому типу - если $n=5,6$, либо второму типу - если $n \neq 5,6$.

Циклические последовательности из чисел 3 и 2 мало исследованы. Три циклические последовательности $(2),(2,2)$ и $(2,3)$, например, принадлежат третьему типу. Если числа 3 и 2 строго чередуются и их общее количество четно, но не меньше 10, то такая циклическая последовательность принадлежит первому типу, см. выше. Было бы интересно найти критерий, позволяющий по любой заданной циклической последовательности из чисел 3 и 2 определить, какому типу она принадлежит.

Отметим, что необходимые условия (13) и (14) не достаточны для того, чтобы обобщенный $n-D F$ был лоскутом. Так, например, изображенный на рис. $16, \mathrm{~d})$ обобщенный 6 - $D F$ с $v_{2}=2$ и $f_{5}=8$ не является лоскутом, хотя для него неравенства (13) и (14) выполнены.

Отметим также, что скелет каждого $n$ - $D F$ при $n \neq 1,2$ не имеет ни петель, ни кратных ребер, а степень вершины любого обобщенного $n$ - $D F$ не может быть равна 1.

Мы в основном исследовали склеенные из 5- и 6-угольников $n$-угольники с $q=3$, в которых пересечение любой ячейки с краем $n$-угольника связно. Каждый из них допускает выпуклую реализацию, описанную в замечании 4. Все они являются нерасширяемыми диск-фуллеренами: они нерасширяемы при $n \neq 5,6$, а при $n=5,6$ их можно расширить только до фуллеренов, однако это происходит лишь за счет отказа от диска и перехода к сфере.

Не требуя 3-валентности вершин, можно получить много других разбиений диска на 5- и 6-угольники, например, $(r, q)$-полициклы, где $r=5,6$, а $q \geqslant 3$ (см. определение 3$)$. Все конечные $(6,3)$-полициклы расширяемы и имеют вершины степени 2 (см. [36]). Среди конечных $(5,3)$-полициклов нерасширяем только додекаэдр без грани, т. е. $5-D F_{12}\left(D_{5 \nu}\right)$ с $f_{6}=0$ (см. замечание 1$)$.

Химики рассматривают также другие аналоги фуллеренов, например, боразотные соединения, молекулы которых моделируются как простые выпуклые многогранники, имеющие только 4- и 6-угольные грани (куб, 6-угольная призма и т. д.), см. [62]. О вложениях химических графов в кубы см. [34].

Идея диск-фуллерена может быть перенесена также на диск-октаэдриты разбиения диска на 3 - и 4-угольники с $q=4$. Любой $n$-диск-октаэдрит имеет $f_{3}=n+4, f_{4}=v-n-3$. При $n=3,4$ это октаэдрит [37], взятый без одной грани. Пример с $n \geqslant 5$ : диагонали выпуклого $n$-угольника, соединяющие его вершины через одну, ограничивают новый $n$-угольник; середины его сторон, кроме одной, суть вершины $(n-1)$-угольника; середины его сторон, кроме одной (единственной, препятствующей возникновению пятиугольника), суть вершины $(n-2)$-угольника; завершающий 4-угольник смежен с тремя 3-угольниками; еще один 3 -угольник был получен при построении $(n-1)$-угольника; все $n$ приграничных ячеек суть 3-угольники. 
2.6. Обобщения диск-фуллеренов: некомпактный случай. Одним из обобщений понятия фуллерена на некомпактные односвязные двумерные многообразия является разбиение $\left(6^{3}\right)$. Оно допускает выпуклую реализацию в $\mathbb{R}^{3}$, в которой сохраняется комбинаторное устройство скелета этого разбиения (см. п. 3.2).

Плоскость $\mathbb{R}^{2}$ - неограниченное односвязное двумерное многообразие, а $\left(6^{3}\right)$ это единственное (с комбинаторно-топологической точки зрения) его простое (т. е. все вершины имеют степень $q=3$ ) разбиение на 6-угольники (их можно считать правильными).

Кроме него существуют разбиения плоскости $\mathbb{R}^{2}$ на 5- и 6-угольники, все вершины которых имеют степень 3 . В любом из этих разбиений число 5-угольников ограничено: $1 \leqslant f_{5} \leqslant 6$. Каждое из этих разбиений можно представить в виде бесконечного выпуклого многогранника в $\mathbb{R}^{3}$. Это так называемые наноконусы при $1 \leqslant f_{5} \leqslant 5$ и нанотрубки при $f_{5}=6$ (см. [6], [39], а также [11], где встречаются также компактные нанотрубки в виде продолговатых фуллеренов). Только в случае $f_{5}=1$ разбиение является единственным с комбинаторно-топологической точки зрения. При $2 \leqslant f_{5} \leqslant 6$ имеется бесконечное множество комбинаторных типов таких разбиений. Кстати сказать, рядом с наноконусами и нанотрубками исследуемые нами $n$-диск-фуллерены выглядят как нанодиски. Напомним, что оценка $f_{6} \leqslant 6$ следует из теоремы Александрова для бесконечного выпуклого многогранника, чья поверхность гомеоморфна плоскости и имеет полную кривизну $\Omega=\sum \omega \leqslant 2 \pi$.

ЗАмЕчание 12. Два разбиения плоскости на 5- и 6-угольники с вершинами степени $q=3$ назовем эквивалентными, если после удаления из каждого некоторой конечной части их бесконечные остатки будут изоморфны. Число эквивалентных классов равно (см. работу [6] и ссылки в ней):

○ 1 при $f_{6}=0,1,5$;

○ 2 при $f_{6}=2,3,4$;

○ $\infty$ при $f_{6}=6$.

Если нанотрубка [6] имеет пояс, то его серединная линия $C$ разрезает нанотрубку на две части. Одна часть, которая содержит все 6 старых 5-угольников, является наперстком; он вместе с наперстком, симметричным ему относительно $C$, составляет фуллерен (см. замечание 7). Другая часть, которая не содержит старых 5-угольников, является половиной цилиндра; она вместе с другой половиной цилиндра, симметричной ей относительно $C$, составляет целый цилиндр.

Среди бесконечных односвязных многообразий с краем, т. е. $\infty-D F$, число компонент связности края может быть равно $1,2, \ldots$ : это полуплоскость, полоса между параллельными прямыми и т. д. Каждое их них допускает разбиение на 5- и 6-угольники, в котором все вершины имеют степень 3 . Здесь на $f_{5}$ нет никаких ограничений. Множество 5-угольников может быть даже бесконечным: разбиение $\left(6^{3}\right)$ можно разрезать по прямой линии, разрезающей полосу из 6-угольников на 5-угольники, и рассмотреть разбиение одной из полученных так полуплоскостей. 
Для бесконечного двумерного многообразия, край которого имеет лишь одну компоненту связности, число 5-угольников разбиения может быть любым фиксированным числом $f_{5}=0,1,2, \ldots$. Случай $f_{5}=0$ получается как универсальная накрывающая разбиения $\left(6^{3}\right) \backslash H$, где $H=\operatorname{int}(6$-gon $) \subset\left(6^{3}\right)$. Случай $f_{5}=1$ получается из универсальной накрывающей разбиения $\left(6^{3}\right) \backslash H$ с помощью операции удаления угла $\pi / 3$, как это сделано в аналогичном случае в работе [39]. Случаи $f_{5} \geqslant 2$ получаются точно так же, так как операцию удаления угла $\pi / 3$ на универсальной накрывающей разбиения $\left(6^{3}\right) \backslash H$ можно повторить любое число раз, если каждый новый угол удалять на своем листе накрытия.

В случае бесконечного двумерного многообразия, край которого состоит из двух или более компонент связности, при любом фиксированном $f_{6}=0,1,2, \ldots$, $f_{5}=\infty, q=3$ разбиения существуют. Случай $f_{6}=0, f_{5}=\infty, q=3$ относится к $(5,3)$-полициклам [35].

В случае $f_{6}>0$ есть континуум различных типов разбиений бесконечной в обе стороны полосы, расположенной между двумя компонентами края. Пример такого разбиения изображен на рис. 17; оно состоит из бесконечного множества конгруэнтных элементарных слагаемых; второе элементарное слагаемое получается из первого при помощи параллельного переноса $t$; третье элементарное слагаемое получается из второго при помощи скользящего отражения $g$. Как известно, существует континуум различных бесконечных последовательностей, составленных из двух символов.

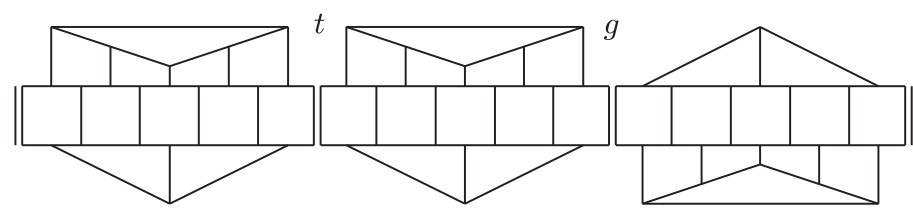

Рис. 17. Три элементарных слагаемых в бесконечной цепи

Тор, бутылка Клейна, бесконечный в обе стороны цилиндр и неограниченный лист Мёбиуса не допускают простых (т.е. с $q=3$ ) разбиений на 5- и 6 -угольники с $f_{5} \geqslant 1$, так как в противном случае плоскость (универсальная накрывающая) допускала бы простое разбиение на 5- и 6-угольники, в котором было бы бесконечное множество 5-угольников. Тор и бутылка Клейна допускают простые (примитивные) разбиения только на 6-угольники. Только сфера и проективная плоскость допускают простые разбиения на 5- и 6-угольники.

Отметим, что были построены обобщения понятия фуллерена на многообразия любых других размерностей [33], [14], [39] и аналоги разбиений пространства $\mathbb{R}^{3}$ на фуллерены [55], [47], [48], но здесь мы не будем их рассматривать.

\section{3. Приложения}

3.1. Параллелоэдры. Выпуклый $n$-мерный многогранник называют $n a$ раллелоэдром, если параллельными ему копиями можно замостить евклидово пространство $\mathbb{R}^{n}$. 
Говоря о замощении пространства, мы имеем в виду, что $n$-мерный параллелоэдр рассматривается как тело и что параллельными ему копиями заполнено все бесконечное пространство $\mathbb{R}^{n}$, причем никакие две копии не имеют общих внутренних точек и каждая точка пространства принадлежит хотя бы одной копии. Такое замощение пространства называют разбиением. Если в разбиении параллелоэдры смежны по целым граням, то разбиение называют нормальнъмм; в противном случае разбиение называют ненормалъным. Нормальное разбиение на параллелоэдры всегда обладает группой параллельных переносов, транзитивной на всех параллелоэдрах. Для ненормального разбиения на параллелоэдры (на параллельно расположенные копии некоторого фиксированного параллелоэдра) мы дополнительно требуем, чтобы разбиение обладало группой параллельных переносов, транзитивной на всех параллелоэдрах. Любой ненормальный параллелоэдр является нормальным (см. [82]); любой параллелоэдр и все его гиперграни центрально-симметричны (см. [66]).

В работе [83] Г. Вороной построил общую теорию примитивных параллелоэдров. Нормальное разбиение пространства $\mathbb{R}^{n}$ на $n$-мерные параллелоэдры называется примитивным, если число параллелоэдров, сходящихся в каждой вершине разбиения, равно $n+1$. (Это минимальное число параллелоэдров, сходящихся в одной вершине. При $n=2$ это наш случай простых $(q=3)$ разбиений.) В противном случае разбиение называется непримитивным. Так как нормальное разбиение на параллелоэдры однозначно определяется заданием одного своего параллелоэдра, то и он сам называется примитивным или непримитивным соответственно.

Вороной доказал, что каждый примитивный $n$-мерный параллелоэдр имеет $2\left(2^{n}-1\right)$ гиперграней и что он аффинно эквивалентен параллалоэдру Дирихле-Вороного. Так называется параллелоэдр, все внутренние точки которого ближе к его центру, нежели к центрам всех остальных параллелоэдров заданного нормального разбиения. Исходя из этого, нахождение примитивных параллелоэдров Вороной свел к нахождению параллелоэдров Дирихле-Вороного.

Параллелоэдры относятся к одному muny, если соответствующие им нормальные разбиения на параллелоэдры имеют аффинно-эквивалентные дуальные им симплициальные разбиения.

Вороной построил алгорифм нахождения всех типов примитивных параллелоэдров для любой размерности. С помощью этого алгорифма Вороной нашел все три типа примитивных 4-мерных параллелоэдров. В случае произвольной размерности он предъявил главную форму I типа Вороного, форму II типа и т. д. Хороший путеводитель к чтению [83], [84] имеется в книге [16].

В нормальном разбиении (т. е. грань-в-грань) каждая грань параллелоэдра является гранью в разбиении. В [42] грань параллелоэдра названа стандартной, если она является пересечением двух параллелоэдров разбиения. Стандартная грань имеет центр симметрии, который является центром симметрии всего разбиения на параллелоэдры. Например, любая гипергрань параллелоэдра является стандартной. В частности, если у параллелоэдра грани всех размерностей являются стандартными, то он является параллелепипедом. 
В ненормальном разбиении некоторые грани в разбиении являются частями граней параллелоэдра. Грань разбиения определяется как пересечение всех его параллелоэдров, содержащих эту грань. Она выпукла. Если она имеет центр симметрии, который совпадает с центром симметрии всего разбиения, то она является стандартной. В ненормальном разбиении она может быть лишь частью пересечения двух параллелоэдров. Однако гипергрань разбиения является пересечением только двух его параллелоэдров. Это не зависит от того, является ли разбиение на параллелоэдры нормальным или нет. А так как мы требуем, чтобы каждое ненормальное разбиение на выпуклые параллелоэдры обладало группой параллельных переносов, транзитивной на всех параллелоэдрах, то гипергрань всегда центрально-симметрична. Более того, ее центр симметрии является центром симметрии разбиения, так как выпуклый параллелоэдр имеет центр симметрии, а по соглашению разбиение обладает группой параллельных переносов, транзитивной на параллелоэдрах разбиения; следовательно, гипергрань ненормального разбиения также стандартна.

Для разбиения пространства $\mathbb{R}^{n}$ на произвольные выпуклые $n$-мерные параллелоэдры в [42] введены следующие два понятия:

о степень грани - число параллелоэдров, содержащих эту грань,

○ индекс грани - это величина, обратная степени заданной грани, и доказано, что сумма индексов стандартных граней равна $2^{n}-1$.

Из этой теоремы об индексе немедленно следует доказательство теоремы Минковского о том, что число $(n-1)$-мерных граней каждого $n$-мерного параллелоэдра не превышает $2\left(2^{n}-1\right)$ (см. [42]).

Таким образом, число гиперграней $n$-мерного параллелоэдра не меньше $2 n$ и не больше $2\left(2^{n}-1\right)$.

При $n=2$ мы имеем один примитивный параллелогон - центрально-симметричный шестиугольник, и один непримитивный - параллелограмм; разбиение на шестиугольники является нормальным, а в ненормальном разбиении параллелогоны являются параллелограммами.

При $n=3$ есть один примитивный параллелоэдр и 4 непримитивных; число граней $6,8,12,12,14$ (см. [53]). Каждое ненормальное разбиение на 3 -мерные выпуклые параллелоэдры получается как предел нормального разбиения, если некоторые двугранные углы параллелоэдра устремить к $\pi$ (конечно, если исходный параллелоэдр не есть параллелепипед). Здесь возможны два случая:

1) комбинаторно-топологический тип разбиения сохранится;

2) комбинаторно-топологический тип разбиения станет иным.

Во втором случае параллелоэдр является параллелепипедом, т.е. он имеет 6 граней. Но в разбиении существует не 6 параллелоэдров, смежных с ним по 2-мерным граням, а 10, так как имеются соседи, смежные не по целым граням, а по частям граней. Эти части граней параллелоэдра являются гранями в ненормальном разбиении. Назовем их декоративными гранями ненормального параллелоэдра. Получим выпуклый 10-гранный параллелоэдр. Имеются ровно три типа 10-гранных ненормальных параллелоэдров [78]; нормальных 10-гранных параллелоэдров не существует. 
При $n=4$ имеются три примитивных параллелоэдра (см. [83]) и $49=48+1$ непримитивных (см. [12] и [15], а также [77]).

При $n=5$ имеются всего 222 типа примитивных параллелоэдров (см. [72], [49], а также [50] и [10]); количество непримитивных параллелоэдров, как оказалось, исчисляется тысячами.

Отметим, что при $n=5$ алгорифм Вороного слишком трудоемкий и поэтому в [72] был применен двуступенчатый алгорифм. Сначала были найдены типы смежности примитивных 5-мерных параллелоэдров. Понятие типа смежности параллелоэдров было введено в [71].

Отметим также, что в [72] решена задача о наименее плотном решетчатом покрытии пятимерного пространства равными шарами: редчайшая решетка задается главной формой I типа Вороного.

Теорема Вороного - примитивный n-мерный параллелоэдр аффинно эквивалентен параллалоэдру Дирихле-Вороного - уточнена в [65]: для любого примитивного $n$-мерного параллелоэдра аффинно эквивалентный ему параллелоэдр Дирихле-Вороного является единственным с точностью до подобия. Это утверждение верно и при наличии непримитивных схождений в $(n-2)$-мерных гранях, если любые две гиперграни параллелоэдра можно соединить цепочкой гиперграней, в которой любые две соседние гиперграни смежны по $(n-2)$-мерной грани с примитивным схождением в ней (см. [45]).

Вороной излагал свои геметрические исследования в аналитической форме (в то время чистая геометрия была не в моде); он доказал, что все локально плотнейшие решетчатые упаковки шаров (предельные формы) находятся среди совершенных решеток; он построил разбиение конуса положительности квадратичных форм от $n$ переменных на совершенные гоноэдры [84].

В [81] введено понятие совершенного полиэдра Вороного П $(n)$ и переизложены исследования Вороного о совершенных решетках в геометрическом виде. В [69] введено понятие полиэдра $\mu_{n}(m)$, дуального полиэдру $\Pi(n)$, доказано, что для нахождения всех попарно неэквивалентных групп целочисленных $(n \times n)$-матриц достаточно найти группы целочисленных автоморфизмов центров тяжести всех попарно неэквивалентных конечных граней (всех размерностей) полиэдра П $(n)$ или $\mu_{n}(m)$, и в [70] найдены все максимальные конечные группы целочисленных $(5 \times 5)$-матриц.

Работами [23], [40], [9], [41], [46] открыто новое направление в теории правильных разбиений и точечных систем.

3.2. Женератриса. Докажем, что "бесконечный фуллерен" $\left(6^{3}\right)$, т. е. разбиение плоскости $\mathbb{R}^{2}$ на правильные 6-угольники, допускает, как и любой фуллерен или диск-фуллерен, выпуклую реализацию в $\mathbb{R}^{3}$.

В центре одного из 6-угольников разбиения $\left(6^{3}\right)$ восстановим ось, ортогональную к $\mathbb{R}^{2}$. Построим в $\mathbb{R}^{3}$ круговой параболоид, для которого она служит осью. Возьмем на поверхности параболоида точки, которые проектируются вдоль оси в центры ячеек разбиения $\left(6^{3}\right)$. Во всех этих точках построим ка- 
сательные плоскости к параболоиду. Они являются плоскостями граней бесконечного выпуклого многогранника, описанного вокруг параболоида. Его грани проектируются вдоль оси в ячейки разбиения $\left(6^{3}\right)$. Это простой факт из аналитической геометрии.

В этом доказательстве появился основной объект, фигурирующий в доказательстве теоремы Вороного, который он назвал женератрисой. Остановимся на построении женератрисы и доказательстве теоремы подробнее.

Рассмотрим в $\mathbb{R}^{2}$ произвольный центрально-симметричный 6-угольник, не вписанный в окружность. Замостим $\mathbb{R}^{2}$ его параллельно перенесенными копиями. Над каждой копией построим бесконечную прямую призму, для которой эта копия служит основанием. Построим косые плоские сечения этих призм, выбирая их так, чтобы в итоге получилась бесконечная выпуклая многогранная поверхность. А именно, один 6-угольник (назовем его исходным) мы оставим без изменения, а смежную с ним копию заменим на плоское сечение призмы, основанием которого служит эта копия. Плоскость сечения проведем через общее ребро исходного 6-угольника и смежной с ним копии. Сечение является косым. Наклон его плоскости может быть выбран произвольно.

Зафиксируем этот наклон. Получим вполне определенное сечение призмы. Это 6-угольник, проектирующийся в первую копию. Рассмотрим вторую копию, смежную с исходным оригиналом и первой копией. Призма, основанием которой служит вторая копия, содержит ребро оригинала и ребро сечения призмы, основанием которой служит первая копия. Через эти два ребра проходит единственная плоскость, которая по некоторому 6-угольнику пересекает призму, основанием которой служит вторая копия. Точно так же строится сечение призмы, основанием которой служит третья копия, смежная со второй копией и исходным 6-угольником, и т. д. Так строятся все 6 сечений призм, основаниями которых служат все копии первой короны вокруг исходного 6-угольника. Построенные 6 сечений замкнутся в кольцо, так как исходный 6-угольник является выпуклым и центрально-симметричным, а все его копии, расположенные в первой короне, параллельны ему и смежны с ним по целым сторонам.

Точно так же строятся сечения призм, основаниями которых служат копии 6-угольника, расположенные во второй короне, и т.д. В итоге в пространстве $\mathbb{R}^{3}$ получится бесконечный выпуклый многогранник, грани которого проектируются на плоскость $\mathbb{R}^{2}$ в ячейки рассматриваемого разбиения. Поверхность построенного многогранника является описанной вокруг эллиптического параболоида. Она является женератрисой Вороного. Сохраняя ось параболоида перпендикулярной плоскости $\mathbb{R}^{2}$, подвергнем пространство $\mathbb{R}^{3}$ аффинному преобразованию, при котором эллиптический параболоид преобразуется в круговой. Тогда каждая ячейка этого разбиения будет состоять из точек плоскости $\mathbb{R}^{2}$, которые находятся ближе к центру своей ячейки, чем к центрам всех остальных ячеек.

В самом деле, проекция прямой, по которой пересекаются две касательные плоскости к параболоиду, проходят через середину отрезка, соединяющего проекции точек касания, если параболоид эллиптический, и перпендикулярна ему, 
если параболоид круговой. (Для прохождения через середину достаточно эллиптичности параболоида, для перпендикулярности - не достаточно.) Значит, разбиение плоскости $\mathbb{R}^{2}$ превратилось в разбиение Дирихле-Вороного.

Именно так Вороной доказал теорему о том, что произвольный примитивный параллелоэдр является аффинным образом параллелоэдра Дирихле-Вороного. В теореме Вороного размерность параллелоэдра может быть любой. Сущность доказательства теоремы Вороного заключается в построении женератрисы. Для размерности 2 выше дано наглядное построение женератрисы бесконечной выпуклой поверхности, описанной вокруг эллиптического параболоида. Построение женератрисы однозначно определяется выбором наклона плоского сечения одной из 6-угольных призм.

О построении женератрисы в многомерном случае см. [83], [84].

В [73], [74] разработана теория построения женератрисы, установлены необходимые и достаточные условия ее существования. И теорема Вороного, и теорема Житомирского [87], обобщающая теорему Вороного и утверждающая, что $n$-мерный параллелоэдр, который в нормальном разбиении на параллельные ему копии примитивен во всех гранях размерности $n-2$, аффинно эквивалентен параллелоэдру Дирихле-Вороного, являются теоремами существования женератрисы, которая проектируются вдоль оси эллиптического параболоида на заданное нормальное разбиение.

Проблема Вороного - произвольный параллелоэдр афбинно эквивалентен параллелоэдру Дирихле-Вороного - открыта для случаев, когда в нормальном разбиении на параллелоэдры имеются непримитивные схождения в $(n-2)$-мерных гранях (см. [51], [42], [45], [44]).

3.3. Делоне и его тетраэдрический символ. Время бежит и в каждый миг приходится принимать какое-то решение, и его уже никто не отменит, чтобы избавиться от непредвиденных негативных последствий - поезд ушел.

Как-то отправился Б.Н. Делоне навестить своего младшего внука Борю. Зашел в троллейбус, не взглянув на номер маршрута, а тот вскоре повернул в сторону. Там жил редактор последней статьи [20] и Б. Н. решил зайти к нему. Открыв дверь и увидев Б. Н., он начал отмахиваться обеими руками:

- Борис Николаевич, не заходите, у меня сильнейший грипп!

- Ну подумаешь - грипп, я уже 15 лет гриппом не болею, - и Б. Н. заходит к нему. Часа два они оживленно разговаривали, - не по теме статьи, они обсуждали ее лишь в Стекловке (МИАН), - Б. Н. нашел собеседника, который выслушал его завораживающие рассказы. Только вернувшись домой, Б. Н. обнаружил, что у него грипп. Потом случился перелом шейки бедра. Оправиться от болезни ему уже не было суждено.

Время от времени Б.Н. возвращался к своим старым работам, усовершенствовал их, добавлял что-то новое. Вот и в [20] он решил рассказать о своей классификации 3-мерных решеток и, самое главное, о тетраэдрическом символе Делоне, которым он очень гордился. И не без основания: после введения этого символа шаг приведения Зеллинга, задаваемый с его помощью, стал настолько ясным, простым и удобным, что приведение Зеллинга, состоящее из 
конечного числа шагов для каждой 3-мерной решетки, кристаллографы восприняли в качестве приведения Делоне. Подробности см. в [13], [22], [61], [17], [18], [24], [20].

Процитируем одну его фразу [20; с. 170]: "K сожалению, кроме непосредственного подтверждения этого положения для каждого из 24 сортов в отдельности, я не нашел общего естественного доказательства". Увидев эту фразу при оформлении рукописи, третий автор предложил Б.Н. заменить ее на следующее доказательство. В 3-мерной решетке легко найти все приведенные 4-векторники Зеллинга (см. [20]). Точечная симметрия решетки состоит из вращений пространства вокруг точки, являющейся началом всех четырех векторов приведенного 4-векторника Зеллинга, которые переводят его в конгруэнтный ему 4-векторник Зеллинга или в себя. Симметрия произвольного 4-векторника Зеллинга совпадает с группой симметрии 3-мерного симплекса с вершинами в концах векторов 4-векторника (кстати сказать, группы симметрии всех 3-мерных симплексов найдены в [76]). Однако Б. Н. оставил в своей рукописи эту фразу.

16-20 августа 2010 г. в Москве состоялась конференция, посвященная 120-летию со дня рождения Б. Н. Делоне. Основные хлопоты по ее организации взял на себя Н. П. Долбилин, продолжающий активно заниматься тематикой Делоне. Он опубликовал очерк о жизни и творчестве Б. Н. Делоне [43]. Теплыми воспоминаниями о Борисе Николаевиче поделились жизнерадостная, доброжелательная и энергичная дочь Анна Борисовна (1928-2012), вся в отца, и оба ее сына - Серёжа и Боря.

\section{Список литературы}

[1] А. Д. Александров, Выпуклые многогранники, Гостехиздат, М., Л., 1950, 428 с.; англ. пер.: A.D. Alexandrov, Convex polyhedra, Springer Monogr. Math., SpringerVerlag, Berlin, 2005, xii+539 pp.

[2] А. Д. Александров, Избранные труды, т. 1, Наука, Новосибирск, 2006, lii+748 с.; т. 2,2007 , iv +492 с.; т. 3,2008 , iv +734 c.

[3] Д. А. Бочвар, Е.Г. Гальперн, "О гипотетических системах: карбододекаэдре, $s$-икосаэдре и карбо-s-икосаэдре”, Докл. АН СССР, 209:3 (1973), 610-612.

[4] G. Brinkmann, A. W. M. Dress, "A constructive enumeration of fullerenes", J. Algorithms, 23:2 (1997), 345-358.

[5] G. Brinkmann, P.W. Fowler, "A cataloque of growth transformations of fullerene polyhedra", J. Chem. Inf. Comput. Sci., 43:6 (2003), 1837-1843.

[6] G. Brinkmann, N. Van Cleemput, "Classification and generation of nanocones", Discrete Appl. Math., 159:15 (2011), 1528-1539.

[7] В. М. Бухштабер, "Кольцо простых многогранников и дифференциальные уравнения", Геометрия, топология и математическая физика. I, Сборник статей. K 70-летию со дня рождения академика Сергея Петровича Новикова, Тр. МИАН, 263, МАИК, М., 2008, 18-43; англ. пер.: V. M. Buchstaber, "Ring of simple polytopes and differential equations", Proc. Steklov Inst. Math., 263:1 (2008), 13-37.

[8] A. L. Cauchy, "Sur les polygones et polyèdres. Second mémoire", J. Ecole Polytéchnique, 9 (1813), 87-98.

[9] Р. В. Галиулин, Кристаллографическая геометрия, Наука, М., 1984, 136 с. 
[10] В.П. Гришухин, Примитивные L-типь пятимерных решеток, Препринт № WР/2007/229, ЦЭМИ РАН, М., 2007, 47 c.

[11] А. И. Гусев, Наноматериаль, наноструктуры, нанотехнологии, Физматлит, М., $2005,416 \mathrm{c}$.

[12] B. N. Delaunay, "Sur la partition régulière de l'espace à 4 dimensions. Première partie", Изв. АН ССCP. VII сер. Отд. физ.-матем. наук, 1929, №1, 79-110; "Deuxième partie", № 2, 147-164.

[13] B. N. Delaunay, "Neue Darstellung der geometrischen Kristallographie", Z. Kristallogr., 84 (1933), 109-149.

[14] O. Delgado-Friedrichs, M. O'Keeffe, "On a simple tiling of Deza and Shtogrin", Acta Crystallogr. Sect. A, 62:3 (2006), 228-229.

[15] Б. Н. Делоне, "Геометрия положительных квадратичных форм", УМН, 3 (1937), 16-62; "Часть II", 4 (1938), 102-164.

[16] Б. Н. Делоне, Петербургская школа теории чисел, Изд-во АН СССР, М., Л., 1947, 421 с.; англ. пер.: B. N. Delone, The St. Petersburg school of number theory, Hist. Math., 26, Amer. Math. Soc., Providence, RI, 2005, xvi+278 pp.

[17] Б. Н. Делоне, "К теории приведения", Кристаллография, 4 (1959), 501-507; англ. пер.: B. N. Delone, "Reduction theory", Soviet Physics Cryst., 5 (1960), 482-488.

[18] Б.Н. Делоне, "Дополнение к моей работе 1933 года о правильной установке кристалла", Докл. АН ССCP, 161:3 (1965), 511-514; англ. пер.: B. N. Delone, "A supplement to my paper of 1933 on the reduction of a crystallographic lattice", Soviet Math. Dokl., 6 (1965), 449-452.

[19] Б.Н. Делоне, "Многогранник”, БСЭ, т. 16, Советская энциклопедия, М., 1974, 363-366.

[20] Б. Н. Делоне, "24 сорта кристаллических решеток", Наука и человечество, Знание, М., 1981, 160-173.

[21] Б.Н. Делоне, "Многогранник", Математический энииклопедический словаръ, Советская энциклопедия, М., 1988, 370-373.

[22] Б. Н. Делоне, А. Д. Александров, Н. Н. Падуров, Математические основы структурного анализа кристаллов и определение основного параллелепипеда повторяемости при помощи рентгеновских лучей, Гостехиздат, М., Л., 1934, 328 с.

[23] Б. Н. Делоне, Н. П. Долбилин, М. И. Штогрин, Р. В. Галиулин, “Локальный критерий правильности системы точек", Докл. АН СССР, 227:1 (1976), 19-21; англ. пер.: B. N. Delone, N. P. Dolbilin, M. I. Štogrin, R. V. Galiulin, "A local test for the regularity of a system of points", Soviet Math. Dokl., 17:2 (1976), 319-322.

[24] Б.Н. Делоне, М.И. Штогрин, "Об одной демонстрационной модели, наглядно показывающей изменение симметрии решетки при изменении самой решетки", Проблемы современной кристаллографии, Наука, М., 1975, 27-42.

[25] M. Deza, M. Dutour, "Zigzag structures of simple two-faced polyhedra", Combin. Probab. Comput., 14:1-2 (2005), 31-57.

[26] M. Deza, M. Dutour, P. W. Fowler, "Zigzags, railroads, and knots in fullerenes", J. Chem. Inf. Comput. Sci., 44:4 (2004), 1282-1293.

[27] М.-М. Деза, М. Дютур Сикирич, Геометрия химических графов: полицикльь и биполицикль, ИКИ, М., Ижевск, 2012, 384 с.; пер. с англ.: М. Deza, M. Dutour Sikirić, Geometry of chemical graphs: polycycles and two-faced maps, Encyclopedia Math. Appl., 119, Cambridge Univ. Press, 2008, x+306 pp.

[28] M. Deza, M. Dutour Sikirić, M. Shtogrin, "Filling of a given boundary by $p$-gons and related problem", Discrete Appl. Math., 156:9 (2008), 1518-1535.

[29] M. Deza, M. Dutour Sikirić, M. Shtogrin, "Fullerene-like spheres with faces of negative curvature", Diamond and related nanostructures, Carbon materials: Chemistry and Physics, 6, eds. M. V. Diudea, C. L. Nagy, Springer, Dordrecht, 2013, 251-274; 2011, arXiv: 1112.3320 . 
[30] M. Deza, P. W. Fowler, V. Grishukhin, "Allowed boundary sequences for fused polycyclic patches and related algorithmic problems", J. Chem. Inf. Comput. Sci., 41:2 (2001), 300-308.

[31] M. Deza, P. W. Fowler, M. Shtogrin, "Version of zones and zigzag structure in icosahedral fullerenes and icosadeltahedra", J. Chem. Inf. Comput. Sci., 43:2 (2003), 595-599.

[32] М. Деза, С.В. Шпекторов, М.И. Штогрин, "Нерасширяемые конечные полициклы", Изв. РАН. Сер. матем., 70:1 (2006), 3-22; англ. пер.: M. Deza, S. V. Shpektorov, M. I. Shtogrin, "Non-extendible finite polycycles", Izv. Math., 70:1 (2006), 1-18.

[33] M. Deza, M. Shtogrin, "Three-, four-, and five-dimensional fullerenes", Southeast Asian Bull. Math., 23:1 (1999), 9-18.

[34] М. Деза, М. И. Штогрин, "Вложение химических графов в гиперкубы", Матем. заметки, 68:3 (2000), 339-352; англ. пер.: M. Deza, M. I. Shtogrin, "Embeddings of chemical graphs in hypercubes", Math. Notes, 68:3 (2000), 295-305.

[35] М. Деза, М. И. Штогрин, "Экстремальные и нерасширяемые полициклы”, Дискретная геометрия и геометрия чисел, Сборник статей. К 70-летию со дня рождения профессора Сергея Сергеевича Рышкова, Тр. МИАН, 239, Наука, М., 2002, 127-145; англ. пер.: M. Deza, M. I. Shtogrin, "Extremal and nonextendible polycycles", Proc. Steklov Inst. Math., 239:4 (2002), 117-135.

[36] M. Deza, M. Shtogrin, "Clusters of cycles", J. Geom. Phys., 40:3-4 (2002), 302-319.

[37] M. Deza, M. Shtogrin, "Octahedrites", Symmetry Cult. Sci., 11:1-4, Special issue "Polyhedra" (2000), 27-64.

[38] М. Деза, М.И. Штогрин, "Типы и граничная единственность полипентагонов", УМH, 61:6(372) (2006), 183-184; англ. пер.: M. Deza, M. I. Shtogrin, "Types and boundary uniqueness of polypentagons", Russian Math. Surveys, 61:6 (2006), $1170-1172$.

[39] М. Деза, М.И. Штогрин, "Новые примеры обобщенных фуллеренов", УМН, 64:1(385) (2009), 145-146; англ. пер.: M. Deza, M. I. Shtogrin, "New examples of generalized fullerenes", Russian Math. Surveys, 64:1 (2009), 139-141.

[40] Н. П. Долбилин, “О локальных свойствах дискретных правильных систем”, Докл. AH CCCP, 230:3 (1976), 516-519; англ. пер.: N. P. Dolbilin, "Local properties of discrete regular systems", Soviet Math. Dokl., 17:5 (1976), 1333-1337.

[41] N. P. Dolbilin, "The extension theorem", Discrete Math., 221:1-3 (2000), 43-59.

[42] Н. П. Долбилин, “Свойства граней параллелоэдров", Геометрия, топология и математическая физика. II, Сборник статей. К 70-летию со дня рождения академика Сергея Петровича Новикова, Тр. МИАН, 266, МАИК, М., 2009, 112-126; англ. пер.: N. P. Dolbilin, "Properties of faces of parallelohedra", Proc. Steklov Inst. Math., 266:1 (2009), 105-119.

[43] Н. П. Долбилин, "Борис Николаевич Делоне: жизнь и творчество", Классическал и современная математика в поле деятельности Бориса Николаевича Делоне, Сборник статей. K 120-летию со дня рождения члена-корреспондента АН СССР Бориса Николаевича Делоне, Тр. МИАН, 275, МАИК, М., 2011, 7-21; англ. пер.: N. P. Dolbilin, "Boris Nikolaevich Delone (Delaunay): life and work", Proc. Steklov Inst. Math., 275:1 (2011), 1-14.

[44] Н. П. Долбилин, “Параллелоэдры: ретроспектива и новые результаты”, Тр. ММО, 73, МЦНМО, М., 2012, 259-276; англ. пер.: N.P. Dolbilin, "Parallelohedra: a retrospective and new results", Trans. Mosc. Math. Soc., 2012, 2012, 207-220.

[45] N. Dolbilin, J.-i. Itoh, C. Nara, "Affine equivalent classes of parallelohedra", Computational geometry, graphs and applications, Lecture Notes in Comput. Sci., 7033, Springer, Heidelberg, 2011, 55-60. 
[46] Н.П. Долбилин, В.С. Макаров., "Теорема о продолжении в теории правильных разбиений и ее приложения", Дискретная геометрия и геометрия чисел, Сборник статей. K 70-летию со дня рождения профессора Сергея Сергеевича Рышкова, Тр. МИАН, 239, Наука, М., 2002, 146-169; англ. пер.: N.P. Dolbilin, V.S. Makarov, "Extension theorem in the theory of isohedral tilings and its applications", Proc. Steklov Inst. Math., 239:4 (2002), 136-158.

[47] M. Dutour Sikirić, O. Delgado-Friedrichs, M. Deza, "Space fullerenes: computer search for new Frank-Kaspar structures", Acta Cryst. Sect. A, 66:5 (2010), 602-615.

[48] M. Dutour Sikirić, M. Deza, "Space fullerenes: computer search for new Frank-Kaspar structures, II", Structural Chemistry, 23:4 (2012), 1103-1114.

[49] P. Engel, "The contraction types of parallelohedra in $E^{5}$ ", Acta Cryst. Sect. A, 56:5 (2000), 491-496.

[50] P. Engel, V. Grishukhin, "There are exactly 222 L-types of primitive five-dimensional lattices", European J. Combin., 23:3 (2002), 275-279.

[51] R. Erdahl, "Zonotopes, dicings, and Voronoi's conjecture on parallelohedra", European J. Combin., 20:6 (1999), 527-549.

[52] L. Euler, "Solutio problematis ad geometriam situs pertinentis", Comment. Acad. Sci. Petrop., 8 (1736/1741), 128-140; Opera Omnia, Ser. 1, 7 (1766), 1-10.

[53] Е. С. Федоров, Начала учения о фигурах, С.-Петербург, 1885, 279 с.

[54] P. W. Fowler, D. E. Manolopoulos, An atlas of fullerenes, Oxford Univ. Press, Oxford, 1995, $392 \mathrm{pp}$.

[55] F. C. Frank, J.S. Kasper, "Complex alloy structures regarded as sphere packings. I. Definitions and basic principles", Acta Cryst., 11:3 (1958), 184-190; "II. Analysis and classification of representative structures", 12:7 (1959), 483-499.

[56] M. Goldberg, "The isoperimetric problem for polyhedra", Tohoku Math. J., 40 (1935), 226-236.

[57] J.E. Graver, C. Graves, "Fullerene patches. I", Ars Math. Contemp., 3:1 (2010), 109-120.

[58] B. Grünbaum, T. S. Motzkin, "The number of hexagons and the simplicity of geodesics on certain polyhedra", Canad. J. Math., 15 (1963), 744-751.

[59] X. Guo, P. Hansen, M. Zheng, "Boundary uniquenes of fusenes", Discrete Appl. Math., 118:3 (2002), 209-222.

[60] Ф. Харари, Теория графов, 3-е изд., КомКнига, М., 2006, 296 с.; пер. с англ.: F. Harary, Graph theory, Addison-Wesley Publishing Co., Reading, MA-Menlo Park, CA-London, 1969, ix+274 pp.

[61] N. F. M. Henry, K. Lonsdale (eds.), International tables for X-ray crystallography, v. I: Symmetry groups, Kynoch Press, Birmingham, 1952, 558 pp.

[62] X. Jiang, H. Zhang, "On forcing matching number of boron-nitrogen fullerene graphs", Discrete Appl. Math., 159:15 (2011), 1581-1593.

[63] H. W. Kroto, " $\mathrm{C}_{60}^{\mathrm{B}}$ buckminsterfullerene, other fullerene and the icospiral shell", Comput. Math. Appl., 17:1-3 (1989), 417-423.

[64] H. W. Kroto, J. R. Heath, S. C. O'Brien, R. F. Curl, R. E. Smalley, "C60 sterfullerene", Nature, 318 (1985), 162-163.

[65] L. Michel, S. S. Ryshkov, M. Senechal, "An extension of Voronoǔ's theorem on primitive parallelotopes", European J. Combin., 16:1 (1995), 59-63.

[66] H. Minkowski, "Allgemeine Lehrsätze über die konvexe Polyeder", Gött. Nachr., 1897, 198-219.

[67] С. П. Оловянишников, "Обобщение теоремы Коши о выпуклых многогранниках", Матем. сб., 18(60):3 (1946), 441-446.

[68] E. Osawa, "Superaromaticity", Kagaku (Kyoto), 25 (1970), 854-863. 
[69] С. С. Рышков, "Полиэдр $\mu(m)$ и некоторые экстремальные задачи геометрии чисел", Докл. АН СCCP, 194:3 (1970), 514-517; англ. пер.: S.S. Ryškov, "The polyhedron $\mu(m)$ and some extremal problems of the geometry of numbers", Soviet Math. Dokl., 11 (1970), 1240-1244.

[70] С. С. Рышков, "Максимальные конечные группы целочисленных $n \times n$-матриц и полные группы целочисленных автоморфизмов положительных квадратичных форм (типы Бравэ)", Сборник статей. II, Посвящается академику Ивану Матвеевичу Виноградову к его восьмидесятилетию, Тр. МИАН СССР, 128, 1972, 183-211; англ. пер.: S. S. Ryshkov, "Maximal finite groups of $n \times n$ integral matrices and full integral automorphism groups of positive quadratic forms (Bravais types)", Proc. Steklov Inst. Math., 128(1972) (1974), 217-250.

[71] С. С. Рышков, "C-типы $n$-мерных параллелоэдров", Докл. АH CCCP, 212:1 (1973), 46-49; англ. пер.: S. S. Ryškov, "C $C$-types of $n$-dimensional parallelohedra", Soviet Math. Dokl., 14 (1973):5 (1974), 1314-1318.

[72] С. С. Рышков, Е.П. Барановский, " $C$-типы $n$-мерных решеток и пятимерные примитивные параллелоэдры (с приложением к теории покрытий)", Тр. МИАН CCCP, 137, 1976, 3-131; англ. пер.: S. S. Ryshkov, E. P. Baranovskii, "C-types of $n$-dimensional lattices and 5-dimensional primitive parallelohedra (with application to the theory of coverings)", Proc. Steklov Inst. Math., 137 (1976), 1-140.

[73] С. С. Рышков, К.А. Рыбников, "Женератриса. Задачи Максвелла и Вороного", Докл. РАН, 349:6 (1996), 743-746; англ. пер.: S. S. Ryshkov, K. A. Rybnikov, Jr., "Generatrissa. The Maxwell and Voronoŭ problems", Dokl. Math., 54:1 (1996), 614-617.

[74] S. S. Ryshkov, K. A. Rybnikov, Jr., "The theory of quality translations with applications to tilings", European J. Combin., 18:4 (1997), 431-444.

[75] Г. Зейферт, В. Трельфалль, Топология, НИЦ "Регулярная и хаотическая динамика", Ижевск, 2001, 448 с.; пер. с нем.: H. Seifert, W. Threlfall, Lehrbuch der Topologie, B. G. Teubner, Leipzig, 1934, iv+353 pp.

[76] M. Senechal, "Which tetrahedra fill space?", Math. Mag., 54:5 (1981), 227-243.

[77] М. И. Штогрин, "Правильные разбиения Дирихле-Вороного для второй триклинной группы", Тр. МИАН СССР, 123, 1973, 3-128; англ. пер.: M. I. Shtogrin, "Regular Dirichlet-Voronoi partitions for the second triclinic group", Proc. Steklov Inst. Math., 123 (1973) (1975), 1-116.

[78] М. И. Штогрин, "Ненормальные разбиения трехмерного евклидова пространства на выпуклые параллелоэдры и их симметрия", Всесоюзный симпозиум по теории симметрии и ее обобщениям, Тезисы докладов, Кишиневский гос. ун-т, Кишинев, 1980, 129-130.

[79] М.И. Штогрин, "Критерий вырожденности выпуклого многогранника”, УМН, 67:5 (2012), 175-176; англ. пер.: M. I. Shtogrin, "Degeneracy criterion for a convex polyhedron", Russian Math. Surveys, 67:5 (2012), 951-953.

[80] E. Steinitz, H. Rademacher, Vorlesungen über die Theorie der Polyeder unter Einschluss der Elemente der Topologie, Grundlehren Math. Wiss., 41, Springer, Berlin, 1934, viii+351 pp.

[81] Б. А. Венков, "Комментарий к работе 'О некоторых свойствах положительных совершенных квадратичных форм'”, Г. Ф. Вороной. Собр. соч., т. 2, Изд-во АН УССР, Киев, 1952, 379-382.

[82] Б. А. Венков, “Об одном классе эвклидовых многогранников", Вестн. Ленингр. ун-та. Матем. Физ. Хим., 9:2 (1954), 11-31.

[83] G. Voronoi, "Nouvelles applications des paramètres continus à la théorie de formes quadratiques. Deuxième mémoire. Recherches sur les parallélloèdres primitifs", J. Reine Angew. Math., 134 (1908), 198-287. 
[84] Г. Ф. Вороной, "О некоторых свойствах положительных совершенных квадратичных форм”, Собр. соч., т. 2, Изд-во АН УССР, Киев, 1952, 171-238.

[85] H. Whitney, "A set of topological invariants for graphs", Amer. J. Math., 55:1-4 (1933), 231-235.

[86] А.А. Зильберберг, "О существовании замкнутых выпуклых многогранников с произвольными заданными кривизнами вершин”, УМН, 17:4(106) (1962), 119-136.

[87] O. Zitomirskij, "Verschärfung eines Satzes von Woronoi", ЖКурн. Ленингр. физ.-матем. о-ва, II:2 (1929), 131-151.

М. Деза (M. Deza)

Поступила в редакцию

École Normale Supérieure, Paris, France

11.10 .2012

E-mail: Michel.Deza@ens.fr

\section{М. Дютур Сикирич (M. Dutour Sikirić)}

Rudjer Bošković Institute, Zagreb, Croatia

E-mail: mdsikir@irb.hr

\section{М. И. Штогрин (М. I. Shtogrin)}

Математический институт им. В. А. Стеклова РАН;

Ярославский государственный университет

им. П. Г. Демидова

E-mail: stogrin@mi.ras.ru 